\title{
NBSIR 88-3752
}

\section{An Experimental Data Set for the Accuracy Assessment of Room Fire Models}

Richard D. Peacock

Sanford Davis

Billy T. Lee

U.S. DEPARTMENT OF COMMERCE

National Bureau of Standards

National Engineering Laboratory

Center for Fire Research

Gaithersburg, MD 20899
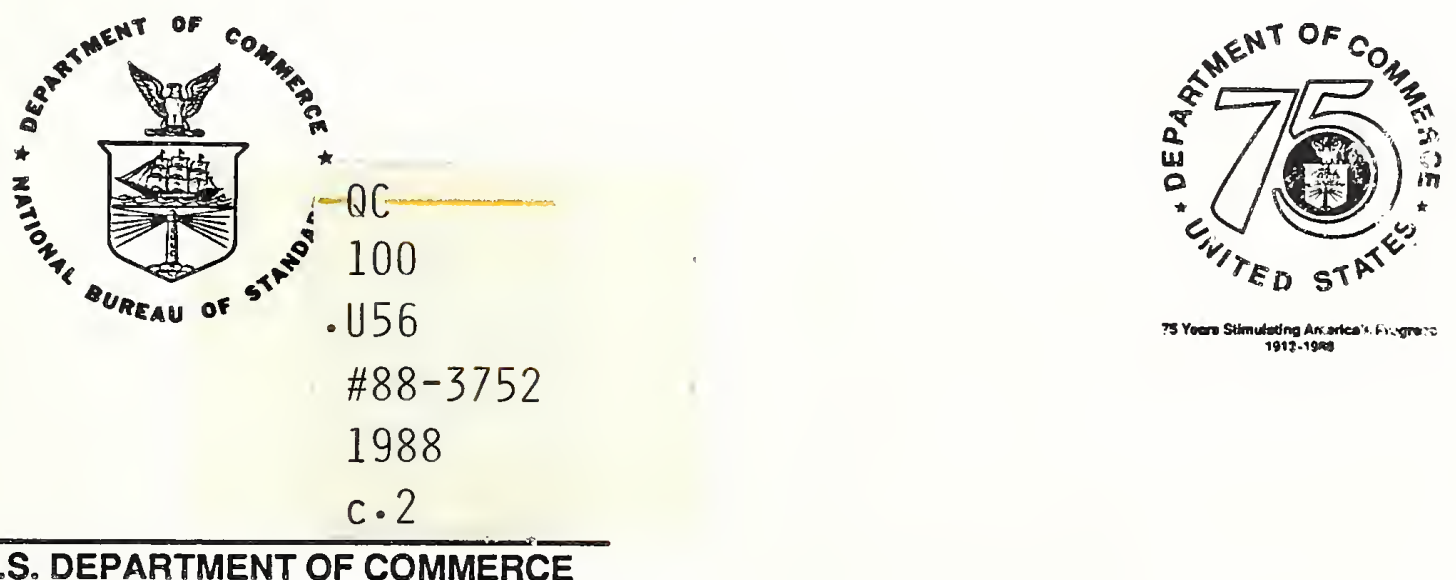

U.S. DEPARTMENT OF COMMERCE 

NBSIR 88-3752

AN EXPERIMENTAL DATA SET FOR THE ACCURACY ASSESSMENT OF ROOM FIRE MODELS

Richard D. Peacock

Sanford Davis

Billy T. Lee

U.S. DEPARTMENT OF COMMERCE

National Bureau of Standards

National Engineering Laboratory

Center for Fire Research

Gaithersburg, MD 20899

April 1988

U.S. DEPARTMENT OF COMMERCE, C. William Verity, Secretary NATIONAL BUREAU OF STANDARDS, Ernest Ambler, Director 

LIST OF TABLES . . . . . . . . . . . . . . . . . . . . . . . v v

LIST OF FIGURES . . . . . . . . . . . . . . . . . . . . . . . . . . . vi

Abstract . . . . . . . . . . . . . . . . . . . . . . 1

1. INTRODUCTION . . . . . . . . . . . . . . . . . . . . . . . 1

1.1 Room Fire Modeling . . . . . . . . . . . . . . . . . . . 4

1.2 Purpose and Scope of the Report . . . . . . . . . . . . . 5

2. THE ACCURACY ASSESSMENT PROCESS . . . . . . . . . . . . . . . . . . . . 7

2.1 Documentation of the Model . . . . . . . . . . . . . . 7

2.2 Sensitivity Analysis . . . . . . . . . . . . . . . . . 8

2.3 The Experimental Phase . . . . . . . . . . . . . . . . 10

2.4 Review and Analysis of the Model and Experimental Data . . . . 11

3. APPARATUS AND PROCEDURES . . . . . . . . . . . . . . . . . . . . . . . 14

3.1 Experimental Design . . . . . . . . . . . . . . . . . . . . . 14

3.1.1 Model Parameters to be Examined . . . . . . . . . . . . 15

3.1.2 Tests Conducted and Data Collected . . . . . . . . . . 16

3.2 Room Configuration and Construction . . . . . . . . . . . . . 17

3.3 Test Procedure . . . . . . . . . . . . . . . . . . . . 18

3.4 Instrumentation . . . . . . . . . . . . . . . . . 20

3.4.1 Temperature Based Measurements . . . . . . . . . . . . 21

3.4.2 Pressure Based Measurements . . . . . . . . . . . . . . 24

3.4.3 Smoke Obscuration Based Measurements . . . . . . . . . 24

3.4.4 Exhaust Hood Measurements . . . . . . . . . . . . . 25

3.5 Tests Conducted . . . . . . . . . . . . . . . . . . . 26

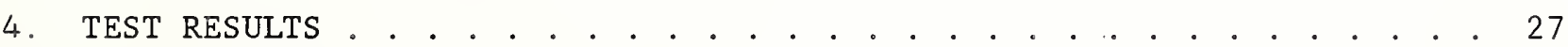

5. ANALYSIS OF TEST RESUlTS . . . . . . . . . . . . . . . . . . . . . 31

5.1 Quantities Derived From Room Measurements . . . . . . . . . . . 31

5.1.1 Quantities Derived From Temperature Based Measurements .. . . . . . . . . . . . . . . . . . . . 31

5.1.2 Quantities Derived From Pressure Based Measurements . . 38

5.1.3 Quantities Derived From Smoke Obscuration Based Measurements . . . . . . . . . . . . . . . . . . 40

5.2 Quantities Derived From Exhaust Hood Measurements ... . . . . . 43

5.3 Mass and Heat Balances .. . . . . . . . . . . . . . . 45

5.4 The Two Zone Assumption . . . . . . . . . . . . . . . . . . . . 46

5.5 Comparison With Model Data, A Sample Use of the Data . . . . . 48

6. SUMMARY AND RECOMMENDATIONS . . . . . . . . . . . . . . . . . . . 51

6.1 General . . . . . . . . . . . . . . . . . . . . . . . . . . 51

6.2 Considerations for Future Test Series... . . . . . . . . . . 52 
7. ACKNOWLEDGEMENTS . . . . . . . . . . . . . . . . . . . . . . 53

8. REFERENCES . . . . . . . . . . . . . . . . . . . . . 54 


\section{LIST OF TABLES}

page

Table 1. Room Dimensions . . . . . . . . . . . . . . . . . . . . . 97

Table 2. Construction Materials . . . . . . . . . . . . . . . 98

Table 3. Location of Instrumentation . . . . . . . . . . . . . . 99

Table 4. Initial Conditions for Tests With Gas Burner (Third Room Closed) .................... . . 103

Table 5. Initial Conditions for Tests With Gas Burner (Third Room Open) . . . . . . . . . . . . . . . . . 104

Table 6. Observed Steady State Smoke Layer Heights . . . . . . . . . 105

Table 7. Effect of Second Room Lights and Pilot Flame on Neutral Plane in Second room exit doorway . . . . . . . . . . 106

Table 8. Average Measurements With Error Estimations for Data Collected During Model Accuracy Assessment Experiments. . . . 107 


\section{LIST OF FIGURES}

page

Figure 1. Experimental layout and instrumentation configuration for gas burner tests. . . . . . . . . . . . . . . . . . . . . . 57

Figure 2. Measured mass flow out through first room doorway estimated from temperature profiles in first room doorway during several tests, along with estimated repeatability for SET 4 (100kW, open second room exit doorway, open third room) . . . 58

Figure 3. Measured height of hot / cold layer interface in second room during several tests, estimated from temperature profiles in second room, along with estimated repeatability for SET 4 (100kW, open second room exit doorway, open third room) . . . 59

Figure 4. Measured average temperature of hot layer in second room during several tests, along with estimated repeatability for SET 4 (100kW, open second room exit doorway, open third room)

Figure 5. Measured rate of heat release measured by oxygen consumption calorimetry during several tests, along with estimated repeatability for SET 4 (100kW, open second room exit doorway, open third room) . . . . . . . . . . . . . 61

Figure 6. Mass flow in through first room doorway estimated from temperature profiles in first room doorway . . . . . . . . . 62

Figure 7. Mass flow out through first room doorway estimated from temperature profiles in first room doorway . . . . . . . . 63

Figure 8. Mass flow in through second room exit doorway estimated from temperature profiles in second room exit doorway . . . . . . . 64

Figure 9. Mass flow out through second room exit doorway estimated from temperature profiles in second room exit doorway . . . . 65

Figure 10. Mass flow in through third room doorway estimated from temperature profiles in third room doorway . . . . . . . . . . 66

Figure 11. Mass flow out through third room doorway estimated from temperature profiles in third room doorway . . . . . . . . 67

Figure 12. Height of hot / cold layer interface in first room estimated from temperature profiles in first room . . . . . . . . 68

Figure 13. Height of hot / cold layer interface in first room doorway estimated from temperature profiles in first room doorway 
Figure 14. Height of hot / cold layer interface in second room near first room, estimated from temperature profiles in second room . . . . . . . . . . . . . . . . . . . . 70

Figure 15. Height of hot / cold layer interface in second room middle, estimated from temperature profiles in second room . . . . . . 71

Figure 16. Height of hot / cold layer interface in second room near second room door, estimated from temperature profiles in second room . . . . . . . . . . . . . . . . . 72

Figure 17. Height of hot / cold layer interface in second room exit doorway, estimated from temperature profiles in second room exit doorway . . . . . . . . . . . . . . . . . . 73

Figure 18. Height of hot / cold layer interface in third room estimated from temperature profiles in third room . . . . . . . . . . . 74

Figure 19. Height of hot / cold layer interface in third room doorway estimated from temperature profiles in third room doorway . . 75

Figure 20. Average temperature of hot layer in first room . . . . . . 76

Figure 21. Average temperature of cold layer in first room . . . . . . . 77

Figure 22. Average temperature of hot layer in second room . . . . . 78

Figure 23. Average temperature of cold layer in second room . . . . . . 79

Figure 24. Average temperature of hot layer in third room . . . . . . . 80

Figure 25. Average temperature of cold layer in third room . . . . . . 81

Figure 26. Layer interface position and layer temperatures in the three rooms for one test (SET 4, 100kW, open second room exit doorway, open third room) . . . . . . . . . . . . . 82

Figure 27. Comparison of mass flow in first room doorway for mass flow calculations based upon temperature profiles and based upon pressure profiles in the first room doorway . . . . . . . . . 83

Figure 28. Neutral plane height in first room doorway . . . . . . . . . . 84

Figure 29. Neutral plane height in second room exit doorway . . . . . . 85

Figure 30. Neutral plane height in third room doorway . . . . . . . . . 86

Figure 31. Comparison of neutral plane height in first room doorway from calculations based upon temperature profiles and based upon pressure profiles in the first room doorway . . . . . . . 87 
Figure 32. Height of hot / cold layer interface in second room estimated from measured smoke obscuration in second room . . . 88

Figure 33. Comparison of hot / cold interface in second room estimated from temperature profiles and from measured smoke obscuration in second room . . . . . . . . . . . . . . . . . . . 89

Figure 34. Rate of heat release measured by oxygen consumption calorimetry . . . . . . . . . . . . . . . . . . 90

Figure 35. Temperature profiles in second room along with estimated height of hot / cold layer interface in second room . . . . . 91

Figure 36. Average temperature profiles for open and closed door tests along with layer temperatures estimated with two zone assumption . . . . . . . . . . . . . . . . 92

Figure 37. Comparison of predicted and measured mass flows out of the doorways in the first, second, and third rooms for SET 4 (100kW, open second room exit doorway, open third room) . . . 93

Figure 38. Comparison of predicted and measured upper gas layer temperatures in the first, second, and third rooms for SET 4 (100kW, open second room exit doorway, open third room) . . . 94

Figure 39. Comparison of predicted and measured lower gas layer temperatures in the first, second, and third rooms for SET 4 (100kw, open second room exit doorway, open third room) . . . 95

Figure 40. Comparison of predicted and measured layer interface position in the first, second, and third rooms for SET 4 (100kW, open second room exit doorway, open third room) . . . 96 
An Experimental Data Set for the Accuracy Assessment of Room Fire Models

Richard D. Peacock, Sanford Davis, and Billy T. Lee

\begin{abstract}
The development of experimental data for use in computer fire model accuracy assessment is described. The tests were conducted in a heavily instrumented structure to provide data on temperatures and mass and heat flows in a simple multi-room configuration. Several series of carefully designed experiments were carried out changing important physical parameters one at a time with several replicates of each configuration.

The current state of understanding in computer fire model accuracy assessment is discussed with the data presented forming an example of one step of the process.
\end{abstract}

Key Words: Accuracy assessment; data analysis; experiments; fire tests; instruments; fire models

\title{
1. INTRODUCTION
}

The development of analytical models for predicting fire behavior has been an ongoing process within the fire research community for a number of years. Individuals have endeavored to describe in mathematical language the various phenomena which have been observed in fire research. These separate representations often describe only a small part of a fire experience but, when combined, create a complex computer code intended to give an estimate of expected behavior based upon given input parameters. These analytical models have progressed to the point of providing predictions of fire behavior; however, it is important to be able to state with confidence how close are the actual conditions to those predicted by the model. 
Several systematic test series have been undertaken specifically to provide data for comparison with model predictions; in other cases, tests in which fire properties have been systematically varied (for various reasons) have been modeled using current computer fire simulations. In the first category are the study of Alpert et al [1]" for a single room connected to a short, open corridor, and that of Cooper et al [2] for gas burner fires in a room-corridor-room configuration. The second category is large, but the works of Quintiere and McCaffrey [3], and Heskestad and Hill [4] are particularly detailed.

Quintiere and McCaffrey describe a series of experiments designed to provide a measure of the behavior of cellular plastics in burning conditions related to real life. They experimentally determined the effects of fire size, fuel type, and natural ventilation conditions on the resulting room fire variables, such as temperature, radiant heat flux to room surfaces, burning rate, and air flow rate. This was accomplished by burning up to four cribs made of sugar pine or of a rigid polyurethane foam to provide a range of fire sizes intended to simulate fires representative of small furnishings to chairs of moderate size. Although few replicates were included in the test series, fuel type and quantity, and the room door opening width were varied. The data from these experiments were analyzed in terms of quantities averaged over the peak burning period to yield the conditions for flashover in terms of fuel type, amount, and doorway width. The data collected were to serve as a basis

Numbers in brackets refer to literature references listed in Section 7 at the end of this report. 
for assessing the accuracy of a mathematical model of fire growth from burning cribs.

Heskestad and Hill performed a series of 60 fire tests in a room / corridor configuration to establish accuracy assessment data for theoretical fire models of multi-room fire situations with particular emphasis on health care facilities. With steady state and growing fires from $56 \mathrm{~kW}$ to $2 \mathrm{MW}$ measurements of gas temperatures, ceiling temperatures, smoke optical densities, concentrations of $\mathrm{CO}, \mathrm{CO}_{2}$, and $\mathrm{O}_{2}$, gas velocities, and pressure differentials were made. Various combinations of fire size, door opening size, window opening size, and ventilation were studied. In order to maximize the various combinations, only a few replicates of several of the individual test configurations were performed.

In 1983, the Center for Fire Research (CFR) initiated a program to develop the generic methodology for the evaluation and accuracy assessment of fire models. Our ultimate goal is to define a mechanism by which the model predictions can be assessed so that a model user can make a judgment as to its soundness and thus measure the confidence limits associated with the model predictions. To this end, one specific model was chosen (the FAST model-Fire and Smoke Transport [5]) which was well advanced in its development and was fairly well documented by the modeler. A carefully constructed and wellinstrumented large-scale fire test facility was developed in order to provide experimental data for the evaluation of the FAST and other models. This report describes one step in the process of the evaluation of fire models by presenting and documenting a series of experimental large scale fire tests, 
independent from the fire model development, which may be used for comparison with fire model predictions.

\subsection{Room Fire Modeling}

Jones [5-7], has developed a model which allows one to predict the evolution of a fire in a room and the subsequent transport of the smoke and toxic gases which evolve from this fire. Using the series of tests described in this report for comparison with the model predictions, the usefulness of the base of data reported herein can be illustrated.

The primary element of this model is the compartment. As the interest in these predictive schemes lies in the environment, the model is structured around fluid transport phenomena. In this context, the predictive equations for the gas layers in each compartment result from conservation of mass, momentum, and energy, an equation of state for each compartment, and the boundary conditions to which each compartment is subject. The actual physical phenomena which drive the transport (e.g., the fire) are then expressed as source terms. Such a formulation allows flexibility in adding, modifying, or deleting terms which are appropriate to the problem at hand.

Each compartment is subdivided into "control volumes." The choice is based on the premise that the details which occur within such a volume do not concern us (at present), but their interaction does. Each control volume is called a zone. The rationale for such a choice arises from the observation 
that when a fire grows and spreads, the gas layers in the compartments actually stratify into distinct zones. It is a compromise between a network model and a finite difference model. The former is computationally fast but yields no information on the internal structure. The latter is too computationally intensive to be useful for the problems at hand. The present model (FAST) uses two zones for each compartment. Thus, the model outputs (in the form of calculated quantities within an assumed homogeneous layer) and the experimental outputs (in the form of measured or derived quantities averaged within a similarly defined layer) may be compared for a number of quantities. In addition to the level of agreement between the compared quantities, an assessment of the validity of the two zone and other assumptions underlying the model is critical.

\subsection{Purpose and Scope of the Report}

The initial accuracy assessment experiments were conceived to allow comparisons and accuracy assessment of the major predicted quantities in the FAST model which are driven by energy (heat). These include the temperatures of the upper and lower layers (air), the position of the interface separating the two layers, and the mass flow through the openings between the compartments. Other major predicted quantities in the model relating to the production and distribution of mass in the form of smoke and chemical species will be the subject of future work, as these require the use of a more realistic fire source, carefully defined with respect to smoke and chemical species production. 
This report does not provide a full verification of the FAST model. Rather, it

- documents a series of experiments designed for the accuracy assessment process for the model, and

- provides a base of data, independent from the model development that can be used for the accuracy assessment of room fire models.

Derived outputs from individual raw data elements are presented together with the mathematical treatment used to make the calculations.

Section 2 summarizes a procedure for fire model accuracy assessment and outlines the necessary steps in the process. Section 3 presents a description of the instrumentation utilized in the test series together with a discussion of the techniques of fire test instrumentation. In section 4, the test results and normalization techniques used to minimize the between-test variations are presented. Section 5 examines the test data, combining the raw data collected into several derived quantities to provide a manageable set of data for analysis of model validity. A comparison of the data to a sample model output is presented in section 6 to illustrate the use of the data. While the experiments were designed with one model in mind, they should be applicable to other similar room fire models. 


\section{THE ACCURACY ASSESSMENT PROCESS}

In essence, every experiment is an attempt to verify a model. In the simplest case, the model is a hypothesis which is based on some observed phenomenon - or even a single observation -. and raises the question "why"? The hypothesis then needs to be tested to determine whether the observation is repeatable and to help define the boundaries of the hypothesis. In as simple a case as presented here, a "yes" or "no" answer may suffice in evaluating the agreement between the model and experiment. For more complex models, the question to be answered is not does the model agree with experiment, but rather how close does the model come to the experiment. A quantification of the degree of agreement between a model and perhaps many experiments is the subject of the model accuracy assessment process.

\subsection{Documentation of the Mode1}

For an analytical model designed for predicting fire behavior, the process of accuracy assessment is similar to the single observation case above, but perhaps more extensive because of the complexity of the model. The first step in the process is thorough documentation of the model so that other modelers can use it and so that its testing can be properly designed. The basic structure of the model, including the limitations, boundary conditions, and fundamental assumptions must be clearly described. Additionally, the functional form of the input parameters must be well-defined to allow any experiments carried out in the accuracy assessment process to be properly 
simulated (what are the inputs; what are the appropriate units for each); the same applies to the model outputs. In this way, the format of the experimental input and output can be defined to match that of the model.

\subsection{Sensitivity Analysis}

The sensitivity analysis of a model is a quantitative study of how changes in the model parameters affect the results generated by the model. The parameters through which the model is studied consist of those variables which are external to the program, (i.e., input variables), those variables which are internal to the program, (i.e., encoded in the program), and the assumptions, logic, structure, and computational procedures of the model. For this discussion, the model will be considered to be defined by its assumptions, logic, structure, and computational procedures and its sensitivity will be measured in terms of its external and internal variables. The key questions of interest to be investigated by the analyst are: 1) what are the dominant variables? 2) what is the possible range of the result for a given input that may arise from uncertainties within the model? and 3 ) for a given range of an input variable, what is the expected range for the result?

Sensitivity analysis of a model is not a simple task. Fire models typically have numerous input parameters and generate numerous output responses which extend over the simulation time. So multiple output variables must each be examined over numerous points in time. To examine such a model, many (likely to be more than 100) computer runs of the model must be made and 
analyzed. Thus, if the model is expensive to run or if time is limited, a full analysis is not feasible and the set of variables selected for study must be reduced. When the set of variables to be investigated must be reduced, a "pre-analysis" for the important variables can be performed or the important variables can be selected by experienced practitioners.

Classical sensitivity analysis examines the partial derivatives of the underlying equations behind a model with respect to its variables in some local region of interest. A complex model may be sensitive to changes in a variable in one region while insensitive in another region. In addition, it is most likely to be unfeasible to determine the intervals for each variable for which a complex model is sensitive. This suggests that stating a single value as a measure of sensitivity is not always sufficient and, consequently, some measure of its variability should be determined in order to make a global statement of how sensitive a model is to a variable.

Several methods for estimating the sensitivity of a model to its variables are available, each with its advantages and disadvantages. The choice of method is often dependent upon the resources available and the model being analyzed. It is beyond the scope of this paper to go into the details of any of these. 


\subsection{The Experimental Phase}

Once an assessment has been made of the relative importance of the model parameters, a selection process is carried out to determine which parameters will be studied in the experimental phase of the accuracy assessment process. Typically, with a fixed budget for model testing, tradeoffs are made in the selection of the number and range of variables to be studied, replication of the experiments, and complexity of the experiments to be performed. Elements of a well-designed experimental program, discussed below, address these tradeoffs so that the model assessment can be carried out with the available resources.

The number of possible tests, while not being infinite, is quite large. It is unreasonable to expect all possible tests to be conducted. The need exists to use reason and some form of experimental design strategy to optimize the range of results while minimizing the number of tests. While this is not the forum for a detailed discussion of experimental design, some elaboration is required. Traditionally, a latin-square arrangement or full factorial experimental design is employed to determine the effect of variations in input conditions on output results. [8] This, as expected, results in the number of tests increasing with the number of input variables and variations. However, there exists a reduced factorial experimental plan [9] called fractional replication. The basic concept behind fractional replication is to choose a subgroup of experiments from all possible combinations such that the chosen experiments are representative, amenable to analysis, and provide the maximum 
amount of information about the model from the number of observations available.

The choice of data to be collected during the experimental phase depends upon the model under evaluation. A description of the input and output data of the model provides guidance in the selection of the measurements to be made. After having reviewed the fire model and accepting it for validation, the evaluator or test engineer must constrain the range of test conditions to those which are applicable to the fire model. The test design then selects a varied and representative set of conditions (i.e., enclosure configuration, fuel loading, fuel type, ignition mechanism) from this range.

The evaluator develops the instrumentation design by starting with the model output data and determining suitable algorithms for generating comparable data output from the large-scale tests. This defines the instrumentation requirements, and experience is used to define instrument placement.

\subsection{Review and Analysis of the Model and Experimental Data}

Large-scale tests are performed according to the experimental plan designed by the evaluator. The individual data instrumentation, of which there may be one to two hundred, have to be carefully installed, calibrated, and documented as to what they measure and where they are located. Since it is rare to find an individual raw data observation that can be compared to the 
model output, single data elements are combined to provide derived data which can be compared to the model. Using data collection techniques appropriate to the testing needs, the individual data points are collected and typically processed by computer to provide the desired outputs.

Expected and unexpected variations will define the level of replication for each set of test conditions [10]. There are many sources that can contribute to expected variation in large-scale fire tests, such as variations in the materials or assemblies to be tested, environmental conditions, instruments or apparatus, and calibration techniques used in the measuring process. Because of the non-uniformity of building materials normally encountered and the variability associated with fire exposures and combustion reactions, excellent repeatability is not expected. The development of an experimental plan is, to a large extent, the search for the major factors influencing the outcome of the measurements and the setting of tolerances for their variations. [11]

Within the constraints of a fixed budget, replication is usually limited to less than statistically desired to minimize the unexpected variations. The larger variations that result must be accepted and thus affect the level of confidence in the resulting model accuracy assessment.

As part of the data analysis of the large-scale tests, potential error sources must be quantitatively determined. There are recognized uncertainties in the instrumentation used for each data element as well as random and systematic "noise" in the data acquisition process. The unevenness of burning of a 
material or the turbulent nature of fluid motion in most fire situations also introduce "noise" into the data analysis process and erratic burning does so among replicate tests. Each step in the data reduction process contributes to the accumulated uncertainties.

Data analysis itself requires the development of a series of algorithms that combine individual data elements to produce the desired output parameter. Uncertainties within the experimental data arise from two sources: 1) variability in the physical processes and in their measurement, and 2) variability in initial conditions and experimental procedure. Data normalization, the process of adjusting the outputs of replicate tests to a common set of definitions, facilitates the analysis.

For the former, the raw data need to be normalized within a test because of the sequential nature of the data acquisition process, and replicate tests need to be normalized to separate errors in data output parameters that reflect variations in the physical phenomena and variations in experimental conditions. Time shifting of the data within a test to adjust for transducer response time is very common, as is time shifting of output data between replicate tests to assure that a critical phenomenon occurs simultaneously in all tests. [12] For example, an increase in the energy release rate of a burner or the occurrence of flashover could be defined as the reference point or critical phenomena for an analysis of deviations between replicate tests. The data output from multiple replicate tests may also be synchronized in a similar manner. For example, data collection may begin at different times in the replicate tests. Appropriate time shifting can provide a common defini- 
tion for the start of all tests. Ignoring these errors will increase the deviations observed between replicate tests and the calculated confidence intervals about the data. If the desired information reflects a low frequency phenomenon and the data contains high frequency "noise", appropriate filtering schemes can be applied to extract the desired data and thereby perhaps reduce the deviation error between replicate tests. Error propagation calculations can be used to determine where experimental precision is most limiting.

For the latter, variations in initial conditions are often accounted for with separate model runs at the appropriate conditions. Variations in experimental procedure are the most difficult to account for, often requiring additional testing once the proper technique has been defined.

As can be seen from this short discussion, data analysis of the largescale tests requires a significant effort before comparisons between the model and the large-scale tests are possible. The size of the data reduction program can be as large and complex as the model being evaluated.

\section{APPARATUS AND PROCEDURES}

\subsection{Experimental Design}

The experimental design was not completely set at the beginning due to the exploratory nature of this series of experiments, but was allowed to 
change as the need arose. While the development of the design formed the background for much of the discussion in section 2.3, most of the topics highlighted in that section apply to the design of the experimental plan for the current test series. Specifically, a discussion of the choice of parameters to be examined, the tests to be conducted, the data to be collected, and the level of replication is included below as applied to this study.

\subsubsection{Model Parameters to be Examined}

The parameters to be studied were selected as those major predicted quantities in multi-room fire models that are driven by energy. This choice allowed the study to be limited to a manageable set of parameters while providing insight into many of the predicted quantities in room fire models. The parameters of interest are temperatures of the upper and lower layers, the position of the interface separating the two layers, and the mass flow through the openings in the compartments. With the purpose defined, the experimental configuration and choice of variables for the experiments became clearer. Initially, the experience of a number of researchers defined the major experimental variables affecting the parameters of interest:

Layer temperatures: Interface position: Mass flows: fire size, room size, distance from fire source room door opening size, fire size

fire size, room door opening size, distance from fire source 
Later, a simple sensitivity analysis of a one room fire model confirmed much of this expert opinion. [13] Fire size and room door opening size can be easily varied. Within a limited budget, room size and distance from the fire source are not so easily handled. For the present test series, a three room configuration, with rooms of different sizes provided a workable compromise. This left three major variables whose chosen values were combined to define the experiments:

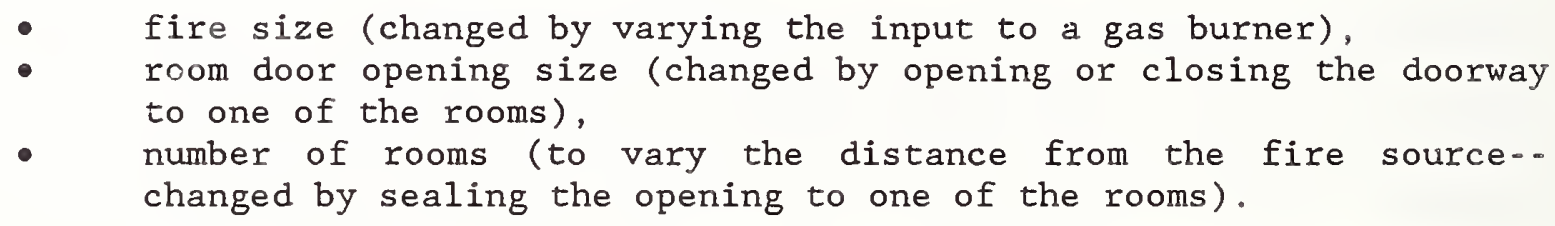

\subsubsection{Tests Conducted and Data Collected}

In total, nine different sets of experiments were conducted, with multiple replicates of each. From the variables to be examined:

- Fire sizes of 100,300 , and $500 \mathrm{~kW}$,

- Second room exit doorway open and closed, and

- Third room doorway open and closed,

a total of 45 tests were conducted. With the testing order randomized to minimize systematic errors, the tests are presented within each group of tests in the order conducted. For ease of discussion, each test was assigned a unique sequence number indicated the fire size and position within the test sequence. Fire size is indicated by a 100, 300, or 500 along with a suffix to 
distinguish between replicates. For instance, the $100 \mathrm{~kW}$ tests were labeled $100 \mathrm{~A}$ through $100 \mathrm{z}$ to $100 \mathrm{AB}$. Sections 3.2 to 3.5 provide details of the room construction, test procedure, and tests conducted.

Ideally, tests with all possible combinations of the variables would be conducted. However, built-in safety devices in the gas burner system prevented tests with the second room exit doorway closed for the 300 and 500 $\mathrm{kW}$ fire sizes. The larger fires reduced the available oxygen below that required to insure complete combustion of the methane / acetylene gas mixture. When this occurred, the safety systems automatically shut off the gas flow. Thus all combinations are available only for the $100 \mathrm{~kW}$ fire size.

The choice of model parameters to be examined dictated the data to be collected. Measurement of air temperature profiles from floor to ceiling allowed quantification of layer temperatures and interface positions. Smoke obscuration measurements provided an alternate method to determine interface position. Mass flows were determined with static pressure measurements along with temperature profiles in the doorways. Section 3.4 provides details of the measurements and of the instrumentation used to collect the data.

\subsection{Room Configuration and Construction}

The experimental arrangement is shown in figure 1 . It was a three compartment configuration, with two smaller rooms opening off of a long room $12.4 \mathrm{~m}$ long. Table 1 summarizes the dimensions of the three rooms. The first 
room, where the fire source was located, had $50 \mathrm{~mm}$ thick ceramic fiber insulation under a calcium silicate ceiling and over fire brick walls to minimize thermal losses through these surfaces and to facilitate the calculation of these thermal losses. The floor of the room was exposed fire brick. The second room ceiling and walls were constructed of steel studding with unfilled stud spaces with gypsum board sheathing with a covering of $13 \mathrm{~mm}$ calcium silicate board to assure structural integrity during prolonged exposures to a possible post-flashover fire plume from the door between the second and first rooms. The concrete floor in the second room was covered with $13 \mathrm{~mm}$ gypsum board to protect the concrete. The passageway from the second room to the first and third rooms was a small corridor (approximately $1 \mathrm{~m}$ wide $\mathrm{x} 1 \mathrm{~m}$ deep $\mathrm{x} 2 \mathrm{~m}$ high) constructed with the same materials as the second room. Since only warm air circulation was anticipated in the third room, the walls and ceiling were constructed from $13 \mathrm{~mm}$ gypsum board over metal studs, without the calcium silicate covering. The floor was exposed concrete. The construction materials used in this test series together with their thermophysical properties are given in table 2.[14-17] All material properties are literature values and should be considered approximate. Actual measurements were not performed on the materials used in the study.

\subsection{Test Procedure}

A diffusion flame burner using natural gas, placed snugly against the middle of the back wall of the first room, served as the fire source. The top side of the burner had a $0.34 \times 0.34 \mathrm{~m}$ porous ceramic surface with a perimeter 
of $13 \mathrm{~mm}$ wide steel plate. The porous surface was positioned $0.50 \mathrm{~m}$ above the floor. A $2.8 \mathrm{~kW}$ pilot flame was attached to the front of the burner. Initially, zinc chloride candles served as the smoke source. Their use was discontinued due to nonuniform time and spatial distributions of the smoke. Later experiments used a mixture of natural gas and acetylene in a heat release ratio of $77 \mathrm{~kW}$ of natural gas to $23 \mathrm{~kW}$ of acetylene $(0.31 \mathrm{~g}$ of acetylene per $g$ of natural gas) to achieve a concentration of smoke which provided a visible separation of the hot and cold layers during a test and provided constant smoke production throughout a test.

Tests were initially performed with the data recording system turned on for $300 \mathrm{~s}$ prior to the ignition of the burner gas, with the pilot ignited within this $300 \mathrm{~s}$ period. Beginning with tests $50 \mathrm{D}, 100 \mathrm{M}, 300 \mathrm{D}$ and $500 \mathrm{~A}$, a $300 \mathrm{~s}$ baseline period, followed by a $300 \mathrm{~s}$ pilot flame interval prior to burner ignition were also recorded for each test. This allowed an adequate time for the second room flow behavior associated with the pilot flame to reach steady conditions. The burner was allowed to run for $900 \mathrm{~s}$ with the data acquisition terminating after recording approximately $300 \mathrm{~s}$ of the cooling period.

Barometric pressure, ambient temperature, and relative humidity in the laboratory were recorded prior to each test within the building housing the test structure. Although no attempt was made to condition the system prior to each test, the building air conditioning system controlled the indoor air temperature. Ambient temperatures at the beginning of the tests ranged from 
20 to $23^{\circ} \mathrm{C}$. The air conditioning system was not capable of humidity control, and the relative humidity ranged from 42 to $74 \%$ for the tests.

Each test combination of fire size and configuration was repeated several times, over a time period where the ambient conditions were significantly different, to develop a statistically meaningful data base for each test situation.

\subsection{Instrumentation}

The locations of all instrumentation initially used in the rooms and adjacent exhaust collection hood are summarized in table 3 . Some of the instrumentation locations are also shown in figure 1. Data were recorded with an automatic data logging system at a rate of 24 channels per second.

Part way through the test program, the placement of thermocouples on the thermocouple trees in the first and second rooms were revised to permit greater resolution of the mass flow exhausting from the rooms. At that time, thermocouples were also installed on the unexposed back side of the second room ceiling and North wall to assist in the calculation of the conductive heat losses through these surfaces. In addition, a weighing platform was later installed in the first room, necessitating the removal of some instrumentation to allow for the placement of cables for the platform suspension system. All of these changes are summarized in part IV of table 3 . 
A $15.9 \mathrm{~mm}$ diameter orifice flow meter was used for metering the natural gas flow and a $200 \mathrm{SCFH}$ gas flow meter was used to monitor the acetylene flow. An ultra-violet flame sensor, facing the flame over the gas burner, was used in conjunction with a safety shut-off device which activated in case the flame extinguished.

Miscellaneous instrumentation listed under section III in table 3 was installed in these first tests to provide data for use in other, related projects. Those data are not discussed in this report.

\subsubsection{Temperature Based Measurements}

Presuming, for the moment, the validity of the two-zone assumption inherent in current fire growth models, temperature measurements were used to quantify upper and lower layer temperatures, the position of the interface between the two layers, mass flows through openings in connecting rooms, and heat conduction through the bounding surfaces of the rooms. Details of the instrumentation used to make these measurements is presented below. A discussion of the calculations along with an analysis of the data is in section 5 .

For all temperature measurements, the voltage outputs from the data acquisition system were converted to temperature units with automatic compensation to adjust the readings for changing ambient temperature. Errors due to conduction along the thermocouple leads were minimized by placing the leads in a horizontal (near isothermal) plane. No corrections were made for 
heat losses from the thermocouple wires for any of the instrumentation. Steckler, Quintiere, and Rinkinen [18] have studied the error introduced by neglecting the radiative losses from the thermocouple leads. They define the radiation error, the difference between the gas temperature of a flowing gas and the indicated thermocouple temperature as a function of the thermocouple temperature and the gas velocity. For a series of 55 experiments studying flow through openings, the errors ranged between -20 and $+16{ }^{\circ} \mathrm{C}$ for temperatures ranging from 50 to more than $250{ }^{\circ} \mathrm{C}$.

Cooper et al [2] have presented a method for defining the height of the interface between the relatively hot upper layer and cooler lower layer induced by a fire as a linear function of a vertical temperature profile within the room. Since the calculation depends upon a continuous temperature profile, linear interpolation is used to determine temperatures between measured points. A spacing of $0.15 \mathrm{~m}$ between measurement points was chosen to insure a resolution in the vertical temperature profile no greater than 5 percent of the room height. Thermocouple trees 1 through 8 were used to determine the interface position (one position per tree). For the first and third rooms, a single tree in each room was adequate due to the small size of the rooms. For the second room, however, three trees were placed along the length of the room to permit examination of the horizontal variation in layer interface height and layer temperature.

Once the interface position has been determined, it is a simple matter to ascertain the upper and lower layer temperatures as simply an average of 
the temperature profile within the respective layers. Again, all eight trees were used for this calculation.

Steckler, Quintiere, and Rinkinen [18] present a technique to calculate mass flows through openings based upon the ideal gas 1 aw and an integral function of the temperature profile within the opening. Again, a spacing of $0.15 \mathrm{~m}$ between measurement points insured a resolution of the vertical temperature profile no greater than 5 percent of the room height.

Temperatures on the exposed wall and ceiling surfaces were measured with chromel-alumel thermocouples fabricated from $0.51 \mathrm{~mm}$ diameter wire. The measurement of temperatures on the material surface or within the material is less affected by thermal radiation than that of air temperature. Consequently, larger size thermocouples which are less prone to breakage, were used. Heat transfer to the wall and ceiling surfaces can be estimated from these measurements using a finite difference method described by Fang and Breese. [19] Again, with the two zone assumption, an estimate of the temperature of surfaces in the upper layer and lower layer are required. Surface temperature measurements near the ceiling and near the floor fulfill this need. Full vertical or horizontal temperature profiles were unnecessary since the validity of the two zone assumption can be tested with the air temperature profiles. Thermocouples were placed on the wall, ceiling and floor surfaces in room 1 and room 2 adjacent to the thermocouple trees used to measure air temperature. Since little heat was expected in room 3, no instrumentation was included in this room to measure surface temperatures. 


\subsubsection{Pressure Based Measurements}

Lee [20] describes a method to calculate the mass flow through an opening as an integral function of the temperature profile in the doorway and of the pressure drop across the doorway. Measurement of the temperature profile has been detailed above. Since the pressure drop across an opening approaches zero and the direction of flow changes, measurement of the pressure profile in the doorway is particularly difficult. Estimation of the pressure in the extreme lower resolution of the instrumentation (as the pressure drop approaches zero) yields an inherently noisy measurement. As such, these measurements were used only as an alternate method to the temperature method described above to provide an assessment of the consistency of the data collected. With the realization of the lesser importance of these measurements combined with dramatically higher instrumentation costs (several orders of magnitude higher than the temperature measurements), a less detailed profile of measurement points was used for the pressure profile. Measurement points approximately every $0.3 \mathrm{~m}$ apart provided a resolution within about 10 percent of the room height.

\subsubsection{Smoke Obscuration Based Measurements}

Bukowski [21] provides designs for instrumentation to measure smoke obscuration in both large and small scale experiments. A collimated light source and directly opposed photometer receiver provide a measure of the 
percentage of the light output by the source that reaches the photometer. Smoke meters designed to Bukowski's recommendations were used to measure smoke obscuration in the second room near the middle thermocouple tree.

Bukowski [22] first suggested a way to use two smoke meters to deduce the location of the interface in a buoyantly stratified compartment. In his method, if a two zone model is assumed ( a smoke-filled homogeneous upper zone and a clear lower zone), the use of a vertical smoke meter and a horizontal smoke meter in the upper zone can be used to determine the smoke layer thickness.

\subsubsection{Exhaust Hood Measurements}

A $3.7 \mathrm{~m} \times 4.9 \mathrm{~m}$ hood, having an exhaust flow capacity of about $3 \mathrm{~m}^{3} / \mathrm{s}$, was situated over the doorway from the second room and collected the exhaust from the fire tests. Temperatures, velocities, and oxygen and carbon dioxide concentrations in the exhaust collection hood were monitored with the instrumentation listed in section II of table 3. With these measurements, Huggett [23] and Parker [24] detail a method to determine the rate of energy production of the fire based upon oxygen consumption calorimetry. 


\subsection{Tests Conducted}

Three sizes of gas fires having heat release rates of $100 \mathrm{~kW}, 300 \mathrm{~kW}$, and $500 \mathrm{~kW}$ were conducted under the following configurations:

a) Open second room exit doorway, third room doorway closed

b) Closed second room exit doorway, third room doorway closed

c) Open second room exit doorway, third room doorway open

d) Closed second room exit doorway, third room doorway open

Al1 of the tests are described in tables 4 and 5 . Tests $50 \mathrm{~K}, 100 \mathrm{~F}$ and $100 \mathrm{~K}$ had experimental difficulties and were excluded from the tables. For tests $50 \mathrm{D}, 300 \mathrm{D}$, and $300 \mathrm{E}$, the fuel to the burner was cut off prematurely by the ultraviolet flame sensor.

Auxiliary experiments were also undertaken as part of these mainstream tests or conducted separately to help elucidate problem areas. One area of concern involved the determination of the thermal discontinuity in the second room and of the neutral plane locations in the first room doorway and second room exit doorway.

In the closed door tests, a doorway having a realistic $20 \mathrm{~mm}$ undercut was used. Unfortunately, measurement or calculation of the flow under the door was difficult. In test $100 \mathrm{0}$, the undercut in the door was sealed. An opening in the floor, near the door, with an orifice having about the same area as the undercut was used to measure the equivalent flow through the latter. 


\section{TEST RESULTS}

Due to the sheer volume of data collected, it was impractical to present all of the data recorded during all of the tests conducted. With judicious definitions of initial conditions for many of the instruments, the data was be combined into a smaller and more manageable set of data. Further computer processing allowed conversion from the voltage outputs of the various transducers to meaningful engineering units and additional calculations on the recorded data. To facilitate the calculation process, a specially designed computer program for the reduction of full scale fire test data was utilized. [25] In addition to easing the burden of repetitive and similar calculations, the program provides a standard set of algorithms for the analysis of fire test data. It was used throughout the test series for all tests conducted.

The tests in this first series can be broken down into nine different categories as follows: 


\begin{tabular}{|c|c|c|c|c|c|c|c|}
\hline Set & $\begin{array}{l}\text { Fire } \\
\text { Size }\end{array}$ & $\begin{array}{l}\text { Second Room } \\
\text { Exit Doorway }\end{array}$ & $\begin{array}{l}\text { Third } \\
\text { Room }\end{array}$ & & Tests & & \\
\hline 1 & $100 \mathrm{~kW}$ & Open & No & $\begin{array}{l}100 \mathrm{~A}, \\
100 \mathrm{D}, \\
100 \mathrm{G}, \\
100 \mathrm{~J}\end{array}$ & $\begin{array}{l}100 \mathrm{~B}, \\
100 \mathrm{E}, \\
100 \mathrm{H}, \\
100 \mathrm{~K}\end{array}$ & $\begin{array}{l}100 \\
100 \\
100\end{array}$ & $\begin{array}{l}\text { C, } \\
\text { F, } \\
I,\end{array}$ \\
\hline 2 & $100 \mathrm{~kW}$ & Closed & No & $\begin{array}{l}100 \mathrm{~L} \\
100 \mathrm{O}\end{array}$ & $100 \mathrm{M}$ & $100 \mathrm{I}$ & $\mathrm{N}$, \\
\hline 3 & $100 \mathrm{~kW}$ & Closed & Yes & $\begin{array}{l}100 \mathrm{P} \\
100 \mathrm{~S}\end{array}$ & $\begin{array}{l}100 \mathrm{Q} \\
100 \mathrm{~T}\end{array}$ & $100 \mathrm{~F}$ & $\mathrm{R}$, \\
\hline 4 & $100 \mathrm{~kW}$ & Open & Yes & $\begin{array}{l}100 \mathrm{U}, \\
100 \mathrm{X}, \\
100 \mathrm{AA}\end{array}$ & $\begin{array}{l}100 \mathrm{~V}, \\
100 \mathrm{Y}, \\
100 \mathrm{AB}\end{array}$ & $\begin{array}{l}100 \\
100\end{array}$ & $\begin{array}{l}\text { W, } \\
\mathrm{Z},\end{array}$ \\
\hline 5 & $300 \mathrm{~kW}$ & Open & No & $300 \mathrm{~A}$ & $300 \mathrm{~B}$ & 300 & C \\
\hline 6 & $300 \mathrm{~kW}$ & Closed & Yes & $300 \mathrm{D}$ & $300 \mathrm{E}$ & & \\
\hline 7 & $300 \mathrm{~kW}$ & Open & Yes & $300 \mathrm{~F}$, & $300 \mathrm{G}$ & 300 & $\mathrm{H}$ \\
\hline 8 & $500 \mathrm{~kW}$ & Open & No & $\begin{array}{l}500 \mathrm{~A} \\
500 \mathrm{D}\end{array}$ & $\begin{array}{l}500 \mathrm{~B} \\
500 \mathrm{E}\end{array}$ & $\begin{array}{l}500 \\
500\end{array}$ & $\begin{array}{l}\mathrm{C}, \\
\mathrm{F}\end{array}$ \\
\hline 9 & $500 \mathrm{~kW}$ & Open & Yes & $500 \mathrm{G}$ & $500 \mathrm{H}$ & 500 & I \\
\hline
\end{tabular}

Before the data from the nine groups can be analyzed, however, some normalization of the test results is necessary. Appropriate techniques for normalization of fire test data and model calculations is the subject of ongoing research sponsored by CFR. Although not sophisticated, the approach detailed below provides one approach to the normalization. As the results of the ongoing research become available, more sophisticated normalization techniques could be utilized. 
As detailed in tables 4 and 5, ambient temperatures, barometric pressures, and humidity changed from test to test due simply to seasonable variations. In addition, the duration of each test was slightly variable during the pretest period with the pilot light and in the cool down period. For a few tests, the main burn period was shortened due to an automatic shutoff in the gas flow line. To insure a self consistent definition across the test series and to allow comparison with model predictions beginning at a preset set of conditions, the data from all tests were normalized to minimize random scatter with a standard definition as follows:

- Time

- Temperature

- Pressure Difference

- Smoke Meters
Overall time bases move laterally so that $t=0$ corresponds to main burner ignition as evidenced by a distinct rise in temperature of a thermocouple located directly above the main burner.

Adjusted so that at $t=0$, all temperatures are equal and at an ambient temperature of $20{ }^{\circ} \mathrm{C}$. For each reading of each temperature channel, a normalization factor was added equal to (20Temperature $_{\mathrm{t}=0}$ ).

Adjusted so that at $t=0$, all measured pressure differences are equal and at an ambient definition equal to the average of the unadjusted pressures at $t=0$. For each reading of each temperature, a normalization factor was subtracted equal to the average of the pressure readings for the replicate tests at time $t=0$.

Adjusted so that at $t=0$, all smoke measurements are equal at a level of $0 \mathrm{OD} / \mathrm{m}$. For each reading of each smoke measurement channel, a normalization factor was subtracted equal to Smoke $_{\mathrm{t}=0}$.

The normalization of the time reading simply provides a consistent definition for the start of an experiment. Normalization for temperature, pressure, and smoke measurements allow elimination of the systematic variations introduced 
by the pilot light and by changes in ambient conditions at the beginning of the test.

With these definitions, the data from each of the nine groups was combined to produce a running mean value and standard deviation for each measurement and calculation, thus reducing the number of data sets to be examined from more than forty to nine. In addition, an assessment of the repeatability of the test procedure could be made.

Although it is unreasonable and not particularly useful to present all of the data collected from every test conducted, figures 2 through 5 show some of the data from one data set (100 kW, open second room exit doorway, open third room) and illustrate the data from the individual tests together with the average and standard deviation of the set of tests ( 8 in this case) as a function of time. Plots of mass flow out the first room door, layer height and upper layer temperature**, and rate of heat release are presented as samples of the data collected. Details of the calculations performed and of the average and standard deviation from all the data sets are discussed in the next section.

For all nine test conditions, table 8 presents the average of measurements over the period of "steady-state" burning, defined as the region between 300 and 900 seconds after ignition of the main burner. For each measurement, at time point, all replicate tests were averaged to determine a mean value and a

* * The uncertainty for the upper layer temperature; shown in figure 4, is due only to replication. A second source of variability, due to the method of calculation of the layer temperature, is discussed in section 5.1.1. 
standard deviation. To determine a "steady-state" value for each measurement, a weighted mean of these averages was computed acroos time. The weights used were inversely proportional to the variance at each time point, thereby placing greater confidence in those readings with a smaller standard deviation.

\section{ANALYSIS OF TEST RESULTS}

\subsection{Quantities Derived From Room Measurements}

\subsubsection{Quantities Derived From Temperature Based Measurements}

Air temperatures measured by the thermocouple trees 1,2 , and 3 were used to calculate the mass flow in and out the first room doorway using the following equations: [18]

$$
\dot{\mathrm{M}}=\mathrm{CW} \rho_{\mathrm{O}} \mathrm{T}_{\mathrm{O}} \int_{\mathrm{N}}^{\mathrm{H}}\left[\frac{2 \mathrm{~g}}{\mathrm{~T}_{\mathrm{D}}(\mathrm{z})} \int_{\mathrm{N}}^{\mathrm{Z}}\left[\frac{1}{\mathrm{~T}_{\mathrm{C}}(\mathrm{z})}-\frac{1}{\mathrm{~T}_{\mathrm{I}}(\mathrm{z})}\right] \mathrm{d} \mathrm{Z}^{\prime}\right]^{3 / 2} \mathrm{~d} \mathrm{z}
$$

Where: $C$ opening flow coefficient of 0.73 for outflow and 0.68 for inflow

$g$ gravitational acceleration $\left(9.80 \mathrm{~m} / \mathrm{s}^{2}\right)$

$\mathrm{H}$ opening height (m)

$M$ rate of air flow $(\mathrm{kg} / \mathrm{s})$

$\mathrm{N}$ height of neutral plane, refer to equation 7 (m)

$\mathrm{T}_{c}$ air temperature outside of room (K)

$\mathrm{T}_{\mathrm{o}}$ ambient air temperature (K)

$\mathrm{T}_{\mathrm{D}}$ air temperature in the room doorway $(\mathrm{K})$ 
$\mathrm{T}_{\mathrm{I}}$ air temperature inside the room $(\mathrm{K})$

$W$ opening width (m)

$\mathrm{Z}$ height above or below neutral plane (m)

$\rho_{\text {o }}$ ambient air density $\left(\mathrm{kg} / \mathrm{m}^{3}\right)$

The above equation is for steady state flow conditions. At early times, there is also a thermal expansion term resulting from the air in the room being heated by the fire source over time which must be added to equation ( 1 ). This additional transient mass flow is given for each time by the equation:

$$
\Delta \dot{\mathrm{m}}=\mathrm{V} \frac{\Delta \rho}{\Delta t}=\frac{V \rho_{0} \mathrm{~T}_{0}}{\Delta t}\left[\frac{1}{\mathrm{~T}_{i}}-\frac{1}{\mathrm{~T}_{i+\Delta t}}\right]
$$

where: $T_{i}$ temperature of air in upper half of room at time $i(K)$

$\mathrm{T}_{\text {o }}$ ambient temperature $(\mathrm{K})$

$\Delta t$ time increment between scans ( $s$ )

$\mathrm{V}$ room volume $\left(\mathrm{m}^{3}\right)$

$\rho$ air density $\left(\mathrm{kg} / \mathrm{m}^{3}\right)$

$\rho_{\text {o }}$ ambient air density $\left(\mathrm{kg} / \mathrm{m}^{3}\right)$

Similarly, air temperatures from trees 5, 7, and 8 were used to ascertain the mass flow through the doorway to the third room and trees 5 and 6 were used to determine flow through the second room exit doorway. Table 8 presents average mass flows through the doorways during the main burn period (from main burner ignition to main burner extinguishment). Figures 6 through 11 present the data over the entire test period.

During the "steady state" burning period, the inflow to any room should equal the outflow out of a room. For all three openings, a statistical t-test 
shows the mean difference between the comparable values for times from 300 to 900 seconds is significant at even the 99 percent confidence level:

\begin{tabular}{llcc} 
Room & $\begin{array}{c}\text { Mean Difference } \\
(\text { Inflow-Outflow }) \\
(\mathrm{kg} / \mathrm{s})\end{array}$ & Standard Deviation & $\begin{array}{c}\text { Confidence } \\
\text { Level }\end{array}$ \\
\hline 1 & 0.072 & 0.12 & 0.99 \\
2 & 0.36 & 0.34 & 0.99 \\
3 & 0.76 & 0.29 & 0.99 \\
\hline
\end{tabular}

The reasons for this are at least three-fold. Firstly, measurement problems with the static pressure probes (used to establish a reference pressure at floor level) led to less accurate measurements for all but SET 4 and SET 9 , introducing unpredictable but systematic errors in the flow measurements. Secondly, the technique used, as described by Steckler, et al [18] was developed for a single room exhausting into an infinite reservoir of ambient air. Applicability or extension of the technique for flow between rooms is currently under study. Since the technique depends upon the temperature gradient across the opening as a function of height, the choice of temperature conditions "outside" the opening may be important. Finally, the technique utilizes temperature changes from the neutral plane to the edges of the opening to calculate the flow. Because the smaller temperature change from the neutral plane is in the lower, cooler region, a small variation in temperature should cause more uncertainty in mass flow than in the upper, hotter region where the temperature gradient is larger. It should be noted that this is only a valid statement if a constant random error in temperature measurements is assumed for the two layers. 
As noted above, measurement problems prevented accurate measurement of the mass flows for many of the data sets. For SET 4 and SET 9 however, the agreement between inflow and outflow, accounting for the input from the gas burner and for thermal expansion, is quite good. A more detailed discussion of the mass balance is included in section 5.3.

As would be expected, flows through the doorway to the first room are significantly lower in tests where the second room exit doorway was closed than when the doorway was open. Comparing curves for SET 1 and SET 2, SET 4 and SET 3, or SET 5 and SET 6 confirm this.

The eight thermocouple trees also provided an indication of the thermal stratification at their respective locations. One of the simplifying assumptions underlying present zone fire models is that the flows within rooms and between rooms can be modeled from a small number (usually two) of distinct layers (zones) of gases. One method for defining an interface height for a two layer zone model, the interface between the smoke-filled upper zone and the relatively clear lower zone has been proposed by Cooper et al. [2] They proposed the following equation:

$$
\mathrm{T}_{s}=\mathrm{C}_{\mathrm{s}}\left[\mathrm{T}_{\mathrm{max}}-\mathrm{T}_{f}\right]+\mathrm{T}_{f}
$$

\footnotetext{
where $\mathrm{T}_{\mathrm{s}} \quad$ layer interface temperature $\mathrm{T}_{\mathrm{s}}(\mathrm{K})$

$\mathrm{C}_{\mathrm{s}}$ an empirically determined value of 0.2

$\mathrm{T}_{\max }$ the maximum measured air temperature (K)

$\mathrm{T}_{\mathrm{f}} \quad$ the air temperature near the floor
} 
The equivalent two zone layer height is the height where the measured air temperature is equal to the temperature $T_{s}$ as calculated from equation (3). Table 8 and figures 12 through 19 present the layer height data. From these figures, it is apparent that the effect of the third room on the layer height in the second room is small, whereas whether the second room exit doorway was open or closed makes a big difference. Comparing sets 1 and 4, 2 and 3, 5 and 7, or 8 and 9 in figure 15 shows a small time delay in the initial filling of the second room, but with a steady state layer height very similar for the sets with the second room exit doorway in the same position. This result follows logically from the added volume of the third room taking some time to fill, but ultimately allowing the second room to fill to the same depth.

Once the location of the interface has been determined, it is a simple matter to determine an average temperature of the hot and cold layers within the rooms as:

$$
T_{\text {avg }}=\int_{z_{1}}^{z_{u}} \frac{T(z)}{\left(z_{u}-z_{1}\right)} d z
$$

With a discrete vertical profile of temperatures at a given location, the integral was evaluated numerically with interpolation between the discrete measurement points. The average layer temperature (either of the lower layer or the upper layer), $\mathrm{T}_{\mathrm{avg}}$, is thus simply an average over the height of the layer from the lower bound of the layer, $z_{1}$, to the upper bound of the layer, $z_{u}$ for either the upper or lower layers. Table 8 and figures 20 through 25 present the layer temperature data. 
Some of the effects of flow through the doorways in the three rooms can be seen in figure 26 which shows layer interface position and layer temperatures in the three rooms for one of the configurations (SET 4, $100 \mathrm{~kW}$, open door, open third room). The following observations can be made from the figure:

- Layer height and layer temperatures in the door to room 1 are lower than those in room 1 , but closer to the readings in room 1 than to those in room 2 .

- Layer height and upper layer temperature at all positions in room 2 and in the door from room to the exhaust hood are almost equal. Lower layer temperature in the doorway to room 2 is lower than the lower layer temperature in room 2 .

- Layer height and upper layer temperature in the door to room 3 is about midway between the layer heights and upper layer temperatures in room 3 and room 2 .

With uniform layer temperatures and no mixing in the doorways, layer temperatures in the doorways should be equal to the temperature of the layer in the room from which the flow through the doorway is coming. For instance, upper layer temperature in the door to room 1 should be equal to the temperature of the upper layer in room 1 and lower layer temperature in the door to room 1 should be equal to the lower layer temperature in room 2. For the doorways to rooms 2 and 3 , this condition is reasonably upheld. For room 1 , however, the upper layer temperature in the doorway is lower than expected and the lower layer temperature is higher than expected. Since the calculated layer temperatures are average values of a temperature gradient in the room and the flow through the doorway comes from the lower portion of the layer, a somewhat lower temperature in the upper layer in the doorway can be expected. 
In addition, there may be mixing in the doorway which is in turn a result of the different layer heights in the two rooms. Jones and Bodart [26] describe the different possible flow fields in a vent depending upon the relative densities and interface heights in the two connected rooms. With different interface heights in the two rooms, multiple flow reversals make doorway mixing inevitable. The degree of mixing depends upon the flow and the amount of overlap of the layers in the two rooms.

Temperatures on the exposed wall and ceiling surfaces were measured with chromel-alumel thermocouples. Heat transfer to the walls and ceiling can be estimated from these measurements using the following equation. For heat conduction through a semi-infinite solid which is exposed to a net heat flux $\dot{q}^{\prime \prime}\left(\mathrm{kW} / \mathrm{m}^{2}\right):[19]$

$$
\dot{q}(N)=\theta^{-\frac{1}{2}}\left[C\left[T_{s}(0, t)-T_{i}\right]-\sum_{n=1}^{N-1} \dot{q}(n)\left[[N-(n-1) \theta]^{\frac{1}{2}}-[(N-n) \theta]^{1 / 2}\right]\right]
$$

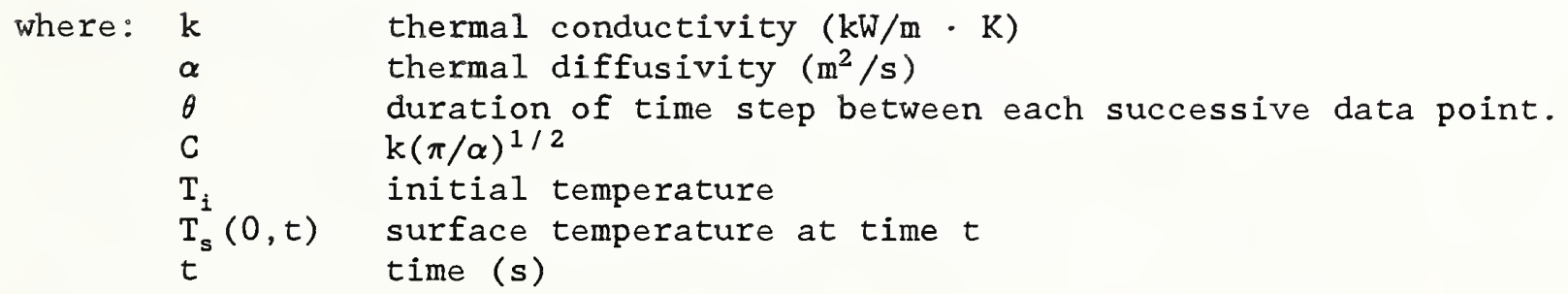

These measurements will be used, along with heat release rate measurements detailed later in the report, in an energy balance on the system. 


\subsubsection{Quantities Derived From Pressure Based Measurements}

Measurements of the pressure drop across doorways were made through the interior wall surfaces adjacent to the doorway opening to the second room and the doorway to the first room. These measurements were used with the following equation as an alternative method for calculating mass flow: [20]

$$
\dot{M}=C W\left(2 g_{0} \rho_{O} T\right)^{1 / 2} \int_{N}^{H}\left[\frac{\Delta P}{T_{D}}\right]^{1 / 2} d z
$$

where $\Delta \mathrm{P}\left(\mathrm{kg} / \mathrm{m}^{2}\right)$ is the air pressure above ambient and the other terms are defined as in equation (1). Equation (6) will be used to calculate the overall mass balance on the system in section 6.3 , below.

Figure 27 shows a comparison of the mass flow through the first room door calculated from temperature measurements, equation (1) and (2), and from pressure measurements, equation (6), made in the doorway for one of the configurations (100 kW, open second room exit doorway, open third room). Comparing the mass flow calculations, it is apparent that the temperaturebased calculations result in a higher mass flow in the doorway and a lower mass flow out the doorway than for the pressure-based calculations. This is consistent with the difference in calculated neutral plane height for the two methods, discussed below. 
The pressure measurements were also used to determine the neutral plane height, $N$, required in equations (1) and (8). The neutral plane is obtained by solving for $N$ in the equation: [20]

$$
\Delta \mathrm{P}_{\mathrm{Z}_{1}}+\rho_{0} \mathrm{~g} \int_{\mathrm{Z}_{1}}^{\mathrm{N}}\left[1-\frac{\mathrm{T}_{0}}{\mathrm{~T}_{\mathrm{D}}}\right] \mathrm{dZ}=0
$$

where $\Delta \mathrm{P}_{\mathrm{Z}_{1}}$ is the increase in air pressure above ambient at height $\mathrm{Z}_{1}$. Table 8 and figures 28 through 30 present the neutral plane height calculated from the pressure probe measurements.

Figure 31 shows a comparison of neutral plane height calculated from pressure profiles, equation (7), and from temperature profiles, equation (3). As can be seen from the figure, the neutral plane height calculated from the pressure profile measurements is significantly lower than that calculated from the temperature profile measurements. The difference can be attributed to the different measurement techniques used to make the measurements. In general, as discussed above in section 4.3, measurement of flows using commercially available pressure transducers is difficult due to the extremely low pressures involved. Compounding the problem for the measurement of the neutral plane height is the desire to know where the flow is exactly zero. Thus, the most important measurement points are those with the smallest magnitude, just on either side of the neutral plane. Since the neutral plane calculation from pressure measurements searches for the point of zero pressure from the floor up, the calculated point of zero pressure is consistently low. 
In addition, the potential for multiple neutral planes within an opening further complicates the measurement of flow with pressure-based measurements. Jones and Bodart [26] have described in detail the fluid transport through vents to incorporate in smoke transport models an improved fluid transport model with up to three neutral planes within a single opening. With potentially different layer boundaries in the two rooms connected to the opening, cross flows are shown possible between the layers leading to from one to three flow reversals depending upon the relative positions of the two layer boundaries.

Temperature based measurements have far less dependency on the low flow region of the opening, relying on only one pressure measurement near the bottom (or top) of the opening where the pressure gradient is highest. Thus, for the determination of neutral plane height, the temperature based measurement technique seems preferable.

\subsubsection{Quantities Derived From Smoke Obscuration Based Measurements}

Smoke concentration is measured by its attenuation of a light beam in a smoke meter, and typically expressed in terms of an optical density measurement, OD, as follows:

$$
O D=\log _{10}\left(I_{0} / I\right)
$$


where Io is the initial beam intensity and $I$ is the attenuated intensity. If the smoke layer is homogeneous, $(O D)_{\mathrm{V}} / \mathrm{L}_{\mathrm{V}}=(O D)_{\mathrm{H}} / \mathrm{L}_{\mathrm{g}}$ and the thickness of the smoke layer $\mathrm{L}_{\mathrm{V}}$ can be given as

$$
L_{V}=\left[\frac{\log _{10}\left(I_{0} / I_{v}\right)}{\log _{10}\left(I_{0} / I_{H}\right)}\right] L_{H}
$$

where $L$ is the measurement path length (in meters) for the smoke and the subscripts $\mathrm{V}$ and $\mathrm{H}$ refer to the vertical and horizontal measurements. Table 8 and figure 32 present the layer height estimates from the smoke meter calculations as suggested by Bukowski. [21]

Figure 33 presents a comparison of the smoke layer thickness calculated from smoke measurements and from temperature measurements for one of the series of tests (Set 4, $100 \mathrm{~kW}$, open second room exit doorway, open third room). For most times, the smoke measurement estimates are higher than the temperature based calculations. This is consistent with the observations of others, notably Zukowski and Kubota, [27] who measured temperature profiles in detail in a scale "room" measuring $0.58 \mathrm{~m}$ square with a doorway in one wall measuring $0.43 \mathrm{~m}$ by $0.18 \mathrm{~m}$. A smoke tracer was used to allow visual observation of the smoke layer thickness along with the temperature profile measurements. They conclude that, since the lower boundary layer is not steady and rather produces distinct waves along the boundary, the smoke measurements produce a less steep boundary than would be measured from instantaneous profiles at a given instant of time. Since the smoke measurements in this 
report are averaged electronically to smooth the noise in the data (with a time constant of roughly 10 seconds), the thermocouple data can be expected to produce a sharper and more distinct layer than the smoke measurements. However, with the typically higher uncertainty of the smoke-based measurements, the significance of any perceived difference between the two different techniques must be questioned. Within experimental uncertainty, the two methods may be considered equivalent for all tests but those where the interface height reaches the floor. In these tests, the temperature based method falters since it is based upon interpolation between adjacent measurement points. Without extensive instrumentation near the floor, a bottom limit at the level of the lowest thermocouple is evident in the temperature-based calculations.

Manual observations of the steady state smoke layers in the first room doorway, in the second room and in the second room exit doorway were made and summarized in table 6. Another concern was the effect of the second room lighting on the temperature and flow characteristics in the second room and second room exit doorway. Experiments were performed involving the second room lighting and small pilot flame sources and the results are given in table 7. The data shows that the neutral plane height did not change over the range of pilot flame sizes studied and was the same even for natural convection without the lights or pilot flame. In the latter test without the pilot flame, the laboratory conditioned inflow air at $22^{\circ} \mathrm{C}$ was cooled as it passed by the colder unheated room surfaces and, consequently, exited at a lower temperature of $21^{\circ} \mathrm{C}$. The results further showed that doubling the pilot flame 
rate to $3.8 \mathrm{~kW}$ overshadowed the effects of the lighting on the flow behavior in the doorway.

\subsection{Quantities Derived From Exhaust Hood Measurements}

The total rate of heat production from the first room was determined from: $[23,24]$

$$
\dot{\mathrm{Q}}=\mathrm{E} \mathrm{X}_{\mathrm{O}_{2}} \dot{\mathrm{m}} \phi \mathrm{W}_{\mathrm{O}_{2}} / \mathrm{W}_{\mathrm{a} \text { ir }}
$$

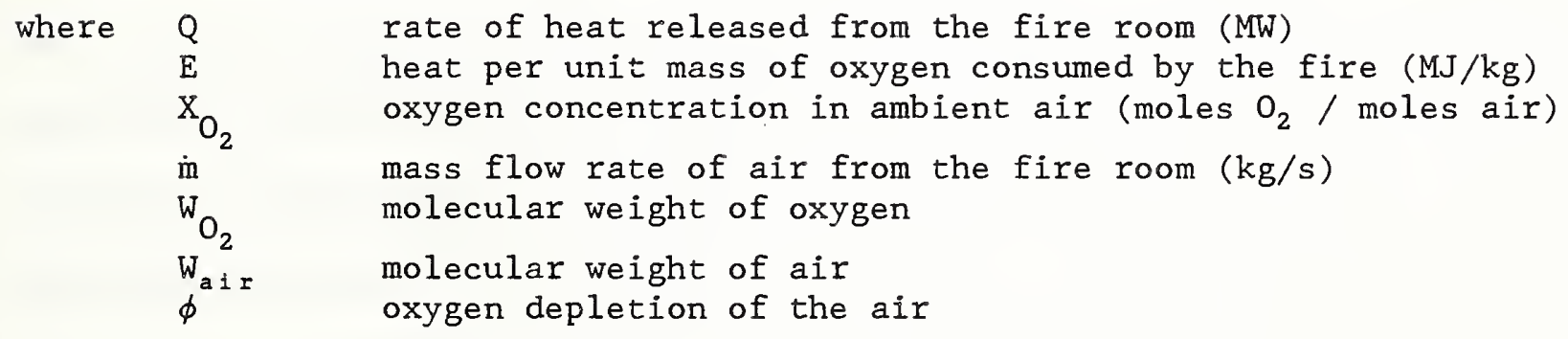

The oxygen depletion, $\phi$, can be further defined as given by Parker: [24]

$$
\phi=\frac{\mathrm{x}_{\mathrm{O}_{2}}-\mathrm{x}_{\mathrm{O}_{2}}^{\mathrm{A}} /\left[1-\mathrm{x}_{\mathrm{CO}_{2}}\right]}{\mathrm{x}_{\mathrm{O}_{2}}\left[1-\mathrm{x}_{\mathrm{O}_{2}} /\left[1-\mathrm{x}_{\mathrm{CO}_{2}}\right]\right]}
$$

where

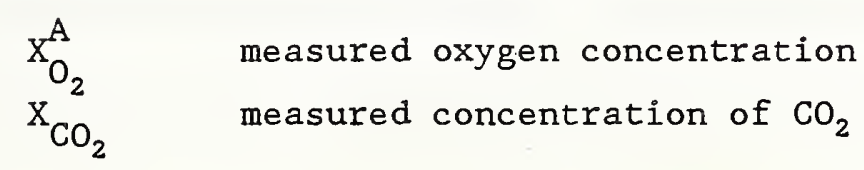


Table 8 and figure 34 present the heat release rate data. These data are only presented for the tests with an open second room exit doorway, since flow through the second room exit doorway to the collection hood was restricted by the closed door, hindering the measurement in the collection hood of the heat release rate of the fire.

Comparing the measured rate of heat release to the heat release calculated from the gas flow rate to the burner (assuming complete combustion of the gas), the measured rate of heat release is consistently low, averaging 19 percent lower than expected. While usually within the experimental uncertainty as exemplified by the average standard deviation for the data sets presented in table 8 , the consistently lower readings deserve attention. In the test configuration, flow through the exhaust collection hood is measured minimally downstream from bends in the system. For this reason, accurate measurement of the flow may be suspect. This particular problem is currently under study and is hoped to be resolved for future test series.

The relative experimental uncertainty for the rate of heat release measurements was also typically higher than many other readings, with coefficients of variation ranging from 4 to 52 percent. With an oxygen depletion for the $100 \mathrm{~kW}$ output of only 0.26 percent, the calculation of rate of heat release suffers the same fate as the calculation of mass flows with pressure probes described above, with much of the uncertainty in the heat release calculations attributable to noise in the underlying measurements. 


\subsection{Mass and Heat Balances}

One method to check the internal consistency of the calculations performed on the data is to insure that the fundamental laws of energy and mass conservation are preserved with the calculated quantities. Since the technique used to measure the rate of heat release from the fire depended upon measurements outside the second room, only the open door tests are amenable to such an analysis.

For the mass balance on the system, the mass flow rate of air in through the second room exit doorway added to the mass flow rate of gas in through the burner should equal the mass flow rate out the second room exit, once expansion due to the temperature rise of the gases has been accounted for. Due to problems in measuring the flows through the second room exit doorway, only two test series contained the appropriate data, SET 4 (100 kW, open door, open third room) and SET $9(500 \mathrm{~kW}$, open door, open third room). For SET 4 , the average mass balance (the difference between inflow and outflow) from 300 to $900 \mathrm{~s}$ is $0 \pm 0.2 \mathrm{~kg} / \mathrm{s}$. For SET 9, the mass balance is $0 \pm 0.3 \mathrm{~kg} / \mathrm{s}$. Good agreement is seen for both data sets with an uncertainty near 10 percent of the higher mass flow rates through the openings in the rooms in both cases.

A similar calculation can be made for the energy balance. The heat input by the burner (including the pilot light) should equal the heat lost out the system by conduction through the walls and convection and radiation out the second room exit. Analogous to the mass balance, the average heat balance 
for SET $4(100 \mathrm{~kW})$ is $14 \pm 24 \mathrm{~kW}$, and for $\operatorname{SET} 9$ is $0 \pm 138 \mathrm{~kW}$. Although the standard deviations are high, within noise limits, mass and energy are conserved within the system.

\subsection{The Two Zone Assumption}

Most of the current room fire growth models assume that the fire environment within a room can be described as a small number (usually two) of control volumes or zones. Within a zone, all properties are assumed constant. Jones, [28] and Emmons [29-30] provide overviews of two-zone room fire models. Backovsky and Emmons [31] have compared a simple two-layer model of flow of fire gases for a room with an opening with photographic and thermocouple data from a series of full-scale fire tests. They report limited agreement with the two-zone assumption and attribute the disparity to the simplicity of the mode1.

Some of the data from the current test series can be used to compare data based upon the two-zone assumption with actual vertical and horizontal profiles of temperature and smoke density. Figure 35 presents a set of temperature profiles for one of the test series (SET 4, $100 \mathrm{~kW}$, open second room exit doorway, open third room). The profiles are presented in $200 \mathrm{~s}$ intervals beginning at $100 \mathrm{~s}$ and overlaid with the calculated layer height at that time period. While no distinct break between an upper and lower layer exists, an explicit rise in temperature above the calculated layer interface 
is evident with a near ambient layer and a warmer layer. The layer temperatures are hardly uniform vertically throughout the assumed layers, however.

Figure 36 shows the average temperature profiles from an open door and a closed door test (both $100 \mathrm{~kW}$ tests with a target room) overlaid with the upper and lower layer temperature calculated using the two-zone assumption for the test rooms. The solid line represents the average temperature profile; the dotted lines describe the results from the two-zone model. Specifically, the horizontal dotted line shows the height of the layer interface, while the two vertical dotted lines represent the lower and upper layer temperatures and extend through the heights appropriate to these layers. Temperature profiles for room 1, with the burner, are very similar for the open and closed door tests - not surprising, since the door to room 2 is open in both tests. Visually, the two-zone assumption holds better for the open door test than for the closed door test in the cooler rooms 2 and 3 . Clearly, no distinct layering is evident in rooms 2 or 3 in the closed door test. With the closed door, the hot gases come far closer to the floor and, along with mixing as the gases reach the end of room 2, lead to a more closely linear temperature profile from the floor to the ceiling. In the test with a closed exit doorway in the second room, mixing occurs at the end of the long corridor in room 2, heating the lower air and cooling the upper air. Even with no distinct break between the layers, interface heights defined using the two-layer assumption show evidence of the mixing with a far more uniform layer thickness in the test with an open second room exit doorway: 


\begin{tabular}{llll}
\hline Room 2 Near Room 1 & 0.49 & 1.18 \\
Room 2 Center & 0.40 & 1.13 \\
Room 2 Near Exit Doorway & 0.31 & 1.14 \\
\hline
\end{tabular}

\subsection{Comparison With Model Data, A Sample Use of the Data}

As an example of the use of the experimental data described in this report, let's consider a comparison to the FAST model outlined in section 1. Predictions were made with the FAST model with the configuration, fire size, and thermal properties matching that of one of the data sets (SET 4, $100 \mathrm{~kW}$, open door, open third room).

There are four measurable quantities for which it is reasonable to make a direct comparison between an experiment and the corresponding theoretical prediction. These are the upper and lower layer temperature, the layer interface height, and mass flow through an opening to a compartment. There are other measurements of interest, but these four will yield an indication of the match of the model to the experiment.

The results of the comparisons are shown in figures 37 to 40 . They show that the relative error of the prediction of upper and lower layer temperatures, interface position, and mass flow rates compared to the experimental values range within the following values: 
Relative Error: (Model-Experiment)/Experiment

(expressed as a percentage)

Quantity

Range Median Mean Standard

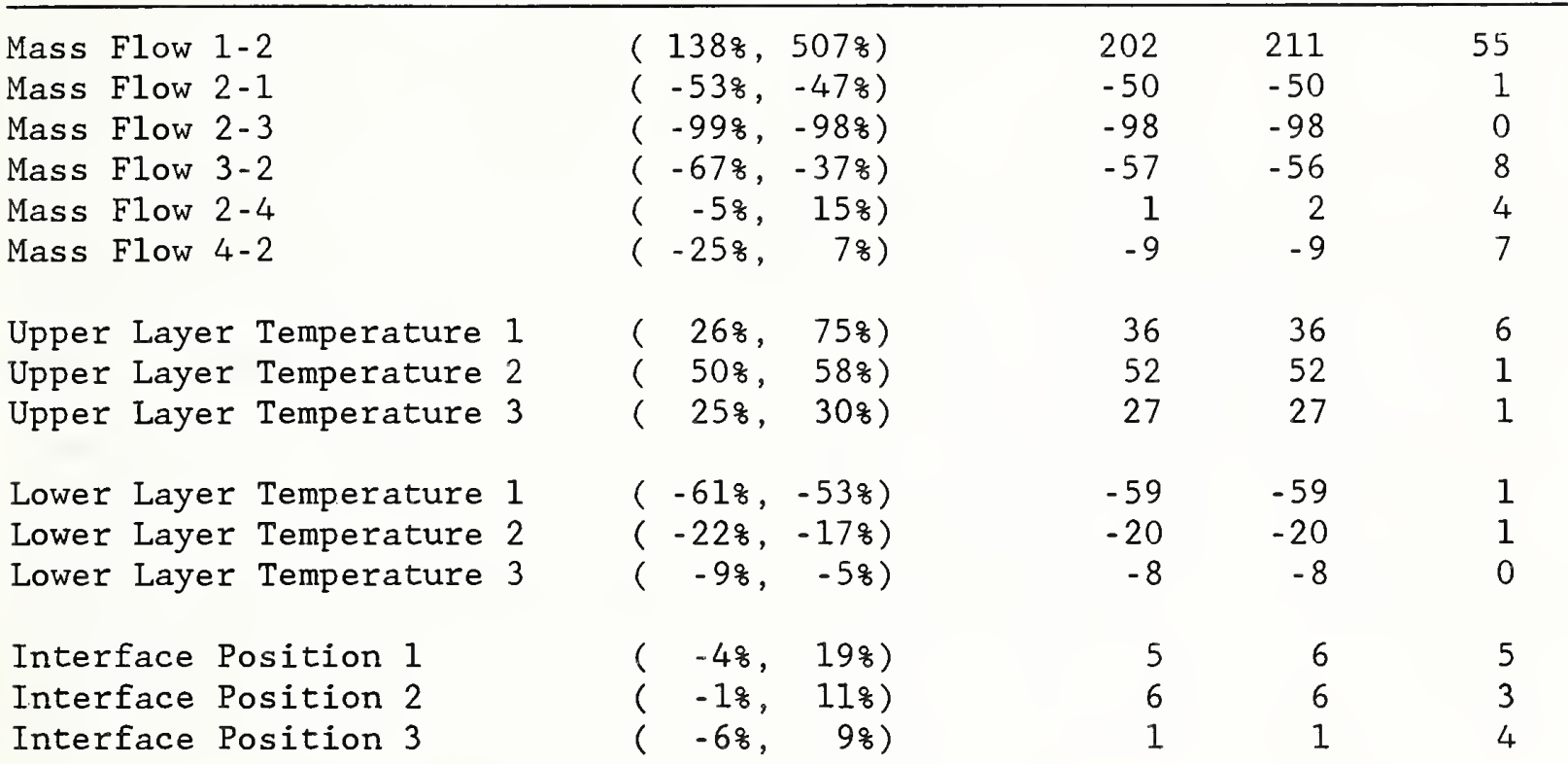

Qualitatively, the curves shapes are quite similar after the initial transient. Quantitatively, the transient response of the model follows the measured values more closely, resulting in better predictive performance at earlier times. This is often the critical region for hazard analysis, since this is when the occupant evacuation process is occurring.

From the above data, the interface heights and layer temperatures are predicted with better accuracy, on the average, than are mass flows and wall temperatures. Upper layer temperatures are always over-predicted by the model. Too hot an upper layer may be caused either by under-prediction of the heat lost by the layer by radiation, conduction and / or convection, or by under-prediction of the heat entering the layer from the fire plume. While the temperature of the lower layer may be important when considering the 
effect on occupants and equipment, there can not yet be a good correspondence between measured and predicted layer temperatures due to the assumption within the model of no radiative heating and no mixing into this zone. Thus, lower layer temperature is typically under predicted by the model. Since the interface position in rooms 1 and 2 is well predicted, the layer volumes will be fairly accurate. Jones [7] has identified mass flows through openings and heat conduction through walls as particular areas for improvement of models predicting the transport of smoke and toxic gases. Specific improvements have been implemented in a new predictive model, resulting in better comparisons. [32] Although mass flows are predicted with less accuracy, not all of the discrepancy must be attributed to the model. Repeatability of the mass flow measurements in the experiments is poorer than other measurements, resulting in more uncertainty in the mass flow measurements.

In addition, while the predicted temperatures in the second compartment were good, small errors in the door flows (particularly entrainment in the door jet) are multiplicative in a multi-compartment model which may be called upon to predict conditions away from the fire. Thus, experiments with multiple compartments in series will be required to study these parameters more closely. 


\section{SUMMARY AND RECOMMENDATIONS}

\subsection{General}

CFR has been working to develop the generic methodology for model evaluation. This report has presented a documentation of the experimental phase of the accuracy assessment process for one particular model. Derived outputs from individual raw data elements were presented together with the mathematical treatment used to make the calculations. An example of a comparison of the experimental data set with model predictions were presented.

Three size gas fires having heat release rates of $100 \mathrm{~kW}, 300 \mathrm{~kW}$, and $500 \mathrm{~kW}$ were conducted under the following room-burner configurations:
a) Open second room, third room closed
b) Closed second room, third room closed
c) Open second room, third room open
d) Closed second room, third room open

Before the data could be analyzed, however, normalization of the test results was required. Ambient temperatures, barometric pressures, and humidity changed from test to test due simply to seasonable variations. In addition, the duration of each test was variable, both during the pretest period, the main burn, and the cool down period. To insure a self-consistent definition across the test series and to allow comparison with model predictions beginning at a preset set of conditions, the data from all tests were normalized to a standard definition. 
Once normalized, the repeatability of a given measurement ranged from excellent to poor. For temperature based measurements and calculations, the repeatability, as evidenced by the average standard deviation during steady state burning, was good -- typically less than ten percent of the measured or calculated values. For pressure-based measurements, the repeatability was not nearly as good, at times approaching 70 percent of the values. Much of the disparity between individual tests can be traced to experimental technique, which was refined as the testing progressed.

The precision of some of the calculations suffer from the propagation of large errors in the individual factors. The rate of heat release or mass flow measurements could be improved by multiple measurements of the same quantity with instruments of different resolution thus allowing more precise determination of the quantity in the range of interest. For the mass and heat balance calculations, however, such an approach would provide less improvement. Alternate techniques for such determinations should be explored which do not depend as strongly on propagated errors.

\subsection{Considerations for Future Test Series}

The test configuration has, and can continue to provide data useful in guiding further refinement of FAST and other multi-room fire models. FAST assumes uniform filling of any space subject to the fire environment or to adjacent spaces which are exposed to the heated smoke and other combustion 
products. For example, in a real fire situation, the movement of smoke along a corridor would take a finite and measurable time to reach the end of, the corridor away from the room of fire origin, particularly during the early stages of a fire. A series of model calculations to compare wjth a detailed series of experiments in which the corridor was divided into a series of rooms, each with doors connecting to the next, would help to refine this aspect of the model and experiment comparison. Additional instrumentation at various locations along the corridor would also allow measurement of the progress of the layer movement along the corridor.

The experimental work described in this report is based on idealized fires using a gas diffusion burner; the use of "real" fuels, such as wood cribs or upholstered furniture, would provide an opportunity for testing the model under actual fire conditions. Some of these data are available for other room configurations. [4,33-34] An analysis similar to the one presented in this report is planned for some of these and other test series and will be the subject of future reports.

\section{ACKNOWLEDGEMIENTS}

S. Steel, R. Zile, M. Womble, R. McLane, G. Roadarmel, and J. Shields provided experimental support in the conduct of the tests described in this report. N. Breese and P. Martin furnished computer expertise in the analysis of the data. The support of all those involved in the conduct and analysis of the data is gratefully acknowledged. Finally, the authors are especially 
indebted to S. Schiller of the Center for Applied Mathematics at NBS for her in-depth review and critique of the report and for her guidance in the proper statistical treatment of the data.

\section{REFERENCES}

1. Alpert, R. L., et al, Influence of Enclosures on Fire Growth: Volume I: Test Data, FMRC No. OAOR2.BU-1 through 7, Factory Mutual Research, Norwood, MA (1977).

2. Cooper, L. Y., Harkleroad, M., Quintiere, J. G., and Rinkinen, W. J., An Experimental Study of Upper Hot Layer Stratification in Full-Scale Multiroom Fire Scenarios, J. Heat Trans., Vol. 104, 741-749 (November 1982).

3. Quintiere, J. G., and McCaffrey, B.J., The Burning of Wood and Plastic Cribs, Nat. Bur. Stand., (U. S.), NBSIR 80-2054, Volumes I and II (November 1980).

4. Heskestad, G., and Hill, J. P., Experimental Fires in Multiroom / Corridor Enclosures, contract to the Nat. Bur. Stand., (U. S.), NBSGCR 86502 CIB W14/85/10 (USA) (January 1986).

5. Jones, W. W., A Model for the Transport of Fire, Smoke, and Toxic Gases, Nat. Bur. Stand., (U. S.), NBSIR 84-2937 (September 1984).

6: Jones, W. W., A Review of Compartment Fire Models, Nat. Bur. Stand., (U. S.), NBSIR 83-2684 (April 1983).

7. Jones, W. W.,. Future Directions for Modeling the Spread of Fire, Smoke, and Toxic Gases, Fire Safety: Science and Engineering, ASTM STP 882, T. Z. Harmathy, Ed., American Society for Testing and Materials, Philadelphia, pp. 70-96 (1985).

8. Freund, J. E., Livermore, P. E., and Miller, I., Manual of Experimental Statistics, Prentice-Hall, Englewood Cliffs, NJ (1960).

9. Zelen, M., Introductory Lectures on the Statistical Design of Experiments, U. S. Army Mathematics Research Center, NTIS, AD707613 (November 1981).

10. Davies, A. D., "Some Tools for Fire Model Validation," Fire Technology, Vol. 23, No. 2, May, 1987 pp 95-114. 
11. Fang, J. B., Repeatability of Large-scale Room Fire Tests, Fire Technology, 17:1, 5-15 (February 1981).

12. Yeager, R. W., Uncertainty Analysis of Energy Rate Measurements of Room Fires, presented at U. S. Nat. Bur. Stand., February 11, 1986, Owens / Corning Fiberglas Fire Testing Laboratory (1986).

13. Khoudja, N., Procedures for Quantitative Sensitivity and Performance Validation Studies of a Deterministic Fire Safety Model, Doctoral Thesis, Texas A \& M University (May 1987), published by Nat. Bur. Stand., (U. S.), NBSGCR 88-544 (March 1988).

14. Wilkes, Gordon B., Heat Insulation, John Wiley \& Sons, Inc. (1950).

15. Johns-Manville Refractory Products, Johns-Manville Corporation, Denver, Colorado (February 1981).

16. Babcock \& Wilcox Ceramic Fiber Products, The Babcock \& Wilcox Company (May 1980).

17. Transactions of the American Society of Heating and Ventilating Engineers, Volume 53 (January 1947).

18. Steckler, K. D., Quintiere, J. G., and Rinkinen, W. J., Flow Induced By Fire In A Compartment, Nat. Bur. Stand., (U. S.), NBSIR 82-2520 (September 1982).

19. Fang, J. B., and Breese, J. N., Fire Development in Residential Basement Rooms, Nat. Bur. Stand., (U. S.), NBSIR 80-2120 (October 1980).

20. Lee, B. T., Effect of Ventilation on the Rates of Heat, Smoke, and Carbon Monoxide Production in A Typical Jail Cell Fire, Nat. Bur. Stand., (U. S.), NBSIR 82-2469 (March 1982).

21. Bukowski, R. W., Smoke Measurement in Large and Small Scale Fire Testing, Nat. Bur. Stand., (U. S.), NBSIR 78-1502 (October 1978).

22. Bukowski, R. W., Quantitative Determination of Smoke Toxicity Hazard - A Practical Approach for Current Use, Fire Safety Science, Proceedings of the First International Symposium, pp 1089-1100 (1986).

23. Huggett, C., Estimation of Rate of Heat Release by Means of Oxygen Consumption Measurements, Fire and Materials; Vol. 4 (1980).

24. Parker, W. J., Calculations of the Heat Release Rate by Oxygen Consumption for Various Applications, Nat. Bur. Stand., (U. S.), NBSIR 81-2427-1 (March 1982).

25. Breese, J. N., and Peacock, R. D., A Users Guide for RAPID, Reduction Algorithms for the Presentation of Incremental Fire Data, Nat. Bur. Stand., (U. S.), NBS Special Publication 722 (March 1986). 
26. Jones, W. W., and Bodart, X., Buoyancy Driven Flow As the Forcing Function of Smoke Transport Models, Nat. Bur. Stand. (U. S.), NBSIR 863329 (May 1986).

27. Zukowski, E. E., and Kubota, T., An Experimental Investigation of the Heat Transfer from a Buoyant Gas Plume to a Horizontal Ceiling - Part 2. Effects of Ceiling Layer, contract to Nat. Bur. Stand. (U. S.), NBS GCR 77-98 (September 1975).

28. Jones, W. W., A Review of Compartment Fire Models, Nat. Bur. Stand., (U. S.), NBSIR 84-2684 (April 1983).

29. Emmons, H. W., The Two Layer Fire Model, Home Fire Technical Report No. 50, Division of Applied Science, Harvard University, Cambridge, MA (February 1982).

30. Emmons, H. W., The Home Fire Viewed as a Scientific System, Society of Fire Protection Engineers, SFPE Technology Report No. 77-5, Boston (May 1977).

31. Backovsky, J., and Emmons, H. W., Layering of Fire Gases, Home Fire Project Technical Report No. 17, Harvard University, Cambridge, MA (Summer 1975).

32. Jones, W. W., and Peacock, R. D., Refinement and Experimental Verification of a Model for Fire Growth and Smoke Transport, paper to be presented at the Second Annual Symposium on Fire Safety Science, Tokyo, Japan (June 1988).

33. O'Neill, J. G. and Hayes, W. D., Full-Scale Fire Tests With Automatic Sprinklers in a Patient Room, Nat. Bur. Stand., (U. S.), NBSIR 79-1749 (June 1979).

34. O'Neill, J. G., Hayes, W. D., and Zile, R. H., Full-Scale Fire Tests With Automatic Sprinklers in a Patient Room. Phase II, Nat. Bur. Stand., (U. S.), NBSIR 80-2097 (July 1980). 


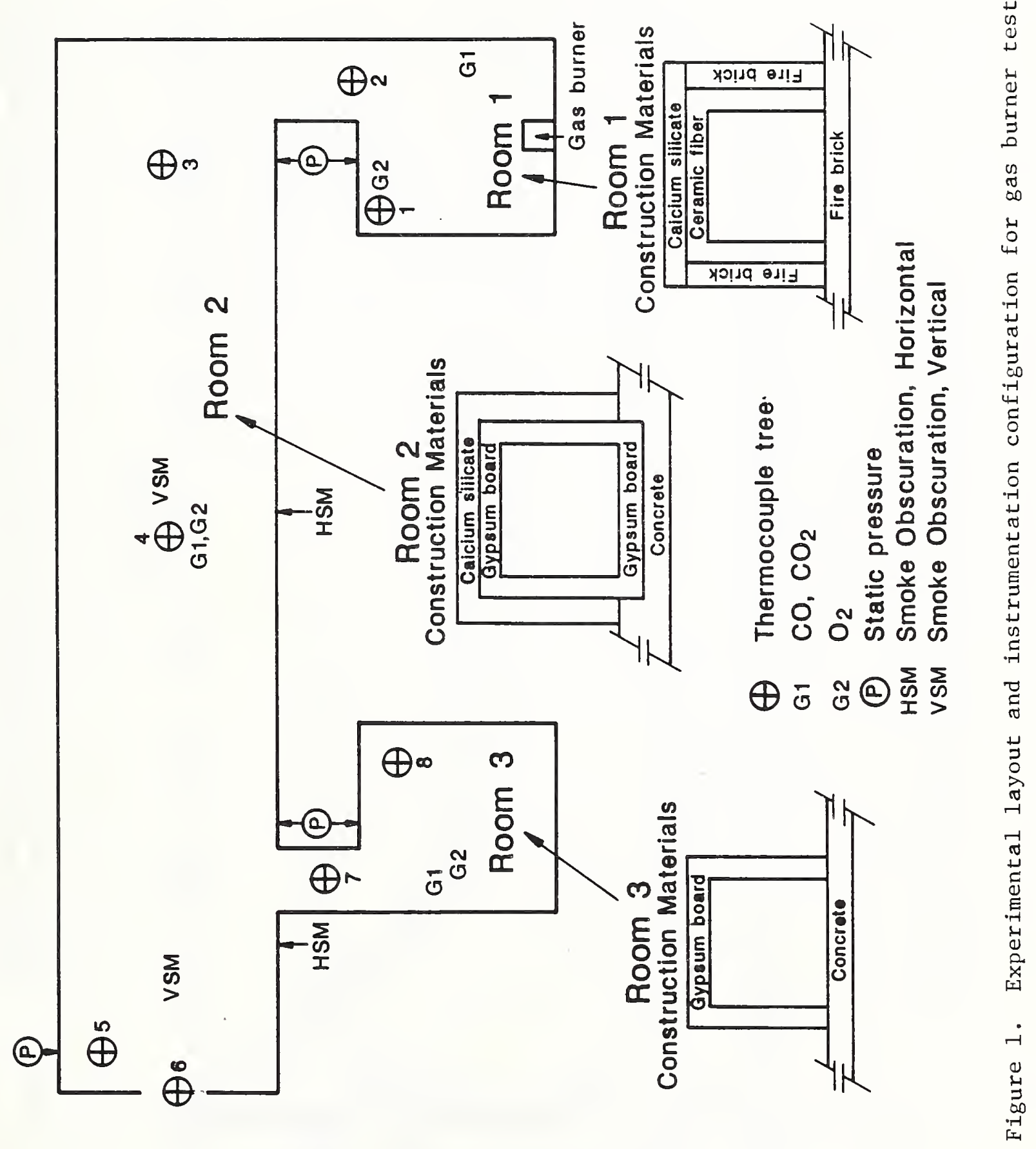




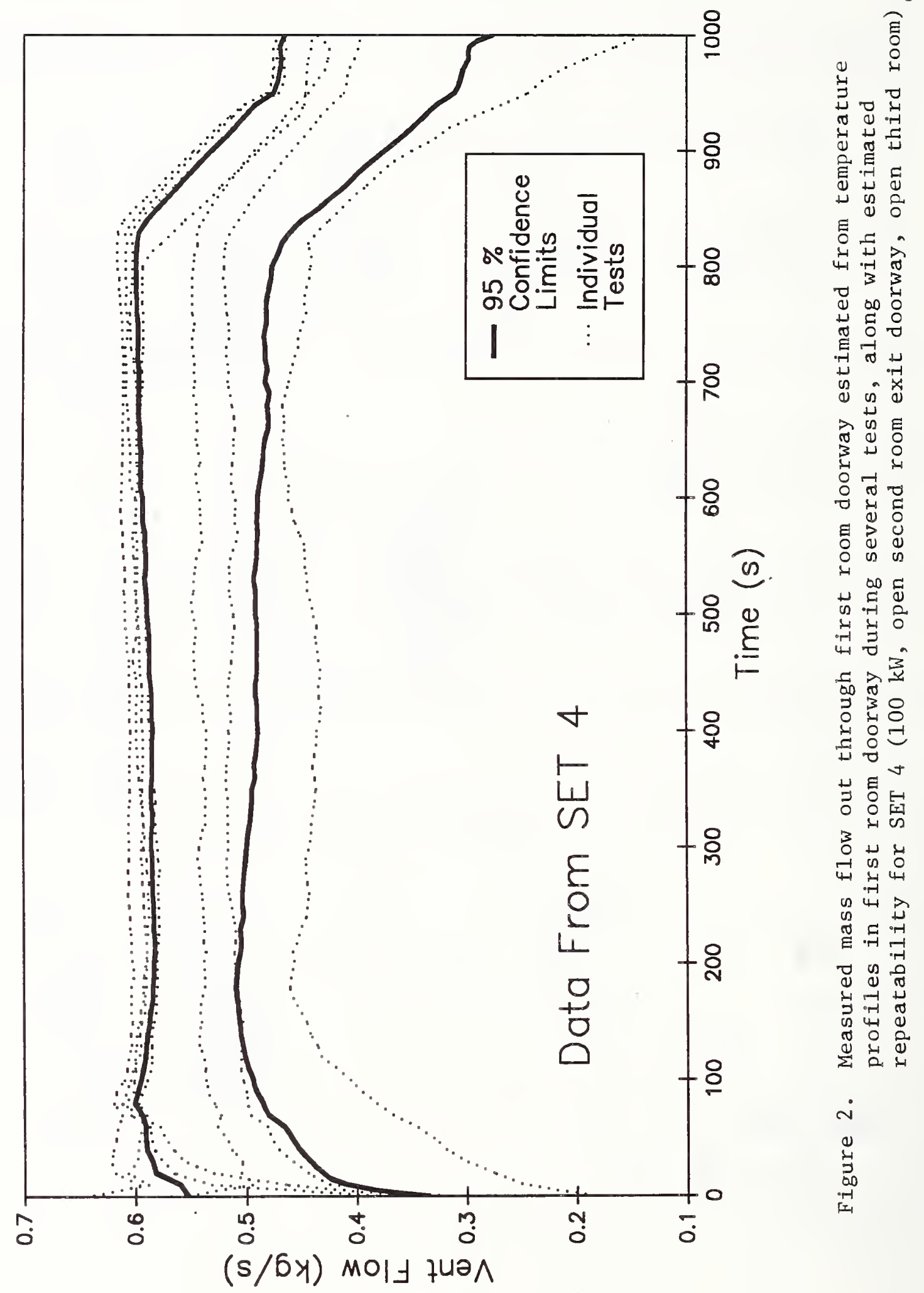




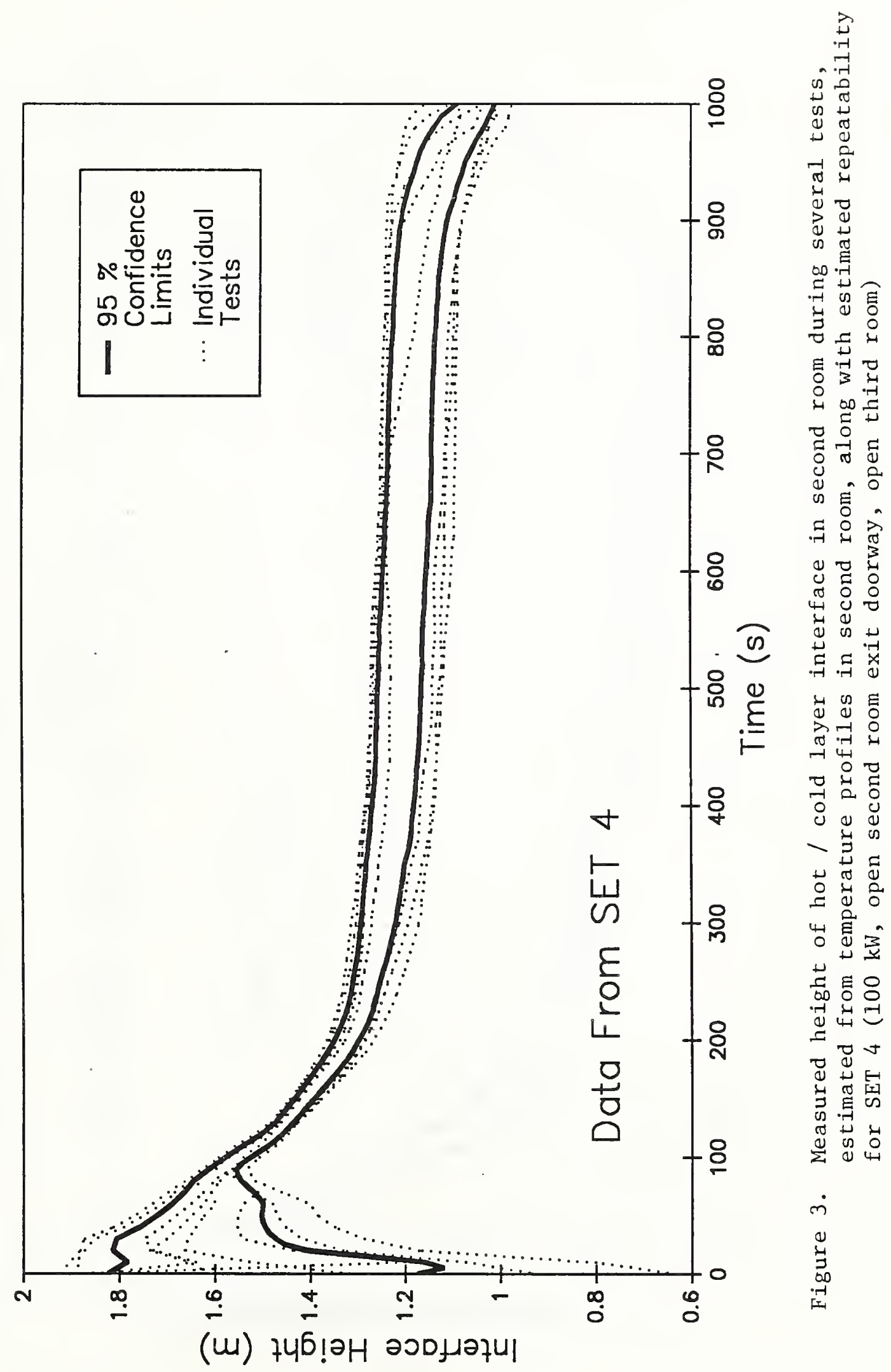




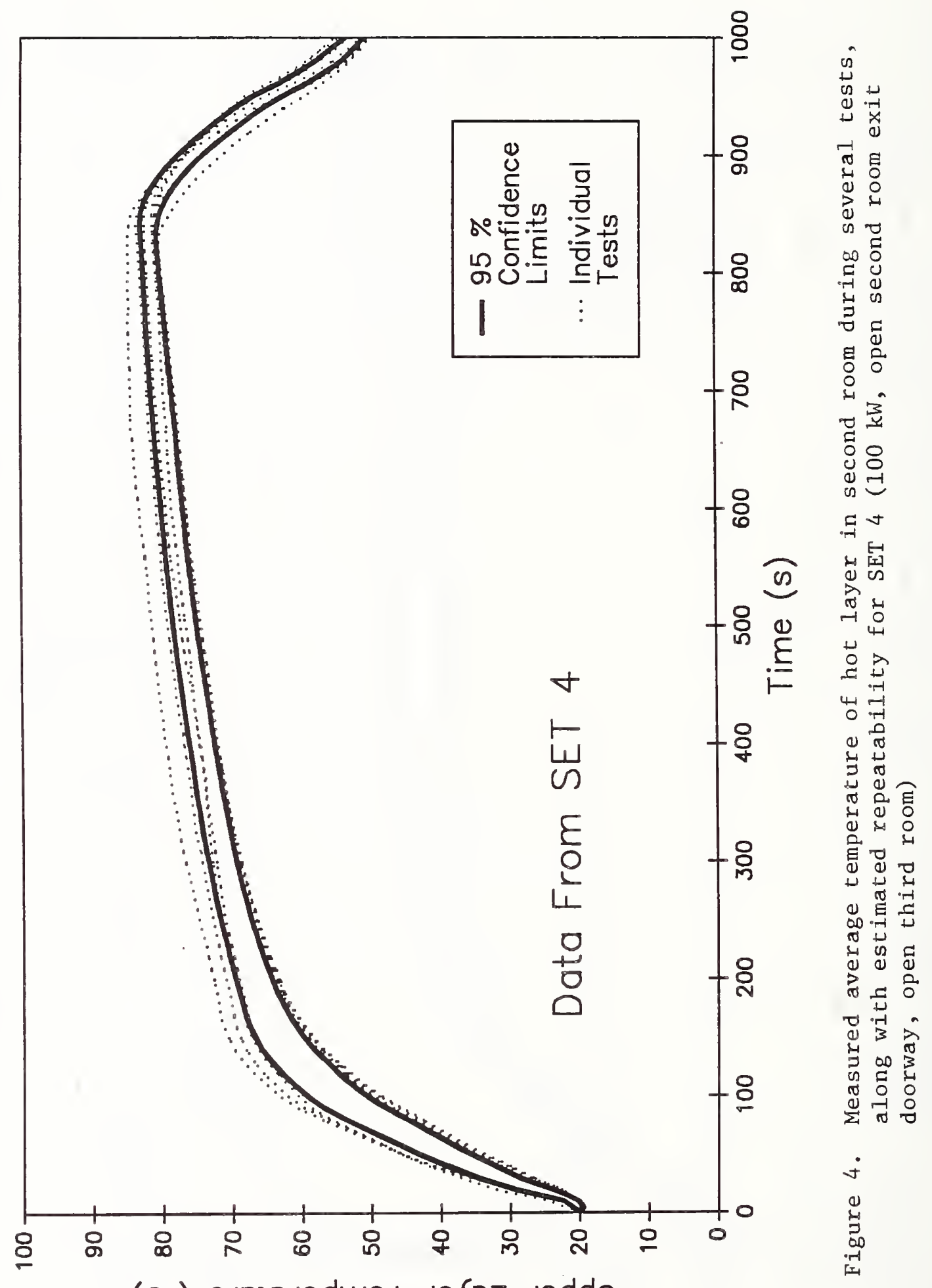

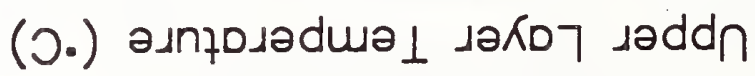




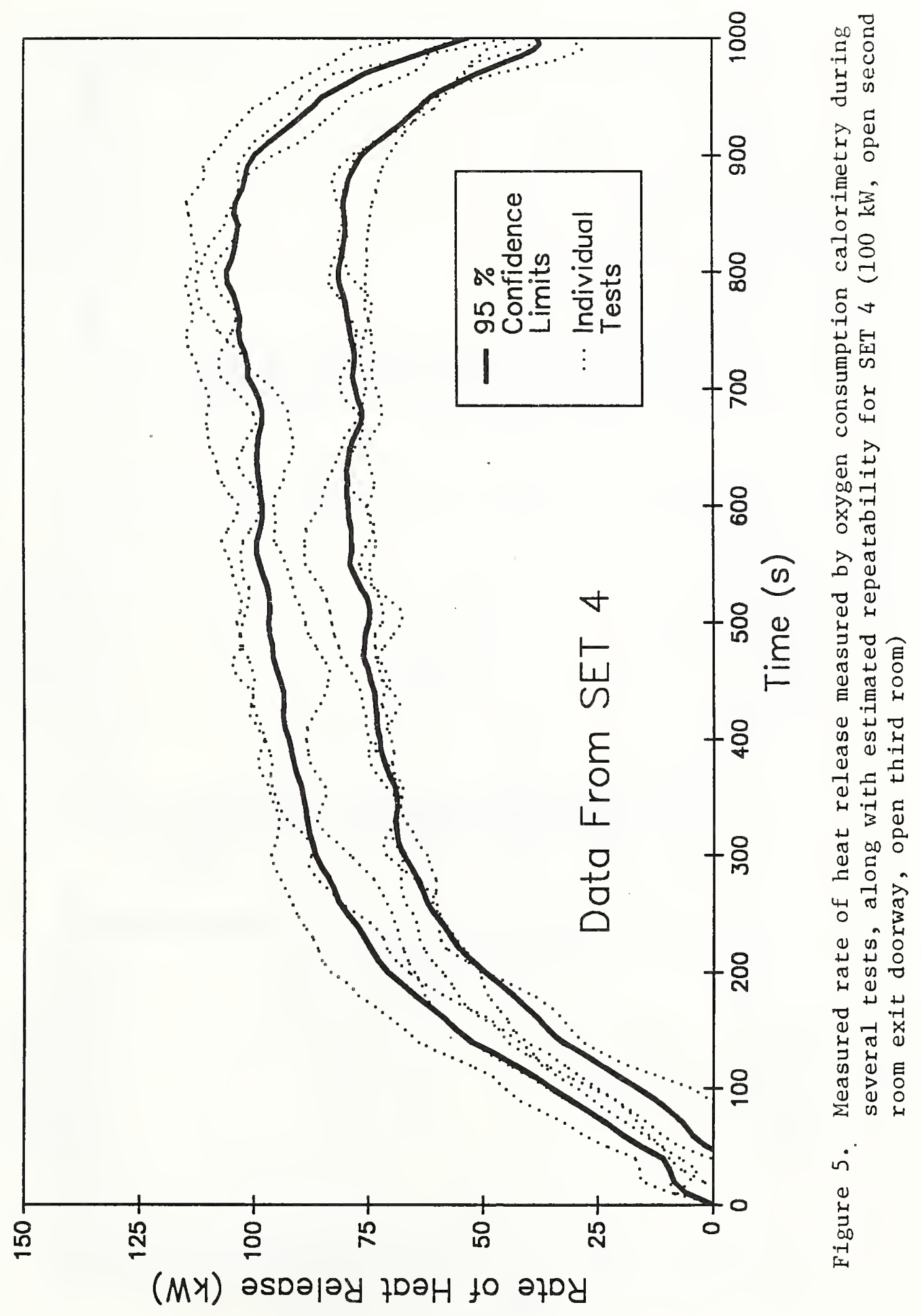



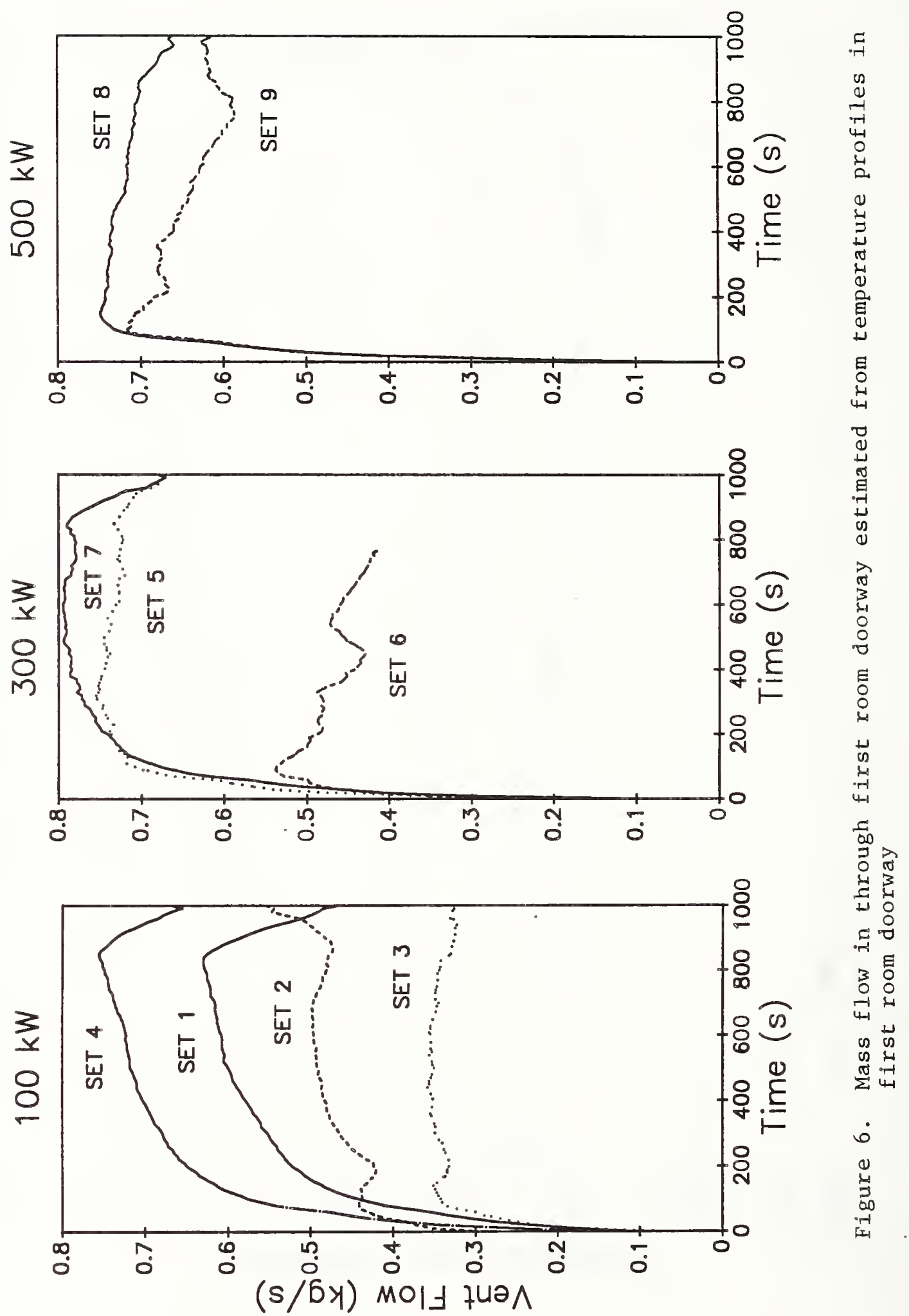

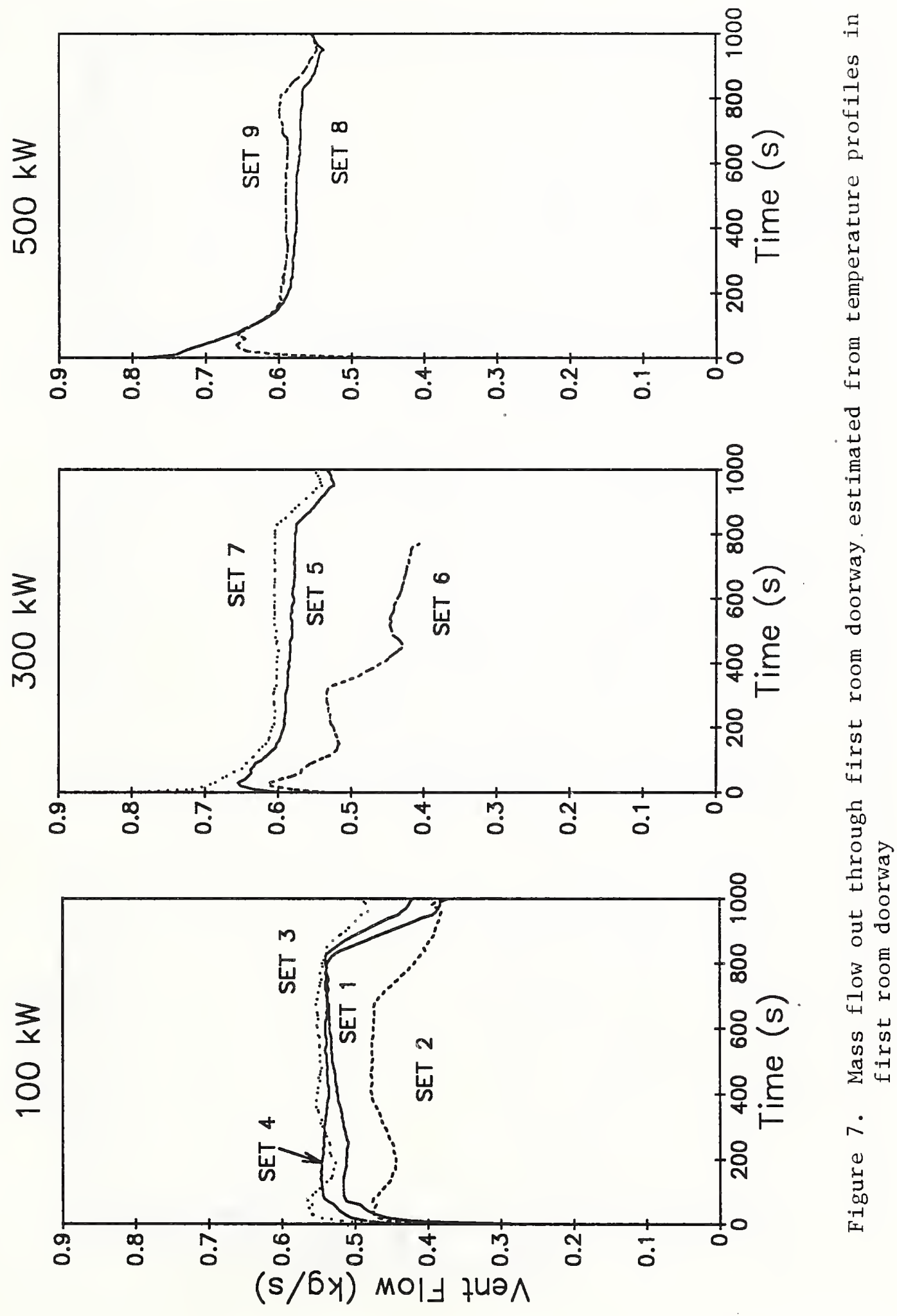

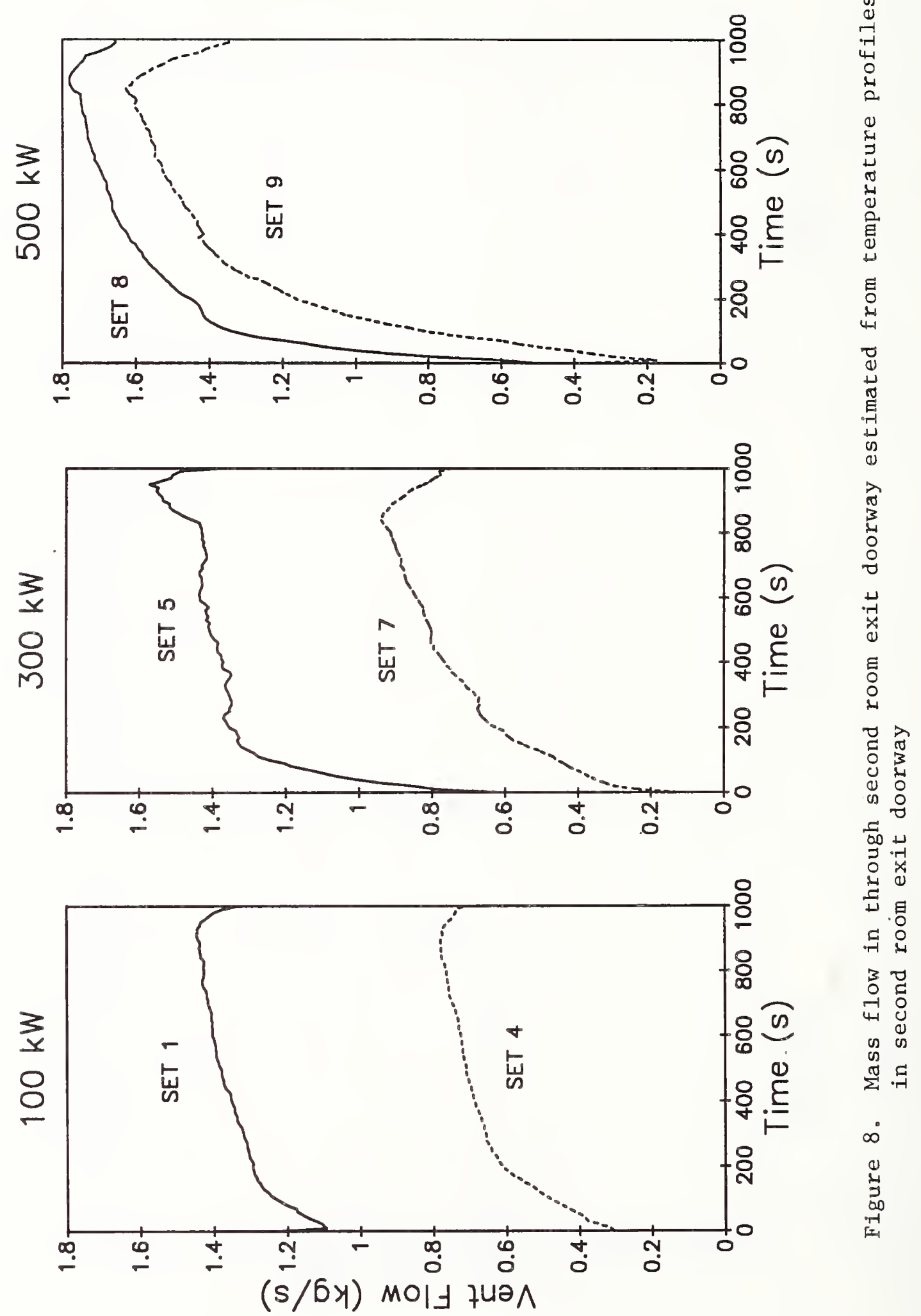

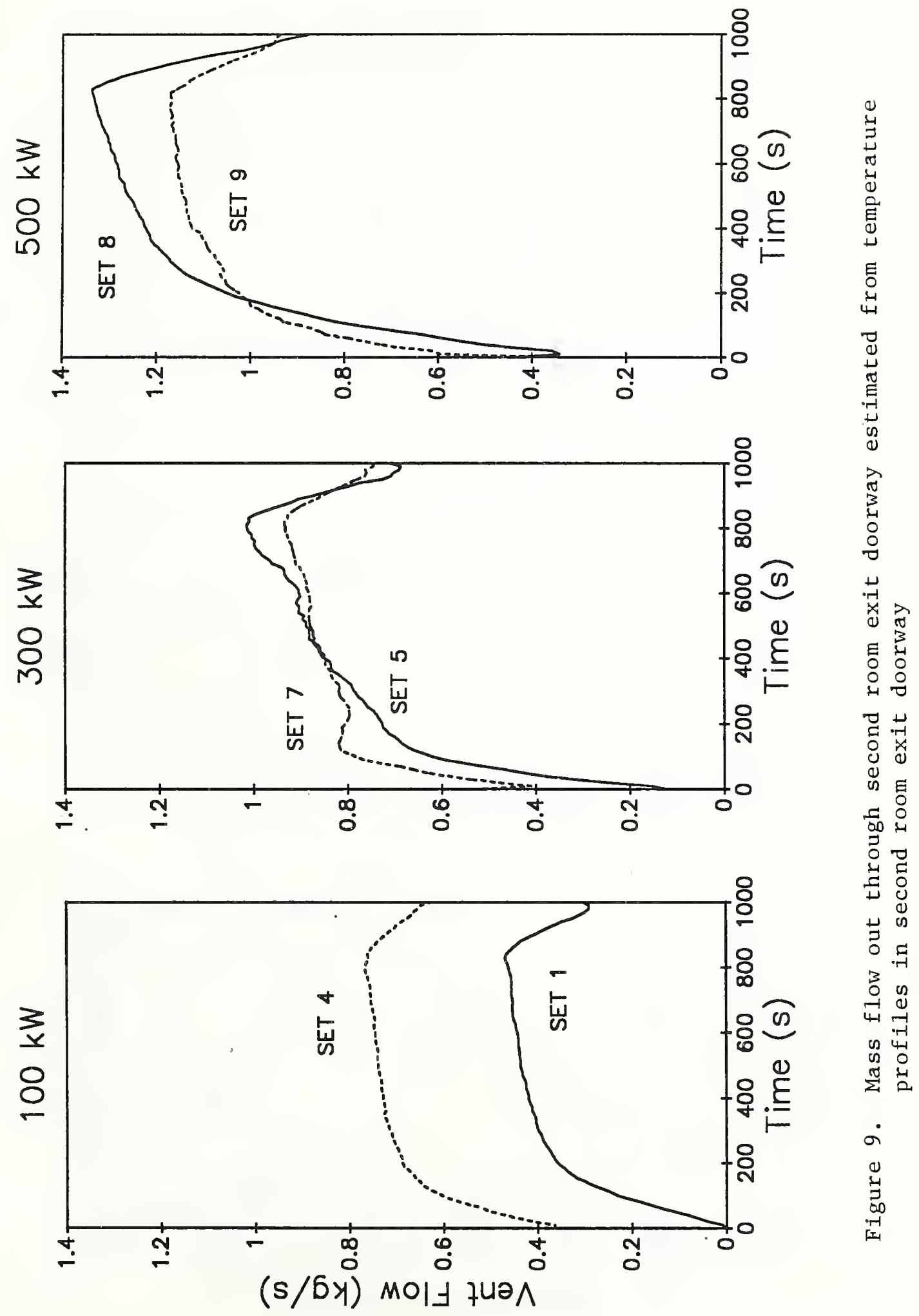


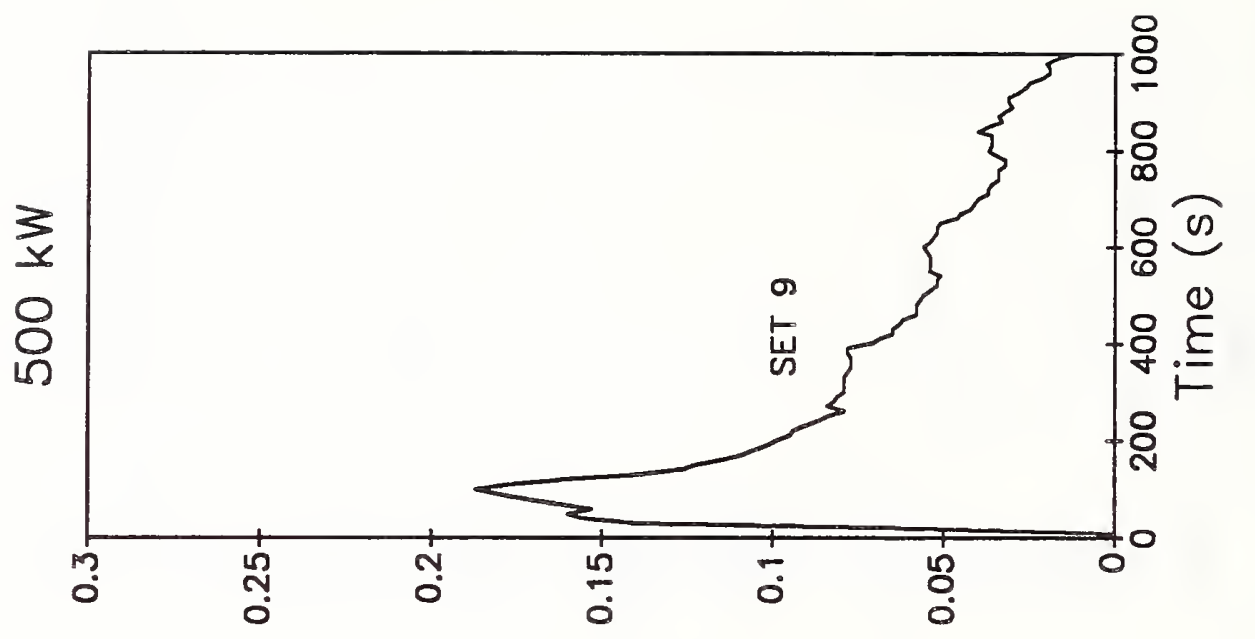

告
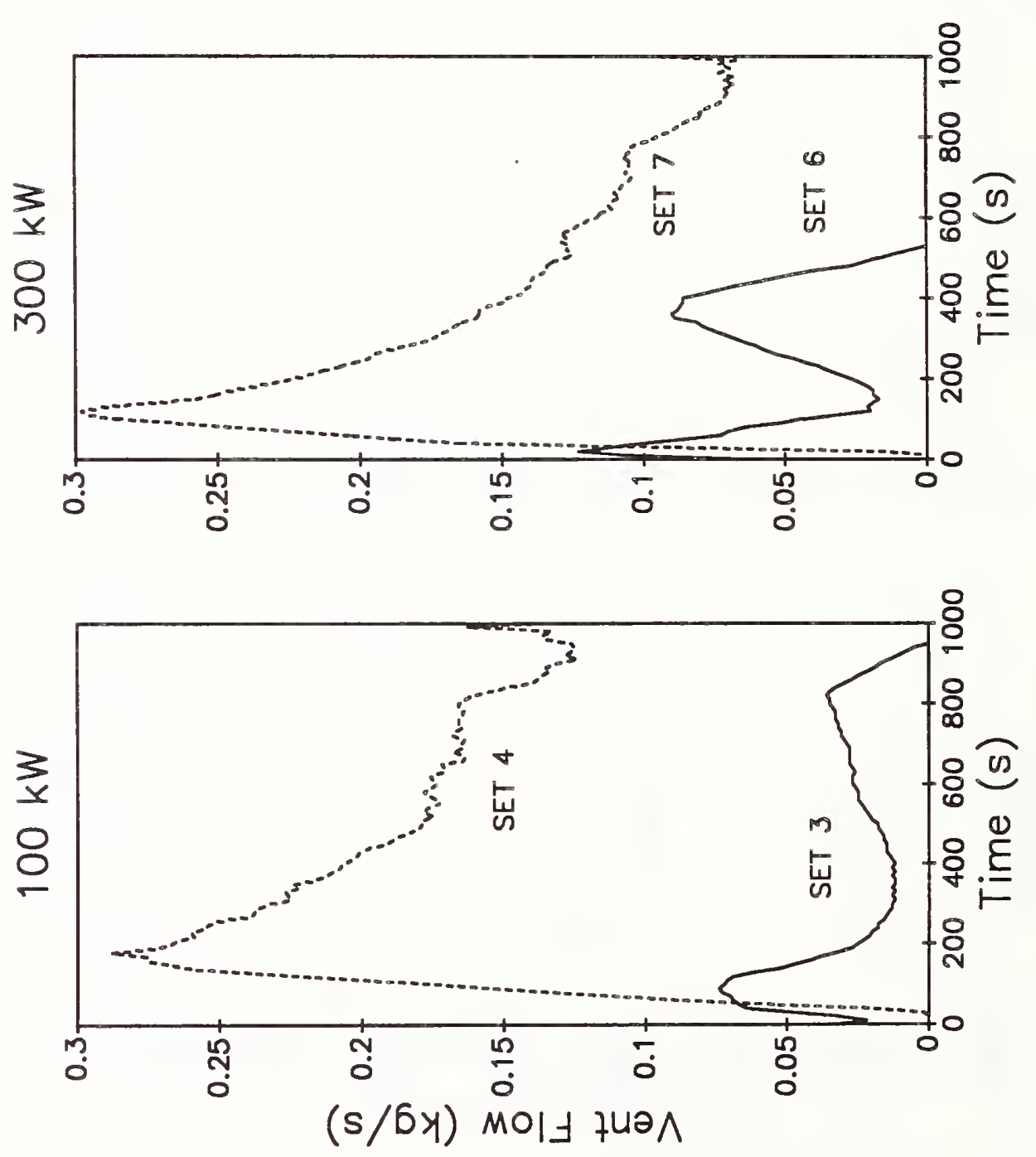

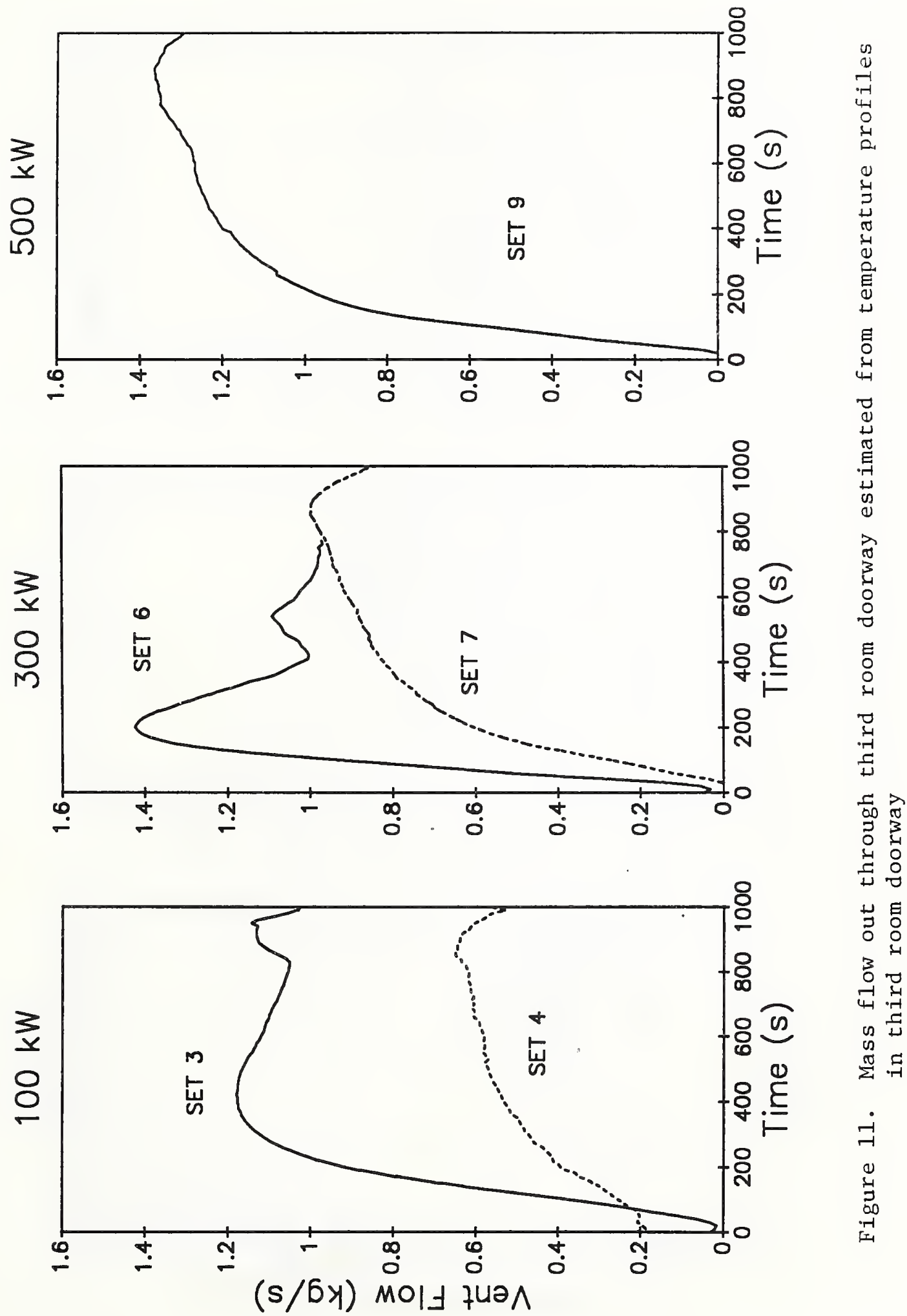

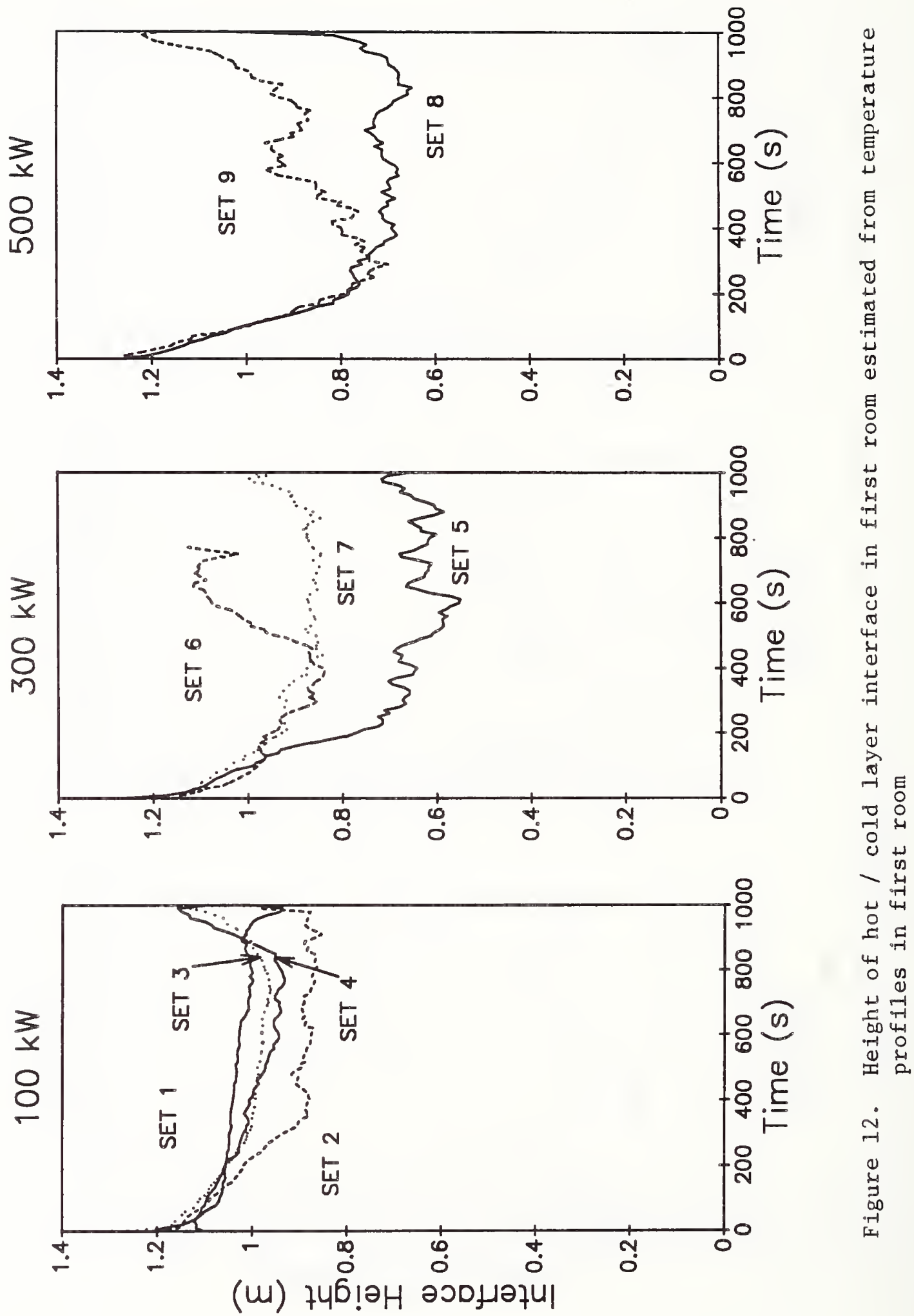


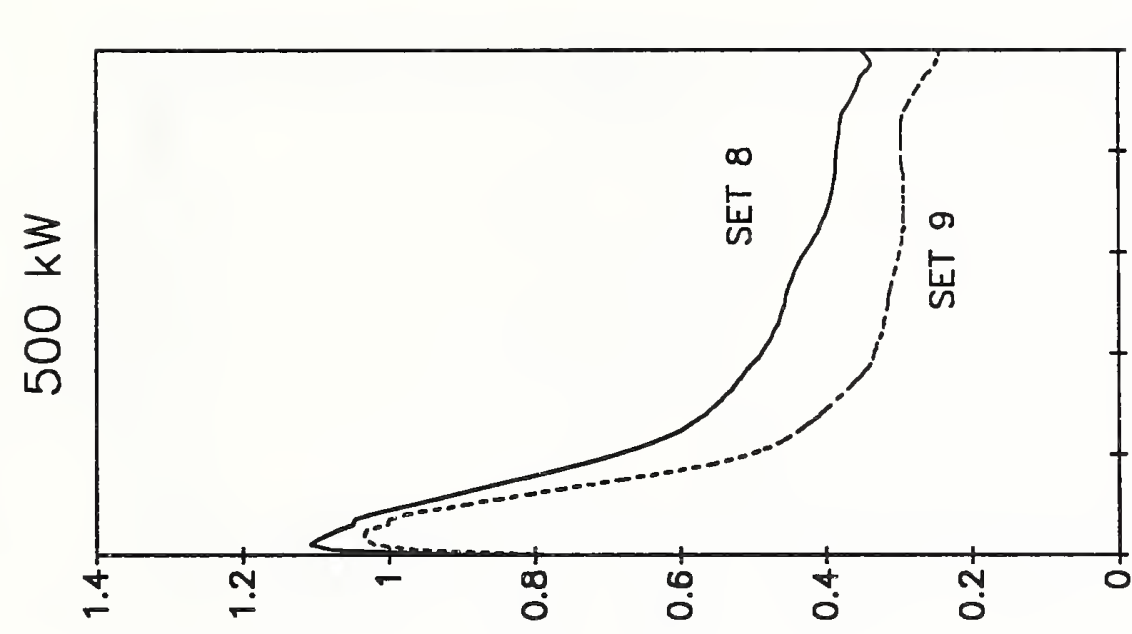

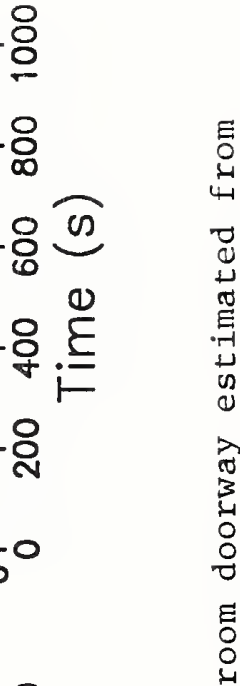

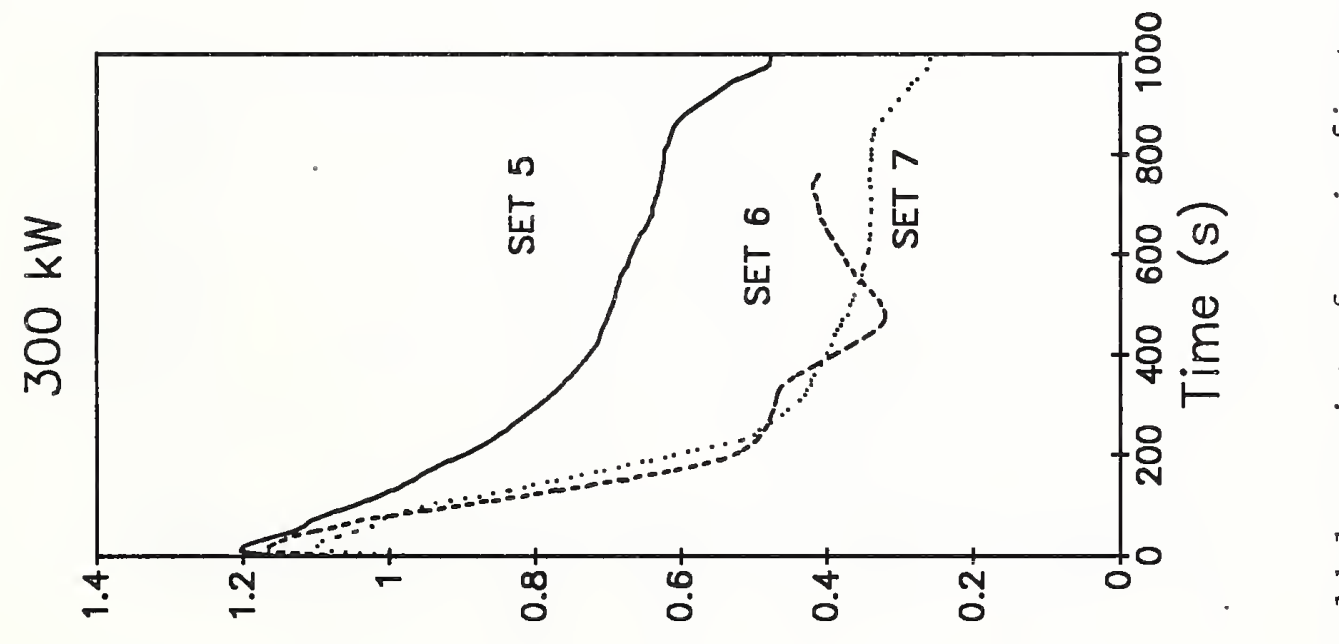

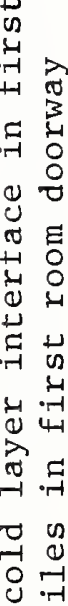

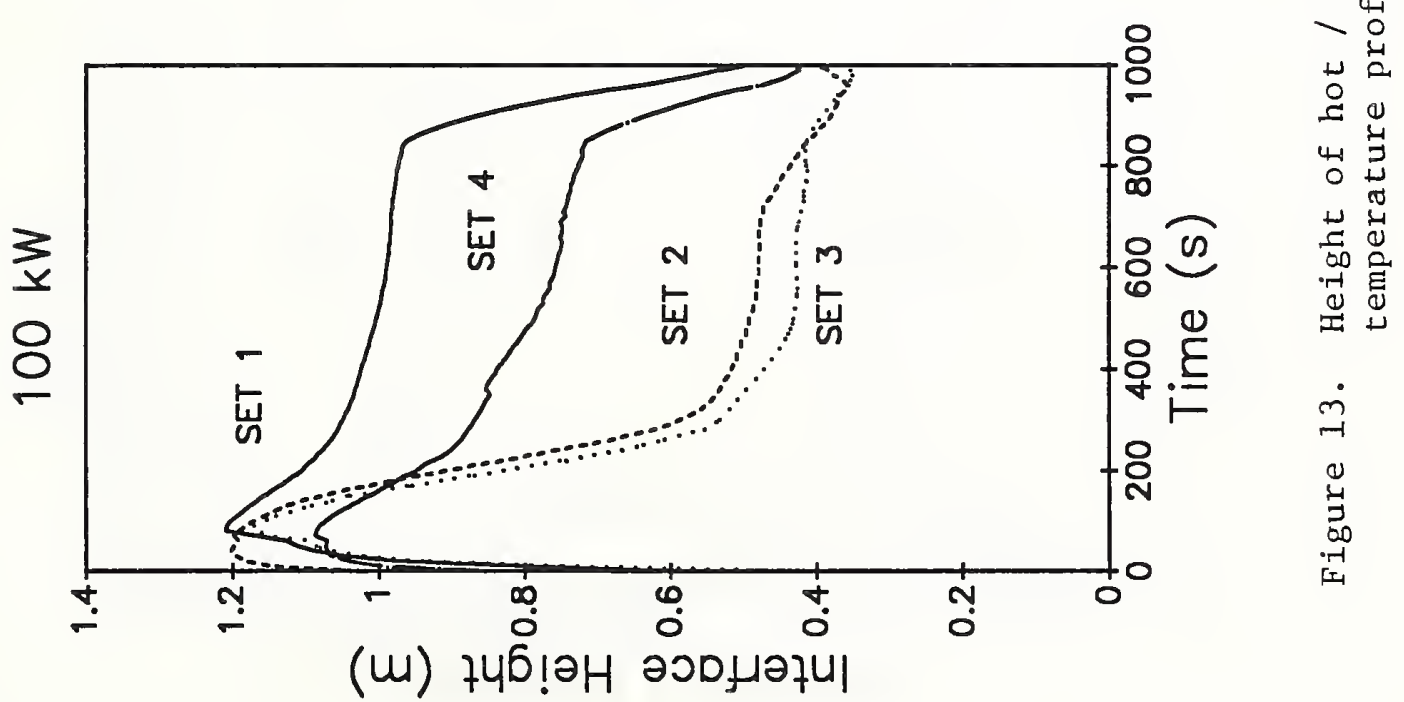



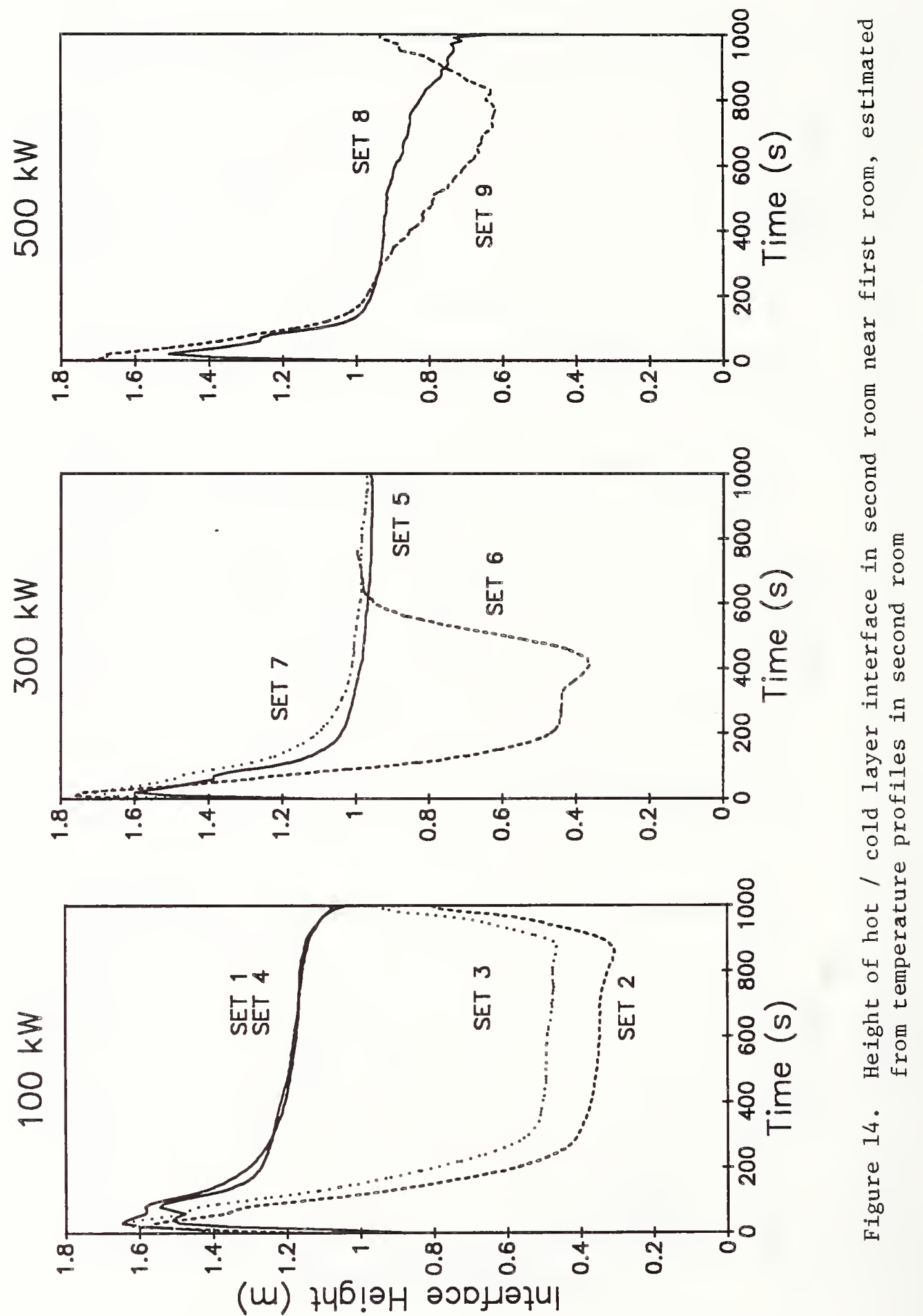


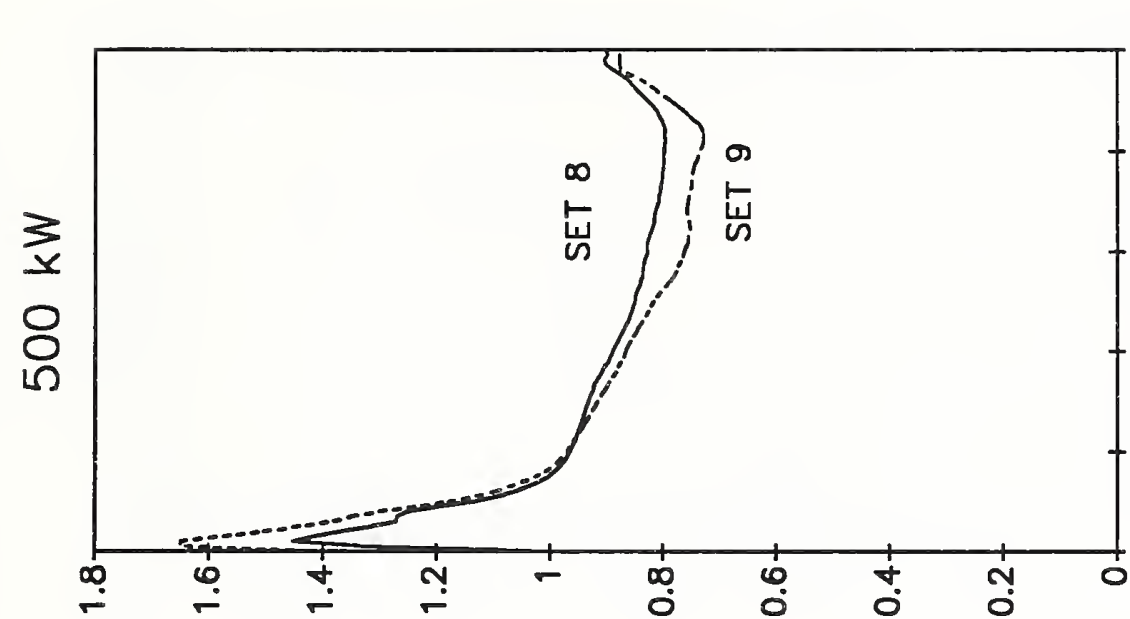

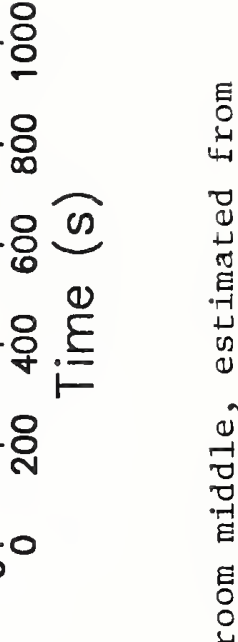

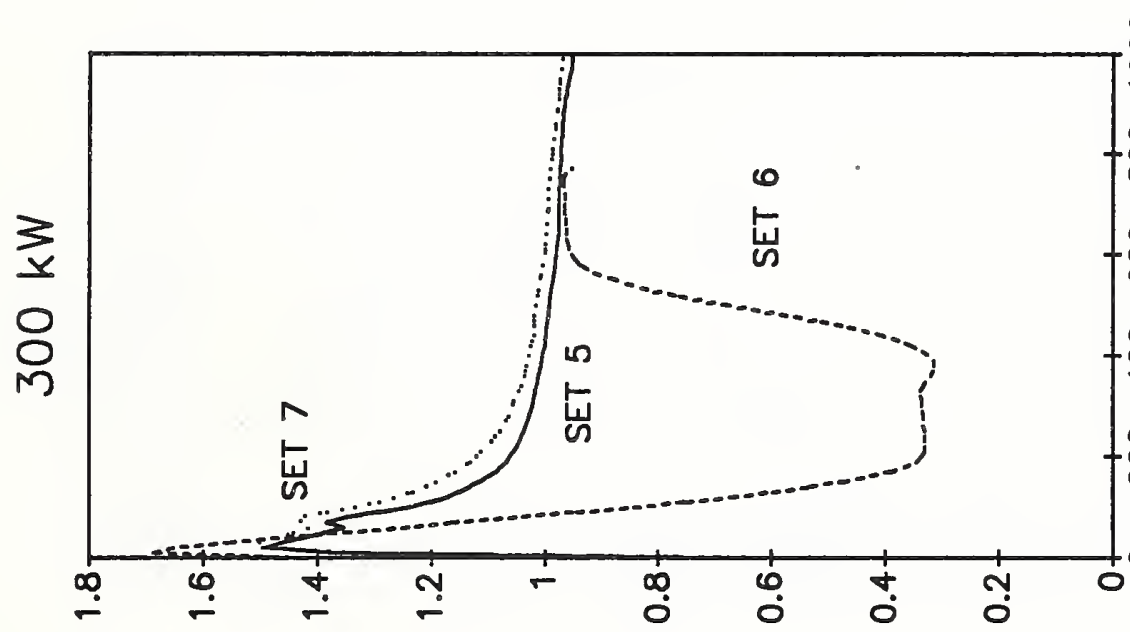

$\begin{array}{r}8 \\ 0 \\ +8 \\ \hline\end{array}$

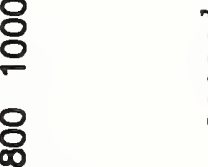

ป

$8 \%$

(1) Uू

E.

8 .

ฟ

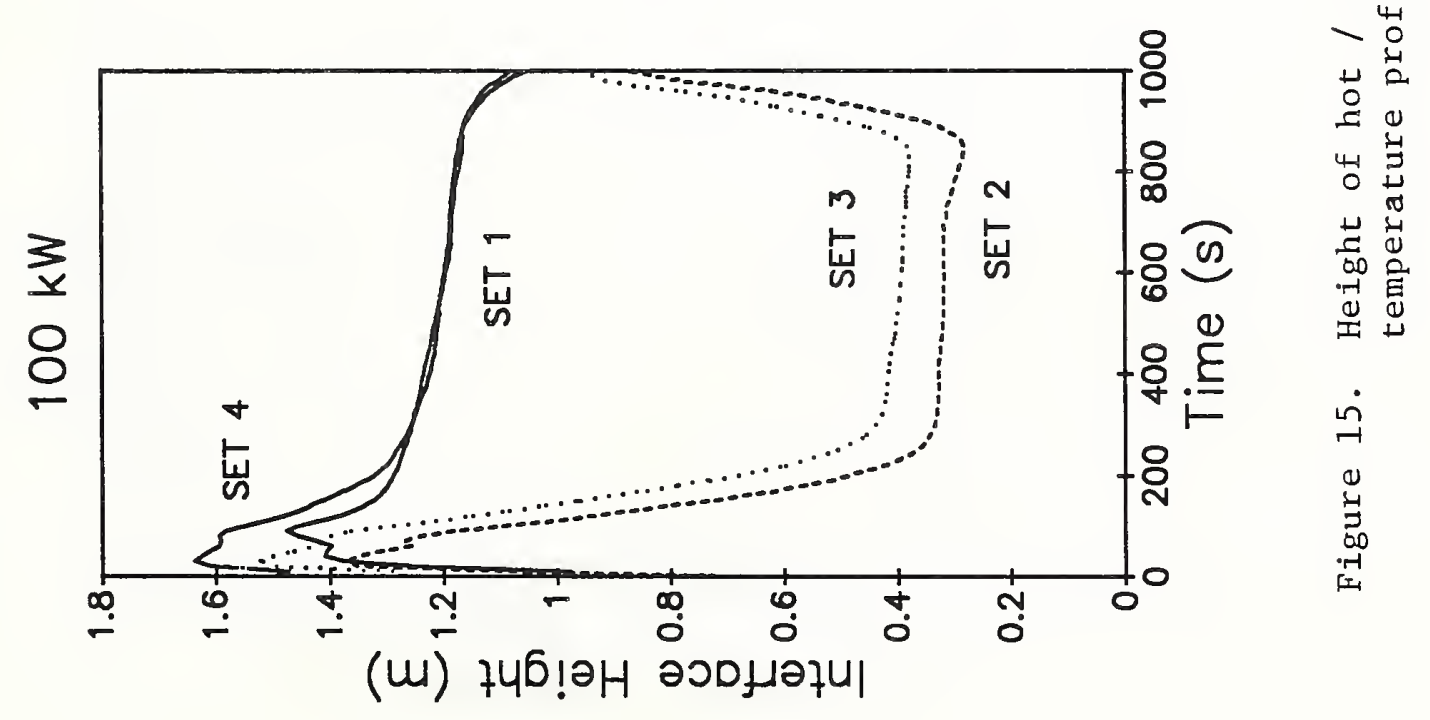



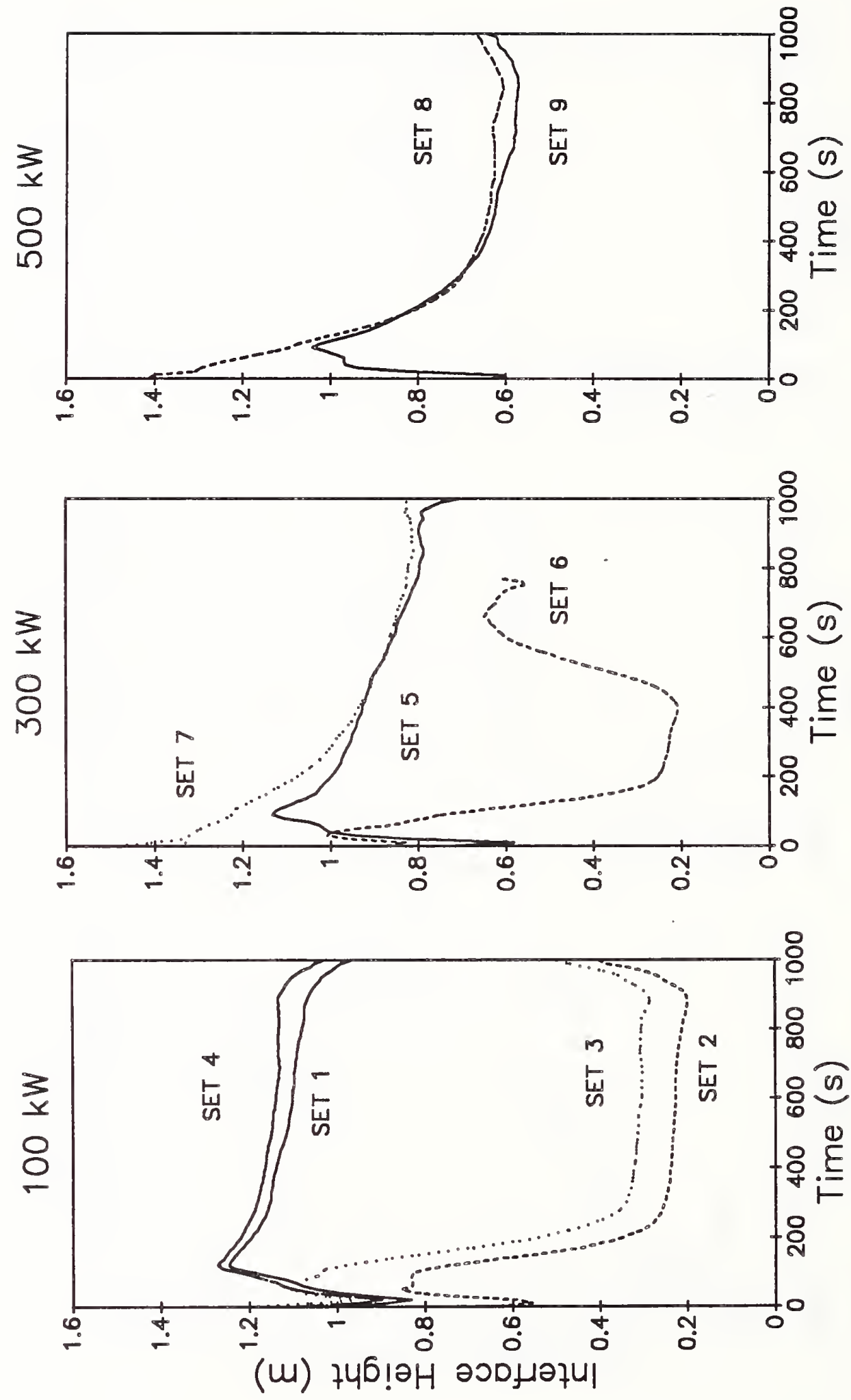

Ш 

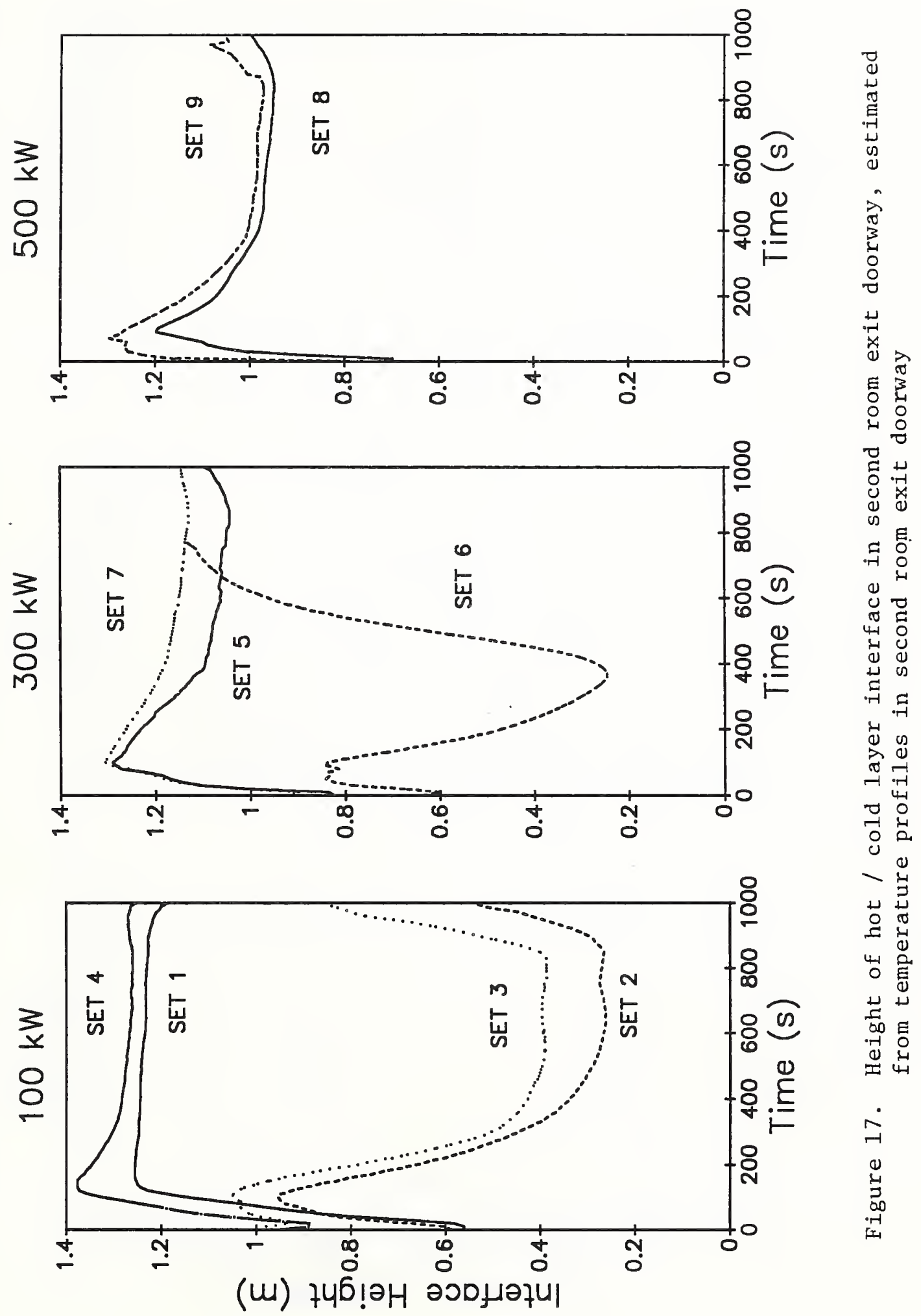

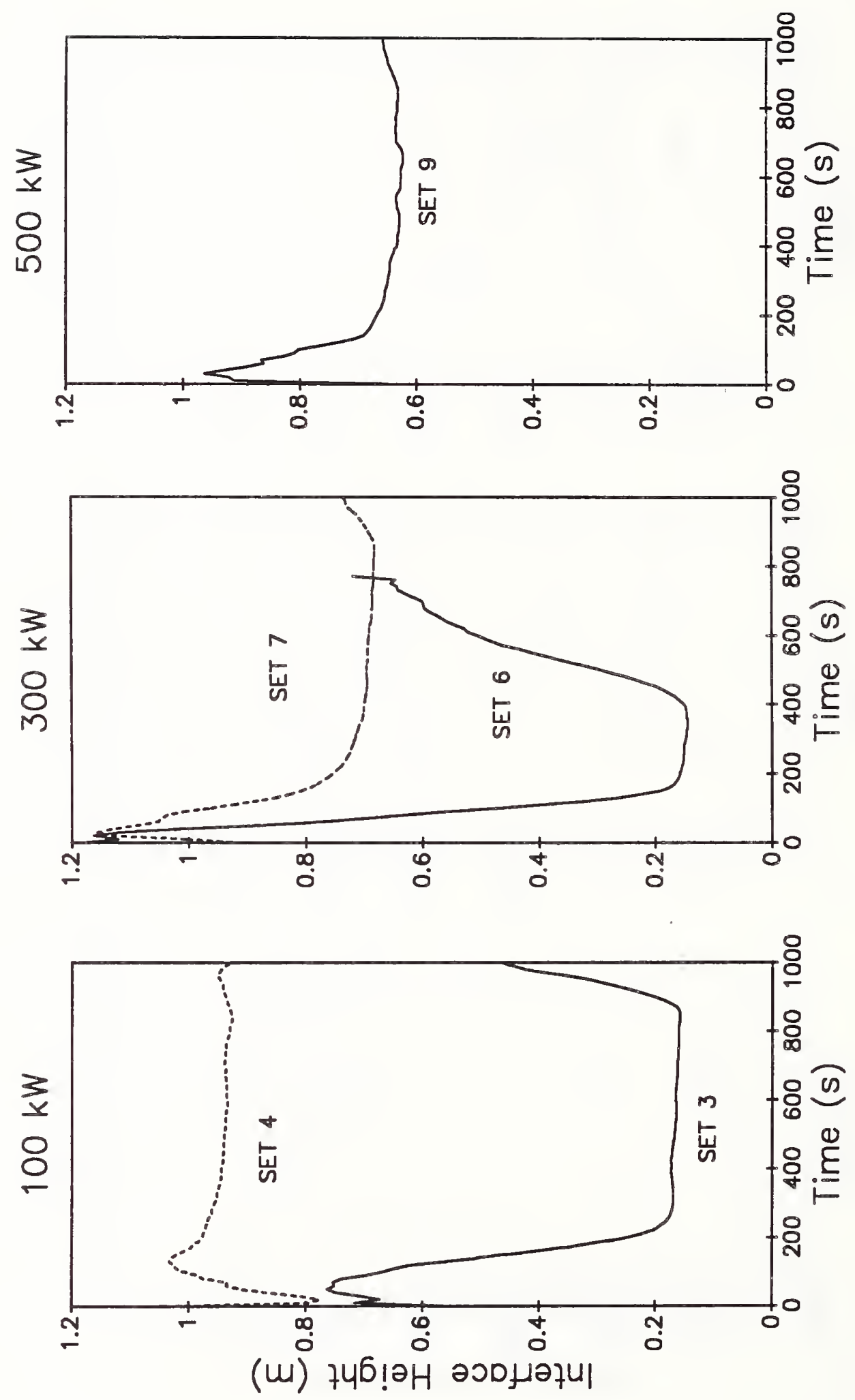

ปี

'담

$\circ$

告

है

-1
-1

엉

$-\stackrel{0}{-1}$

닌

도 댕

4-1

岂

00

o :

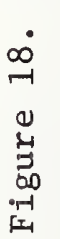



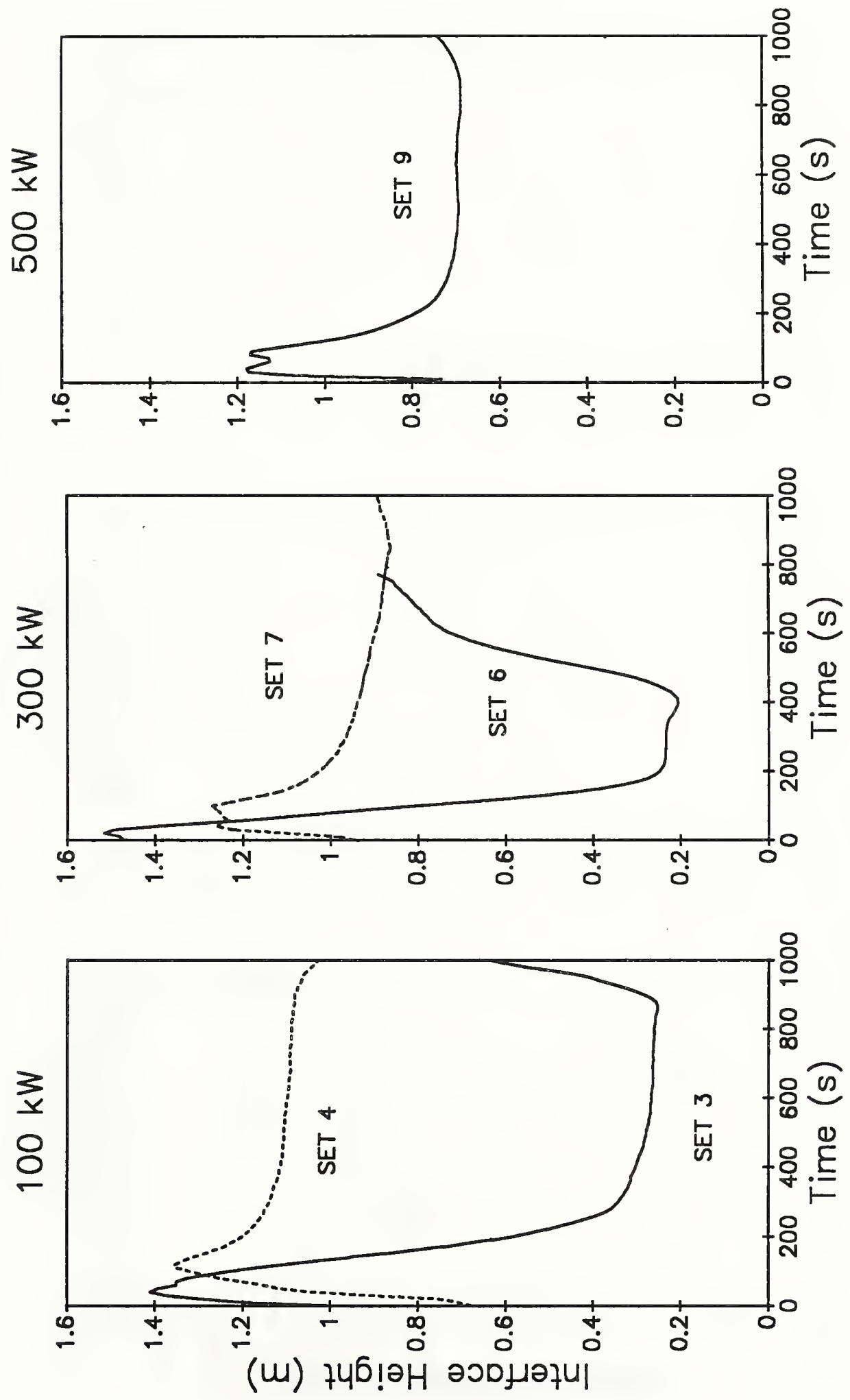

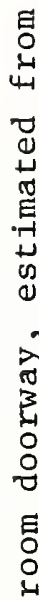

0
3
0
0
0
1
0
0
4

늠

돔 궁

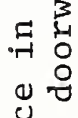

는

(1)

문

4 도

넌

त्र.

므 थ

욤다

$>\quad 0$

曲

오

4

芫

00

멍

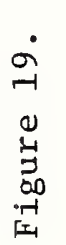



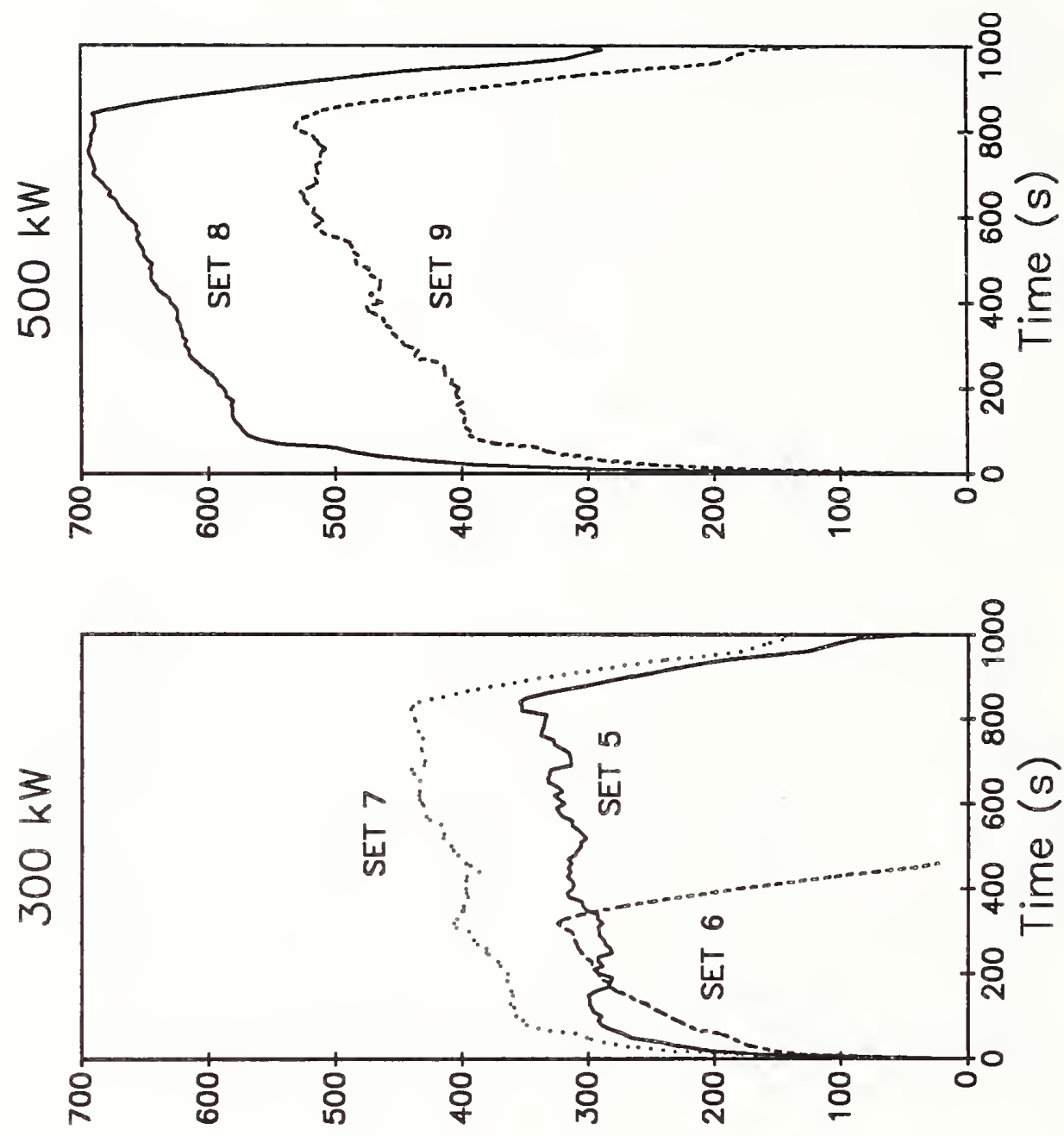

E

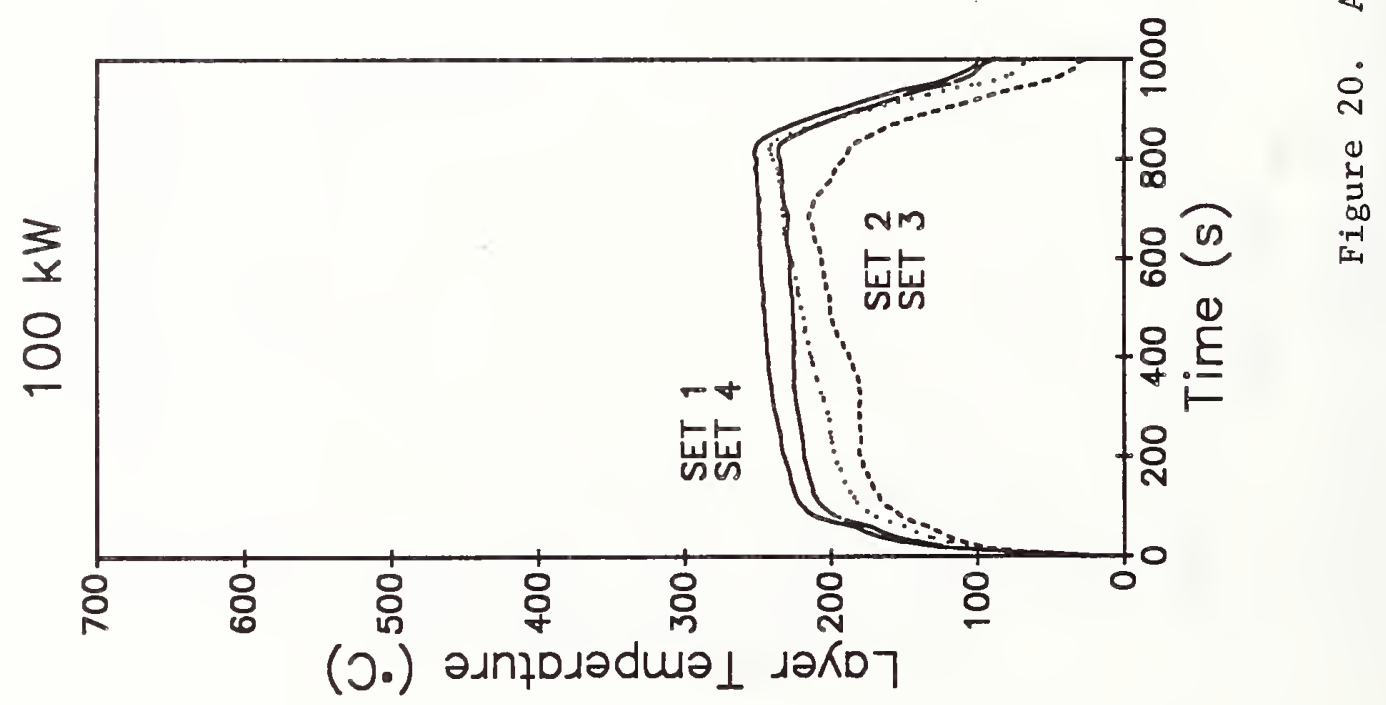



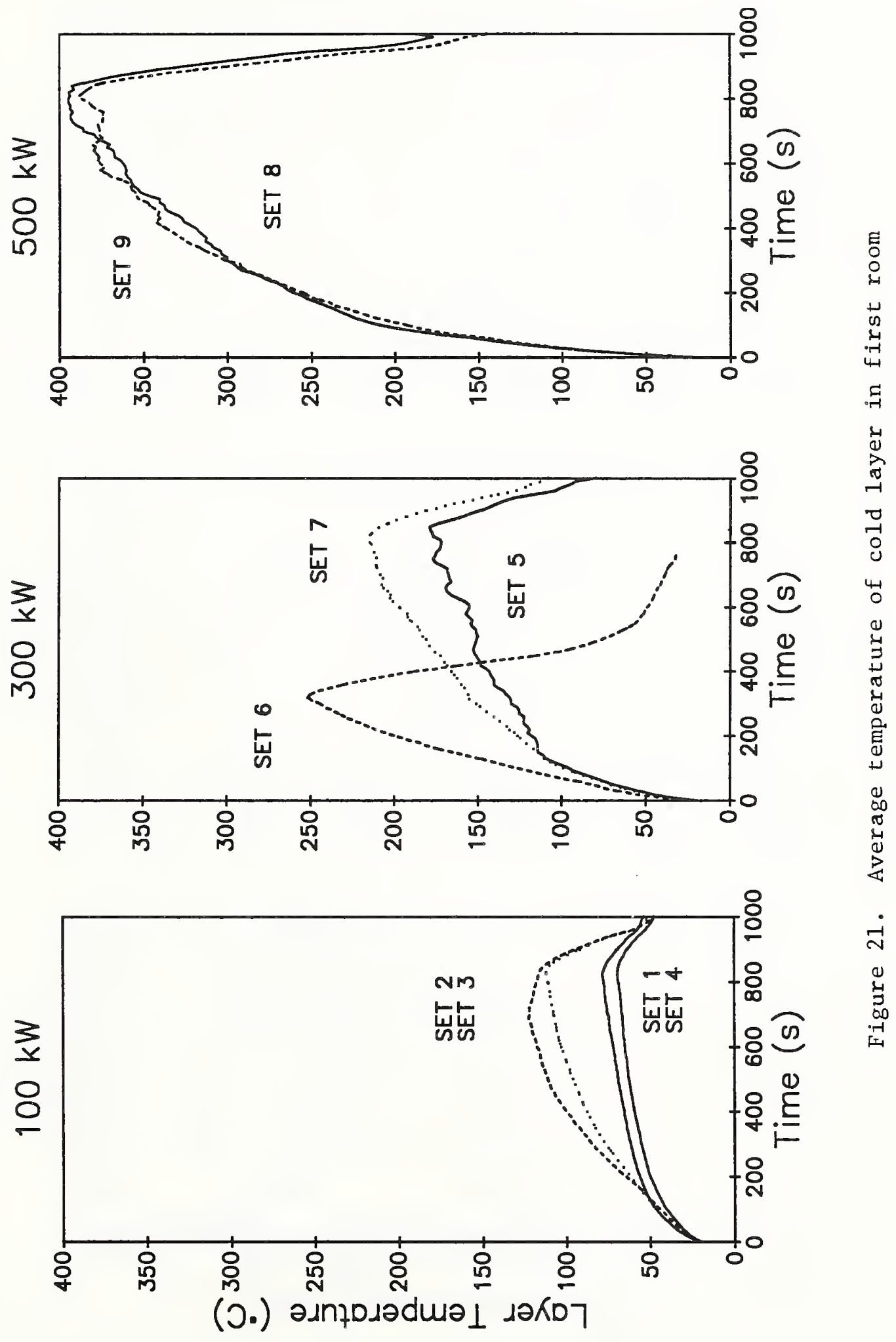

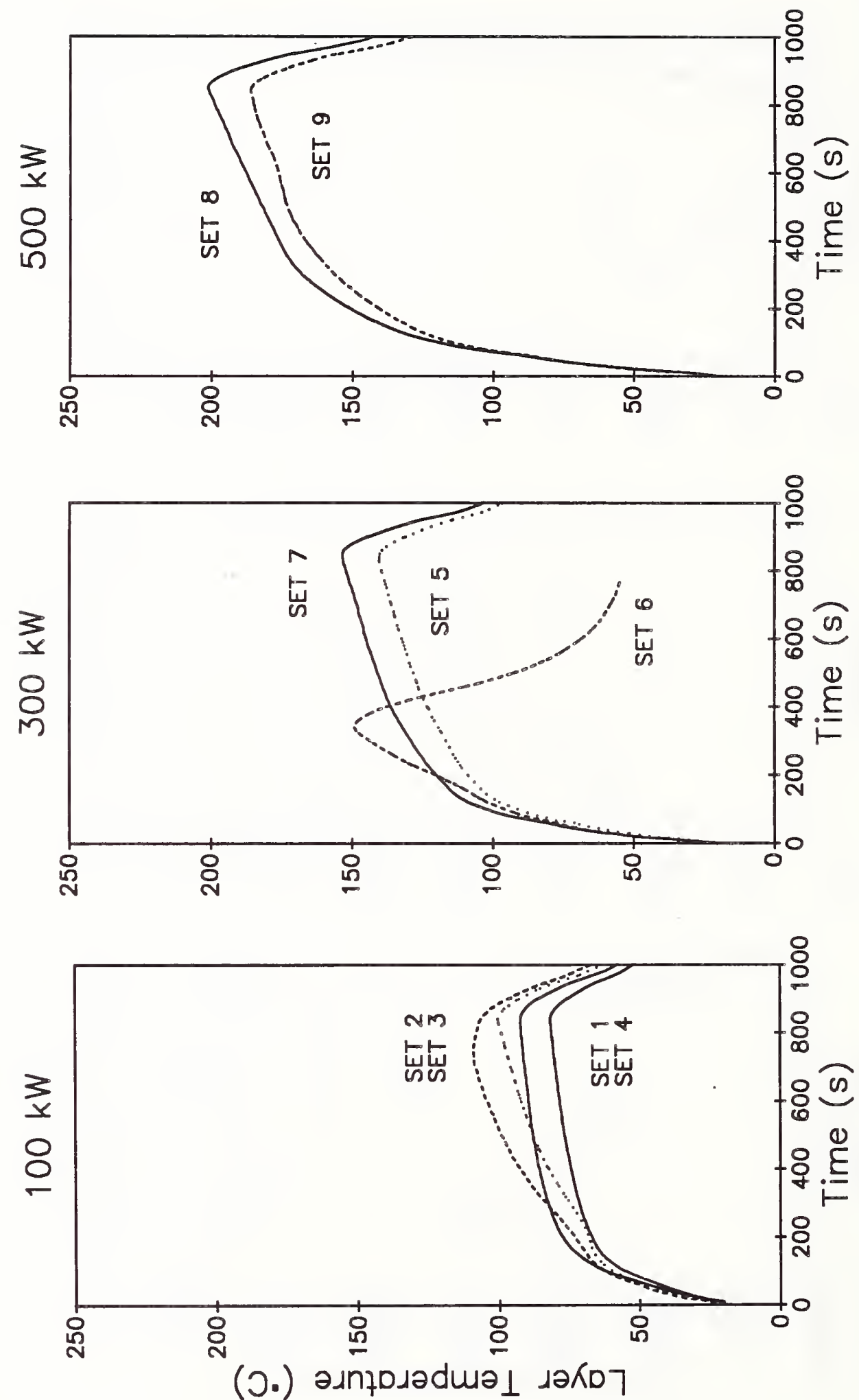


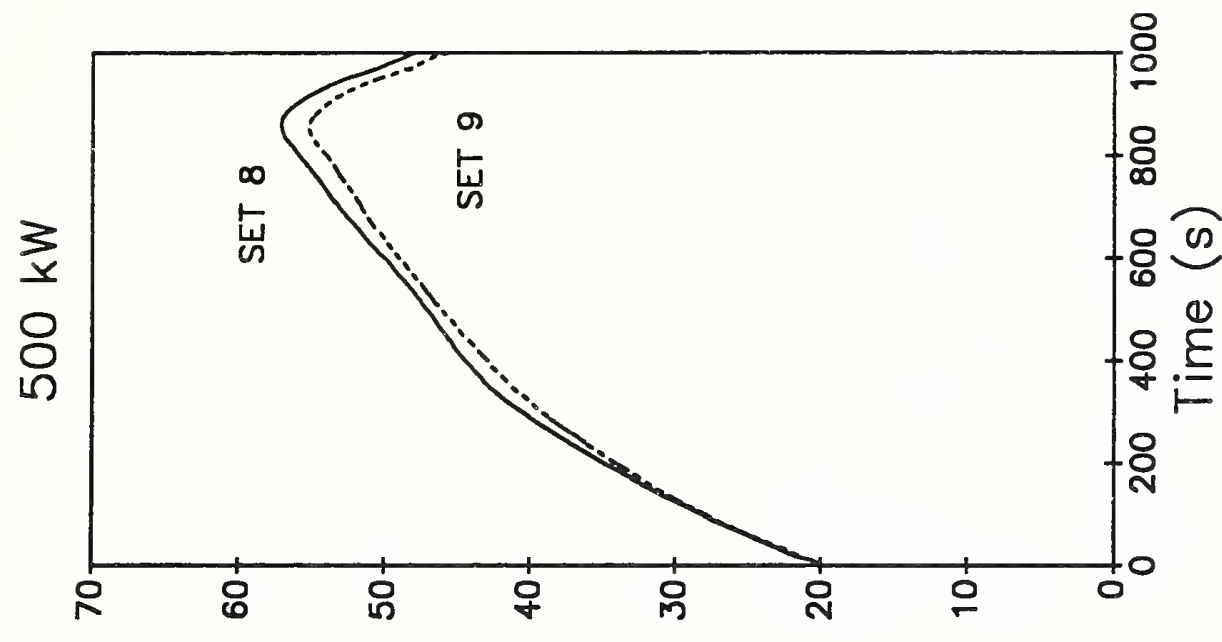

E
0
0
ப
0
0
0
0
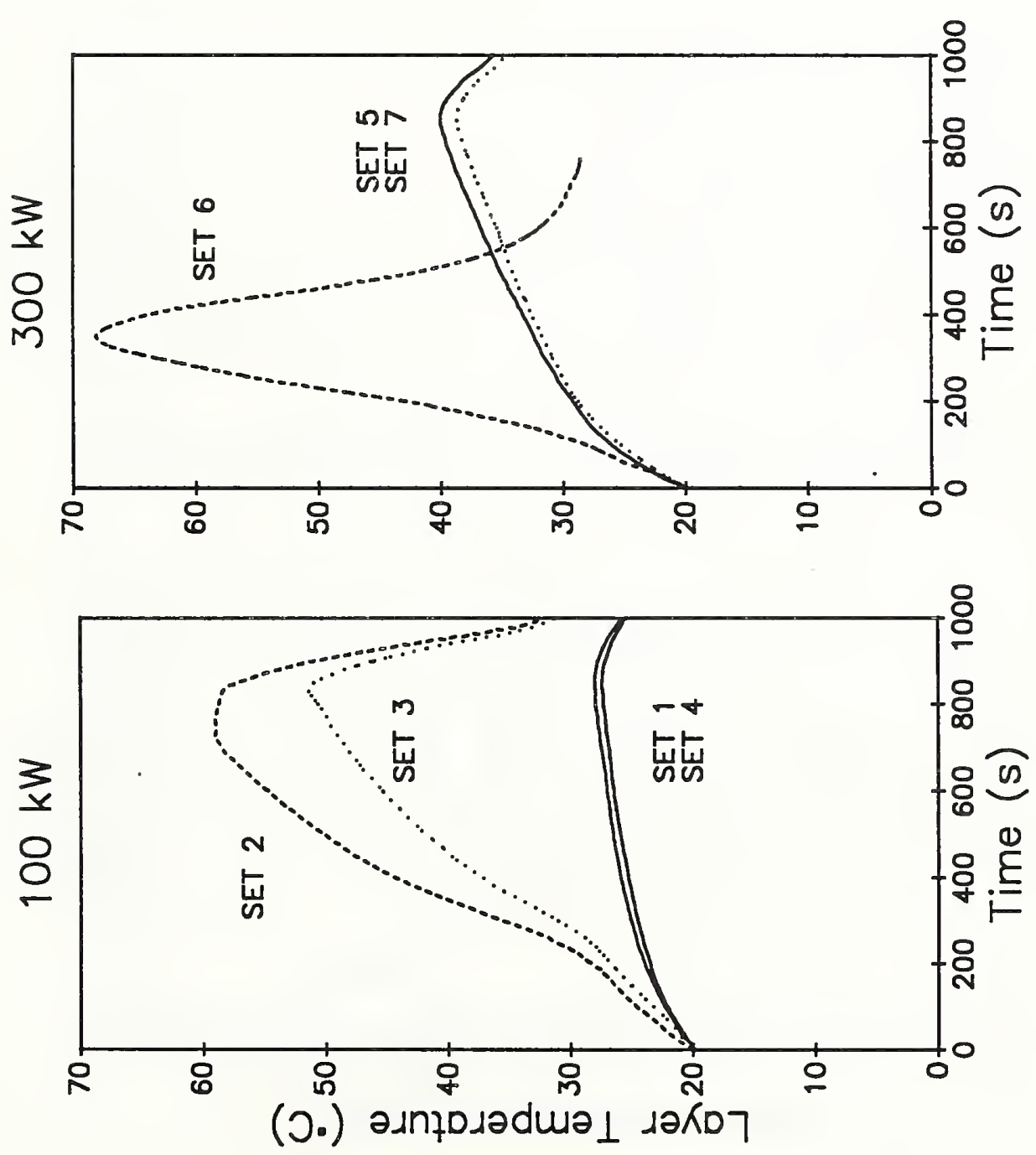

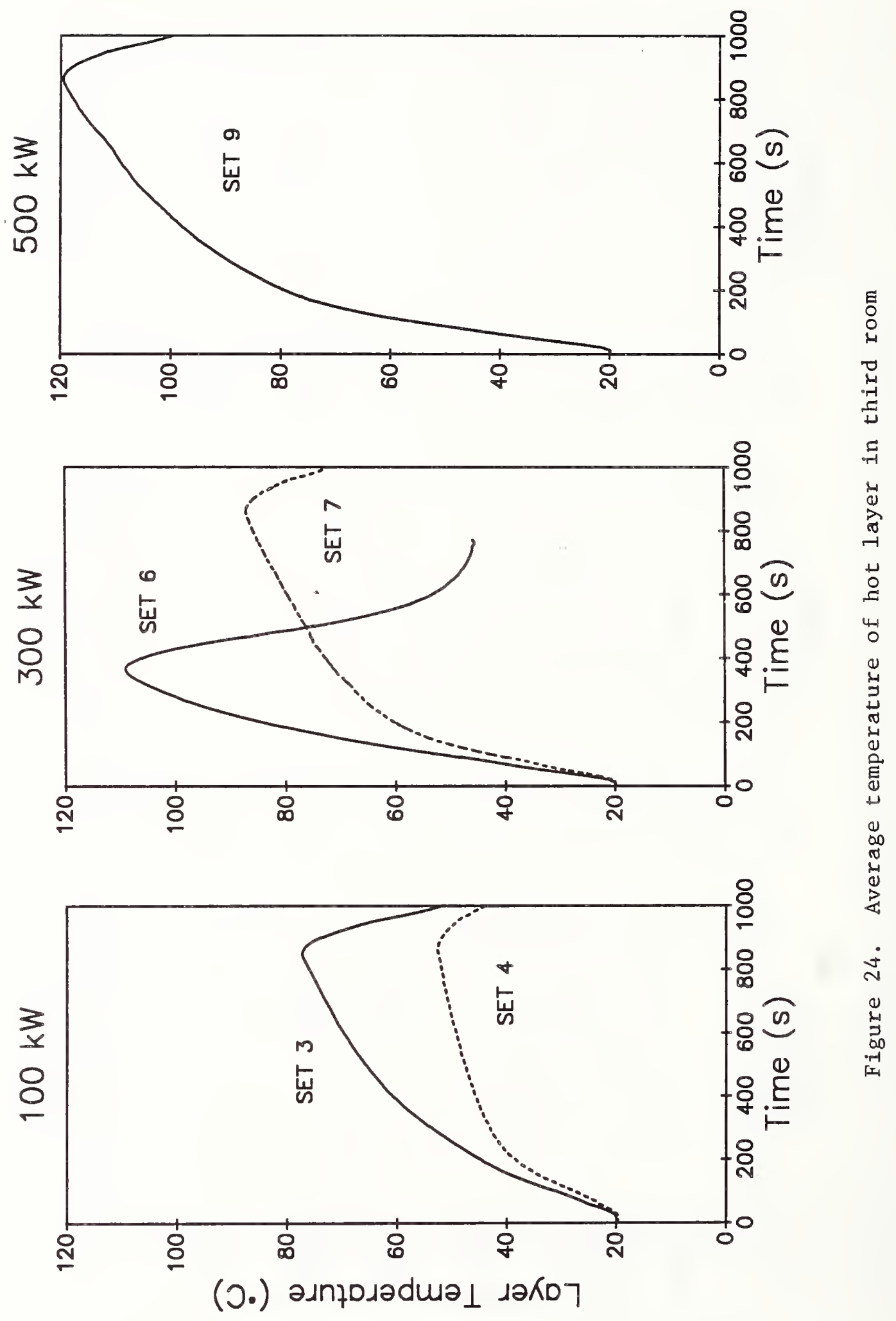

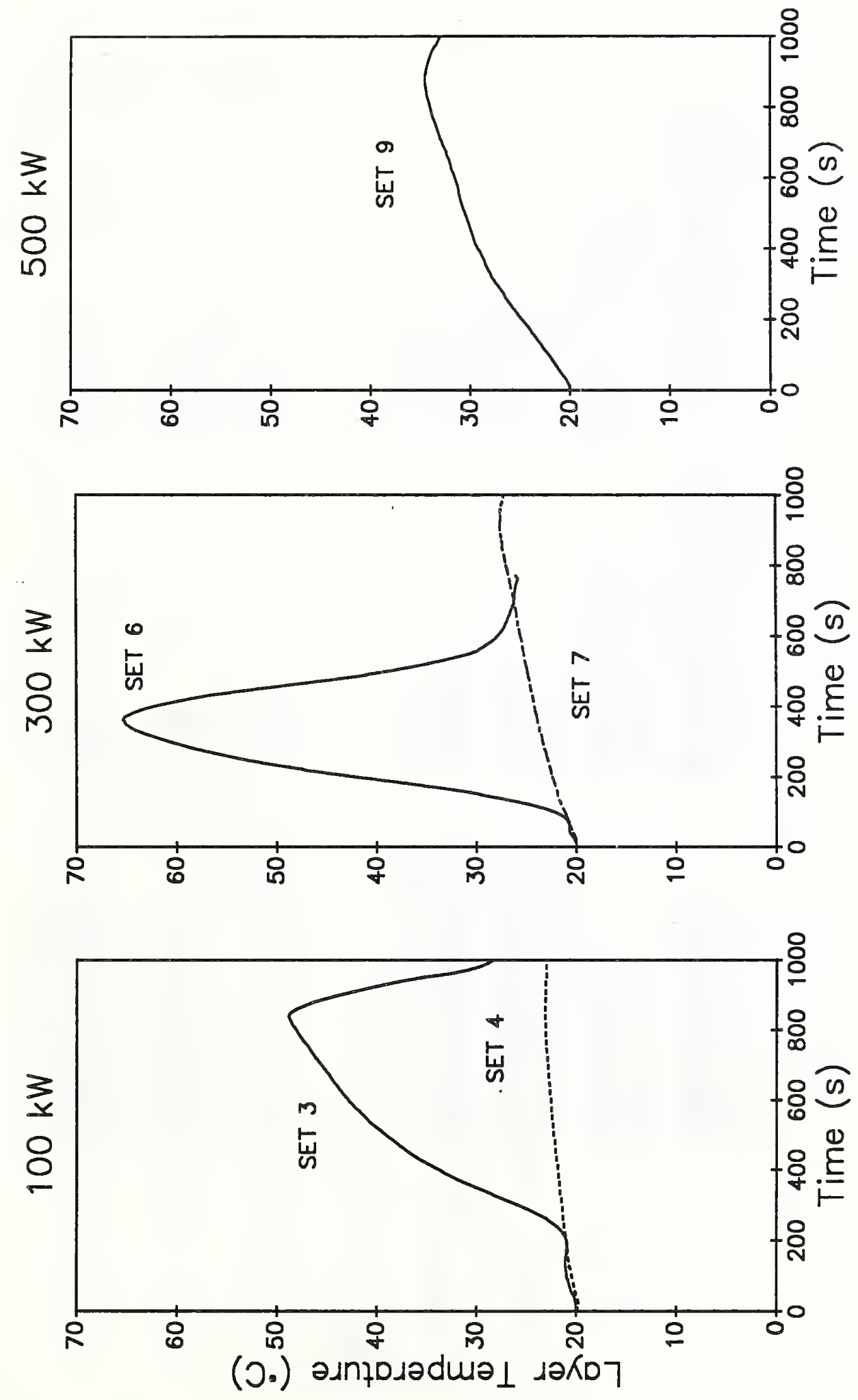


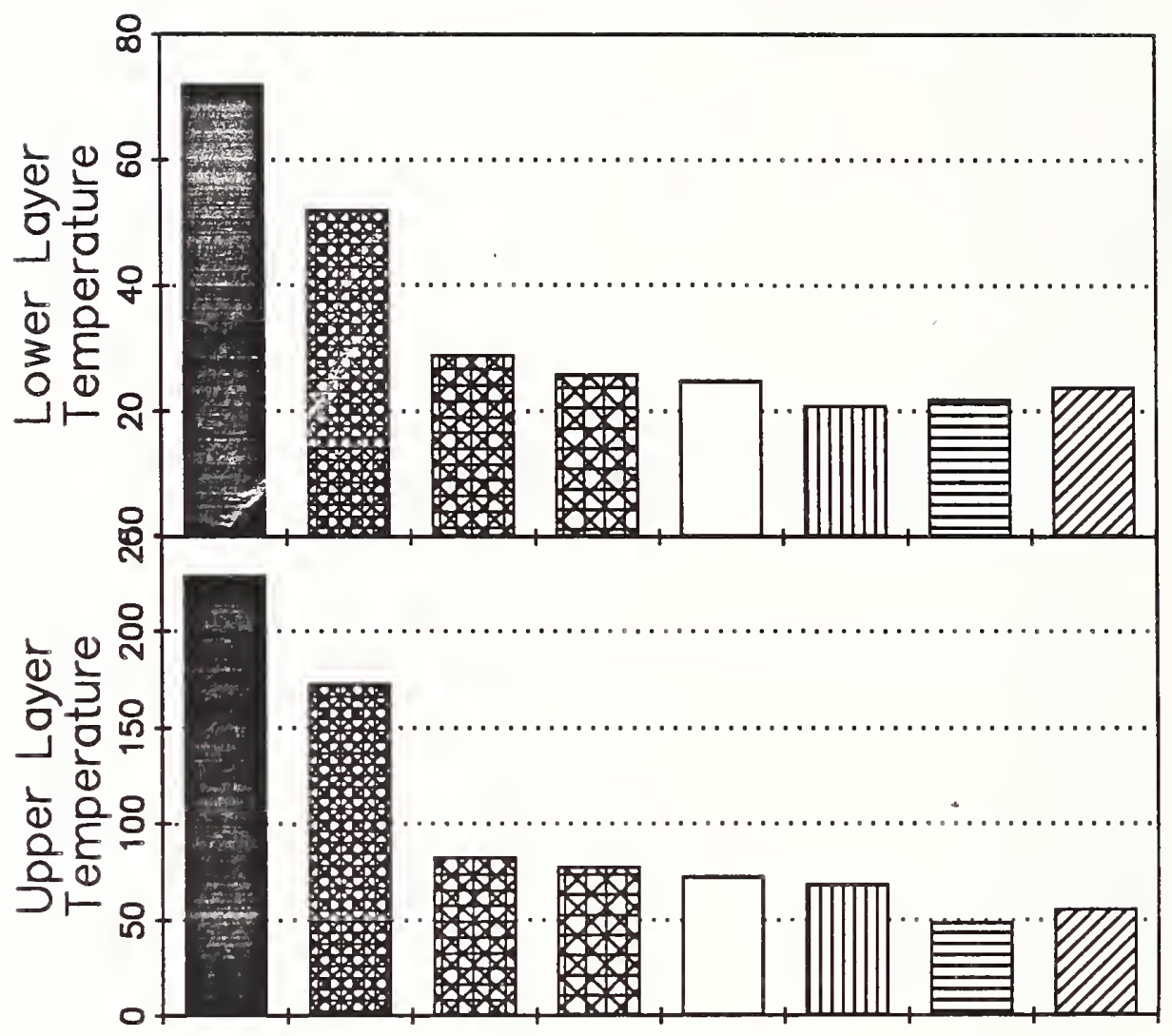

$\stackrel{0}{\circ}$

म당

4

를

은

노 웡

(1)

岳 党

孚

.

os

J

ปี

눙

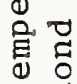

(1)

मा क

(1)

公

它负

용

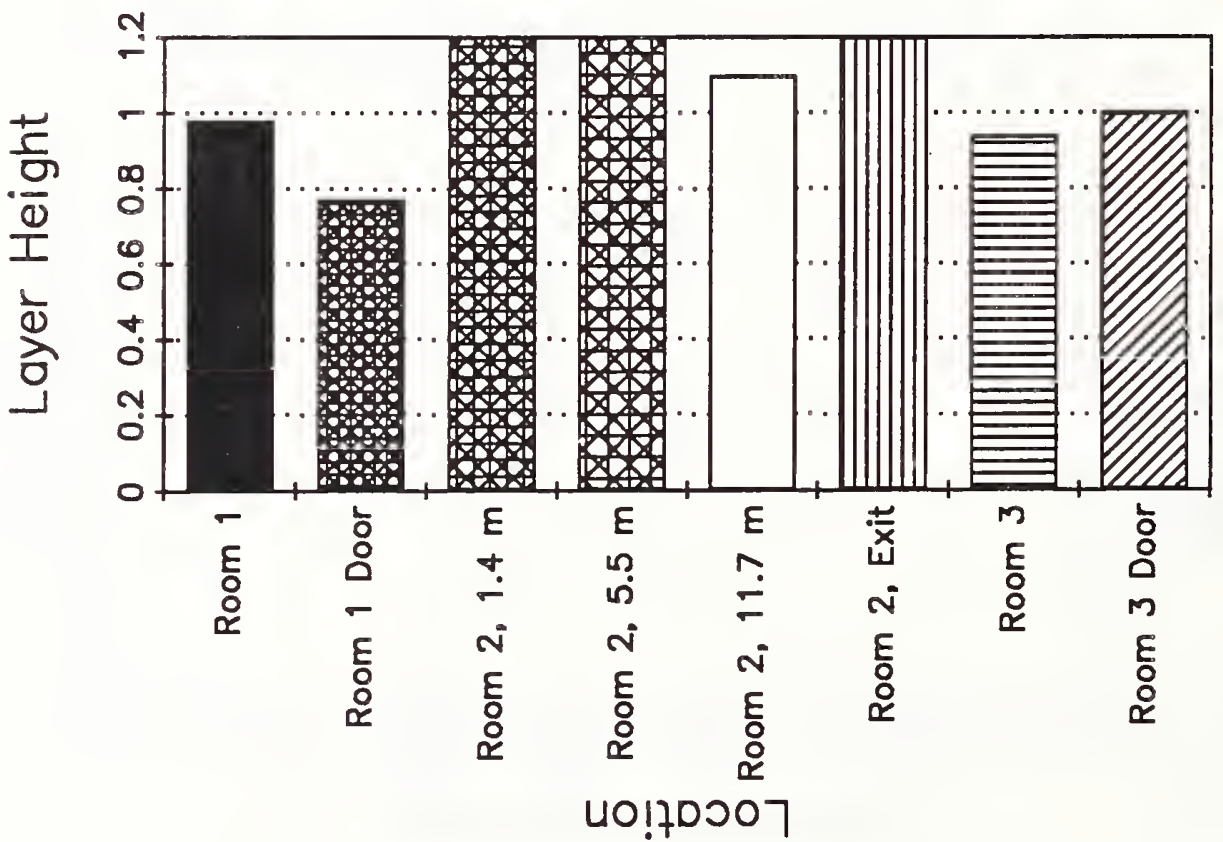

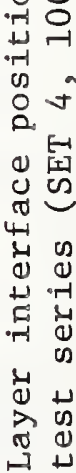

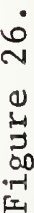




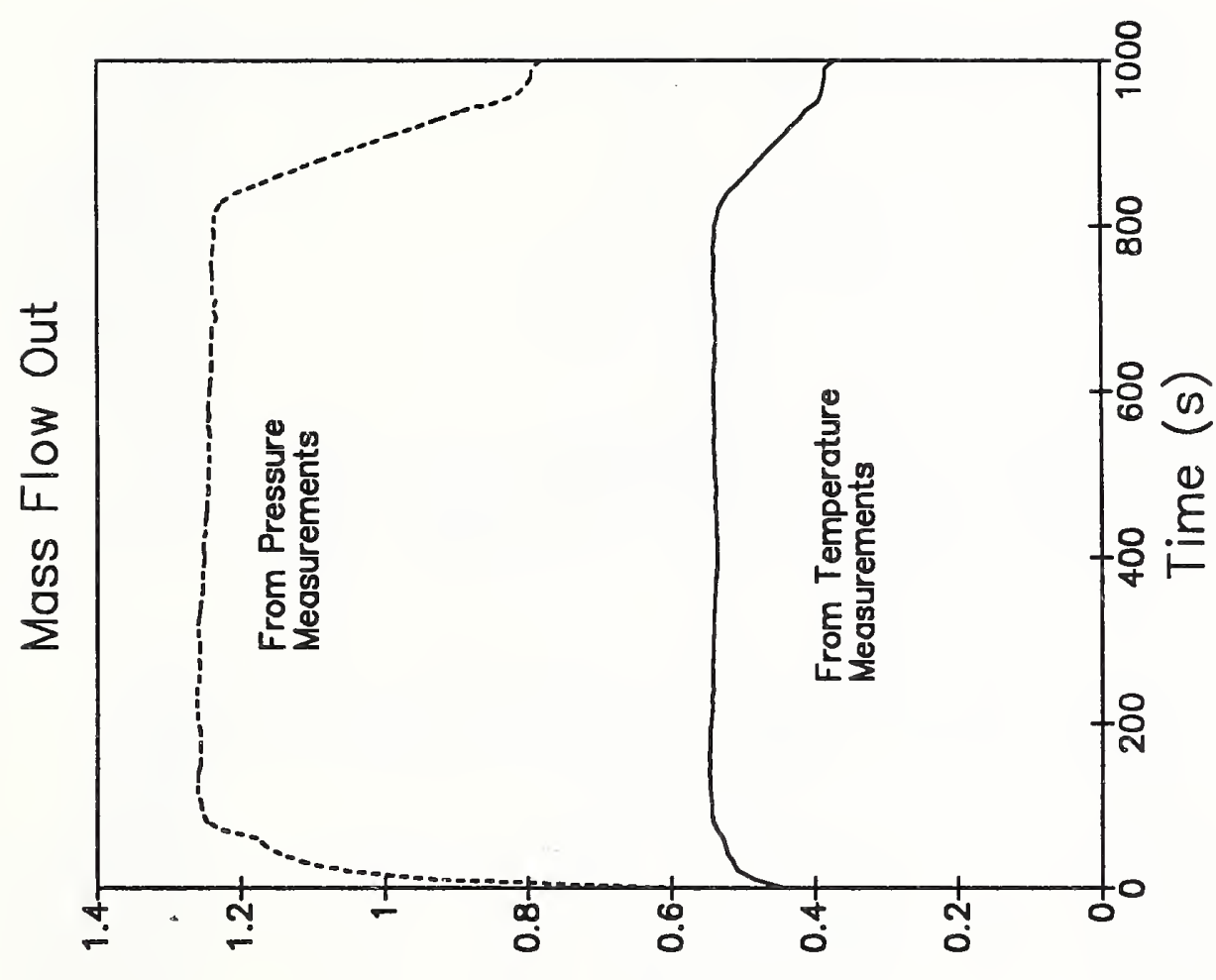

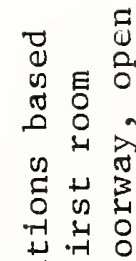

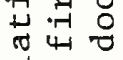

岁艺

겅

U.

络 020

फ

थ

类讨

मै

畮寻

成品

3 .

ㄴ.

움용응

티가

$\circ 0$

4 品

म

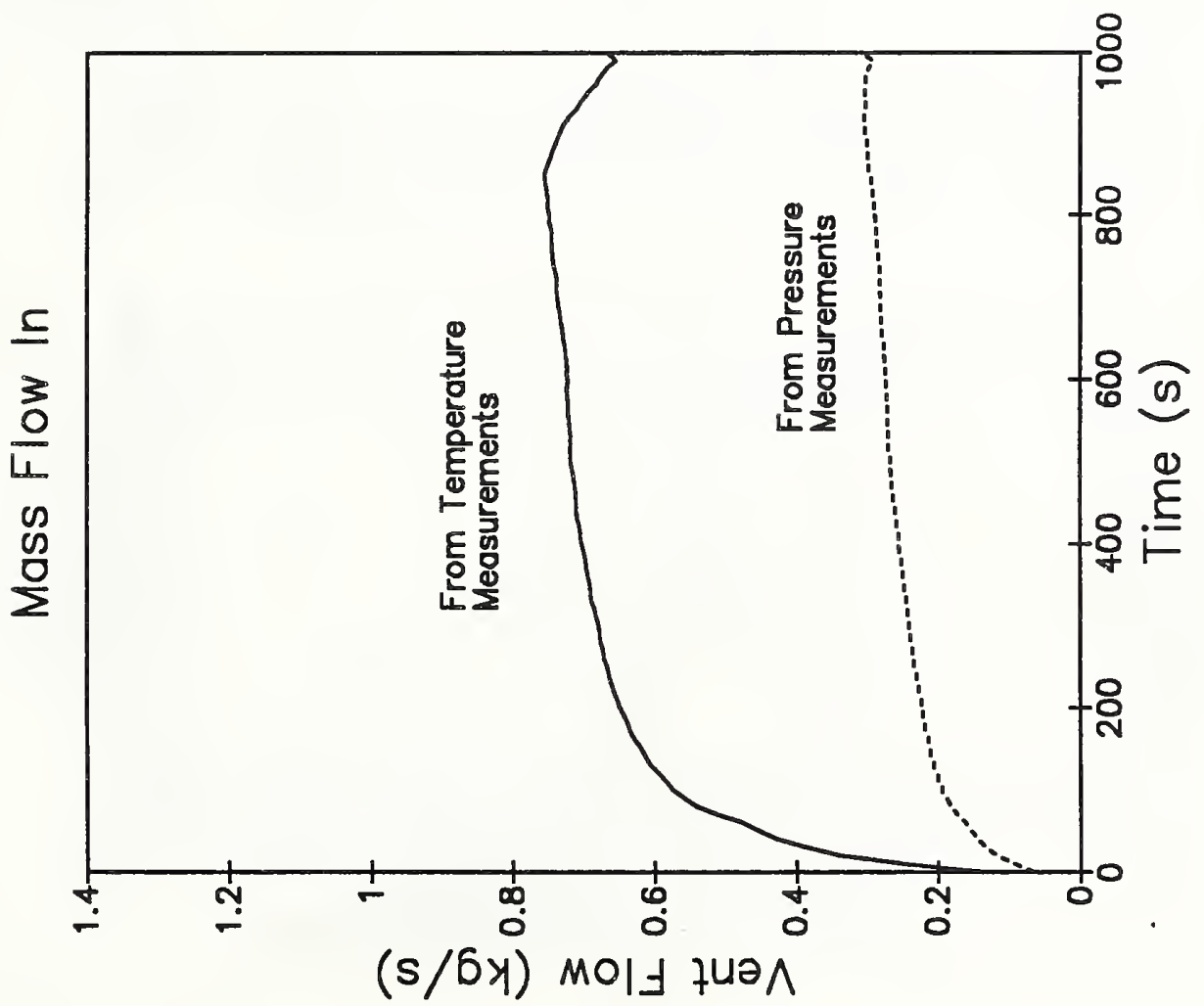

는도

畮

द 000

उ.

난낭

क के है ब

की

臭苛苛

出苟

รั

.

$\ddot{\pi}+\pi$

政

号吕号

N 


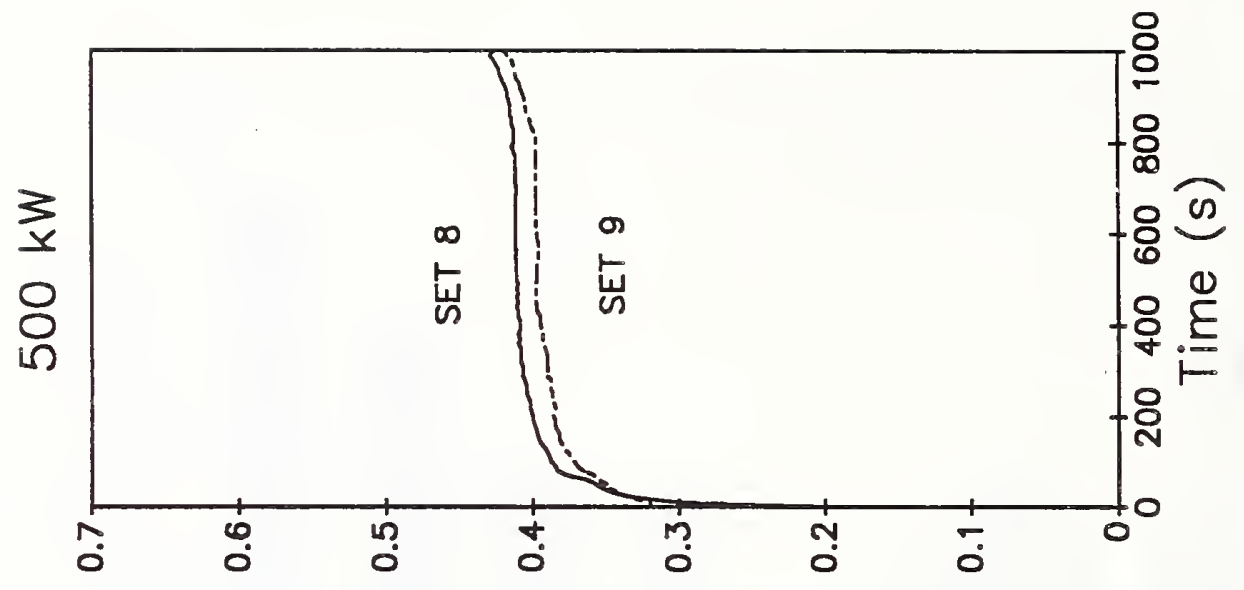

$\pi$
3
3
0
0
0
1
0
0
01
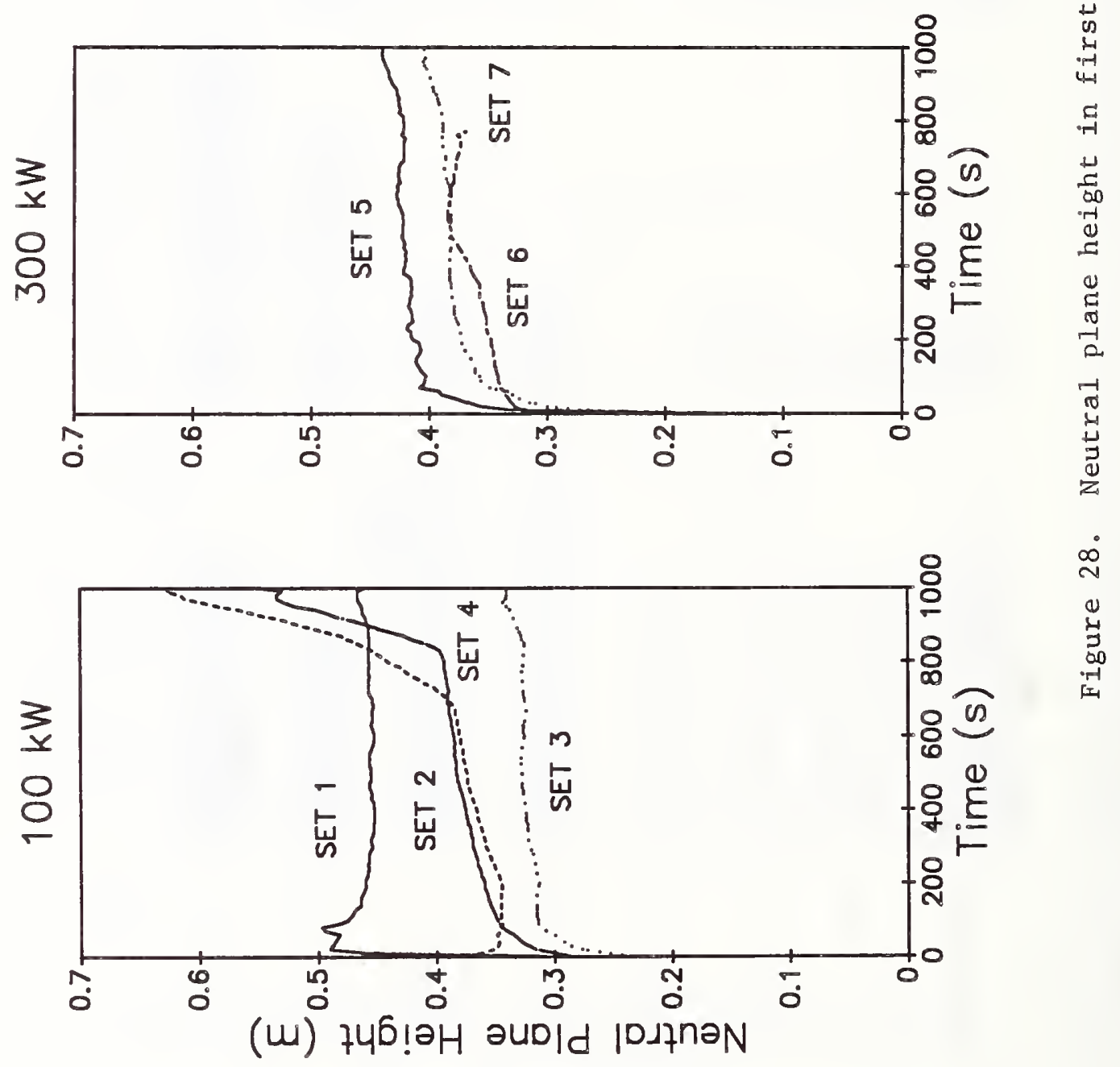

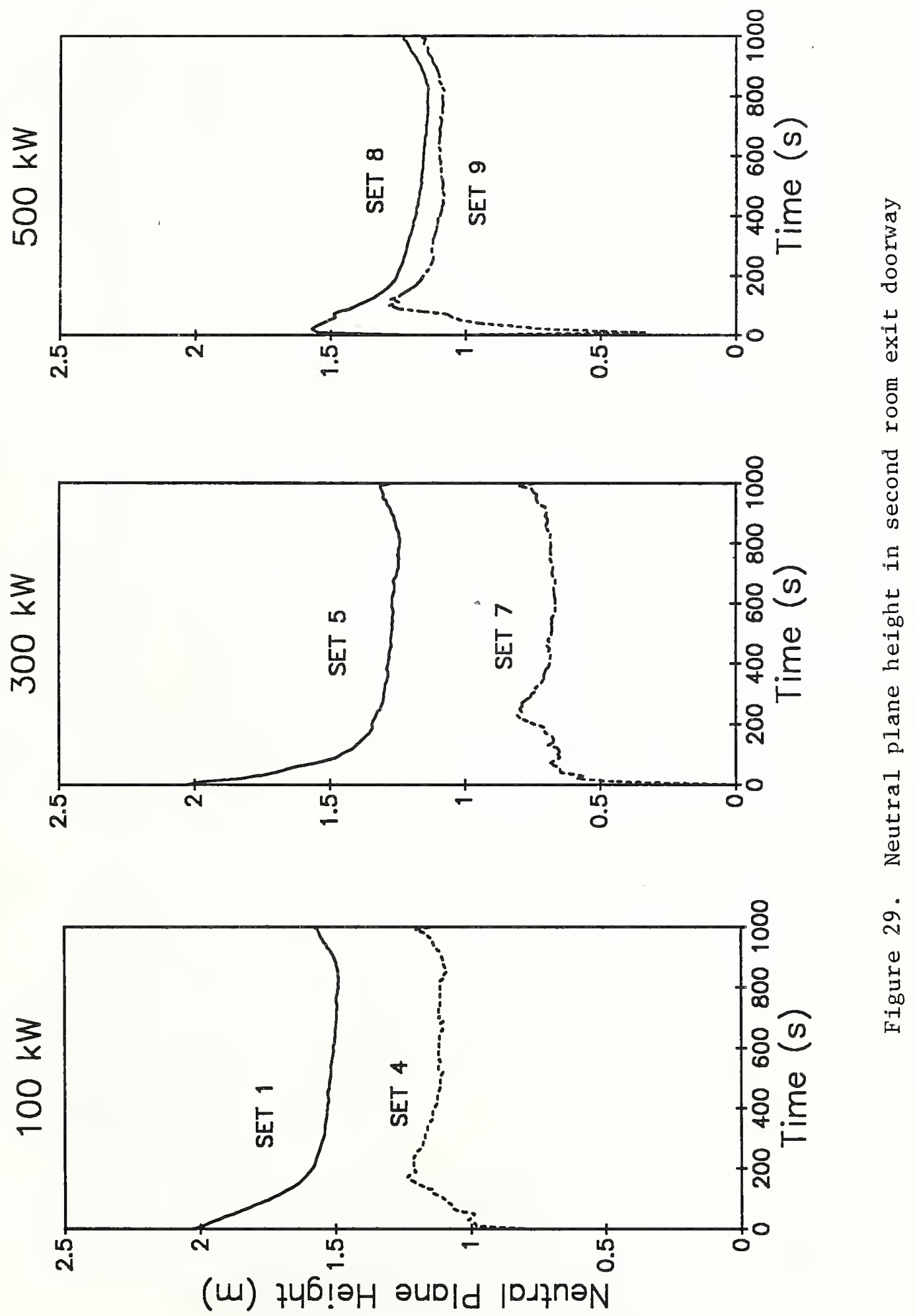

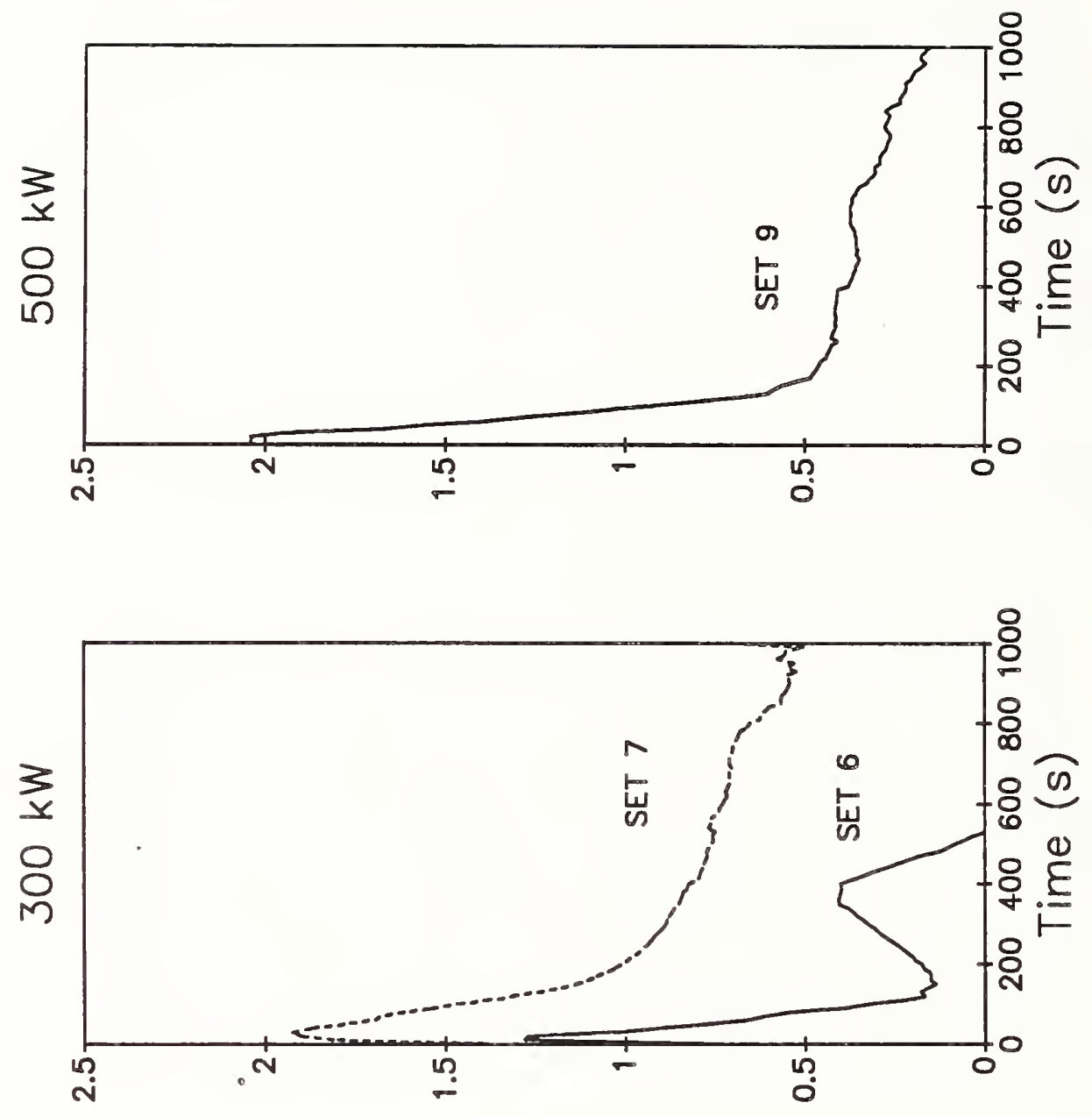

0े

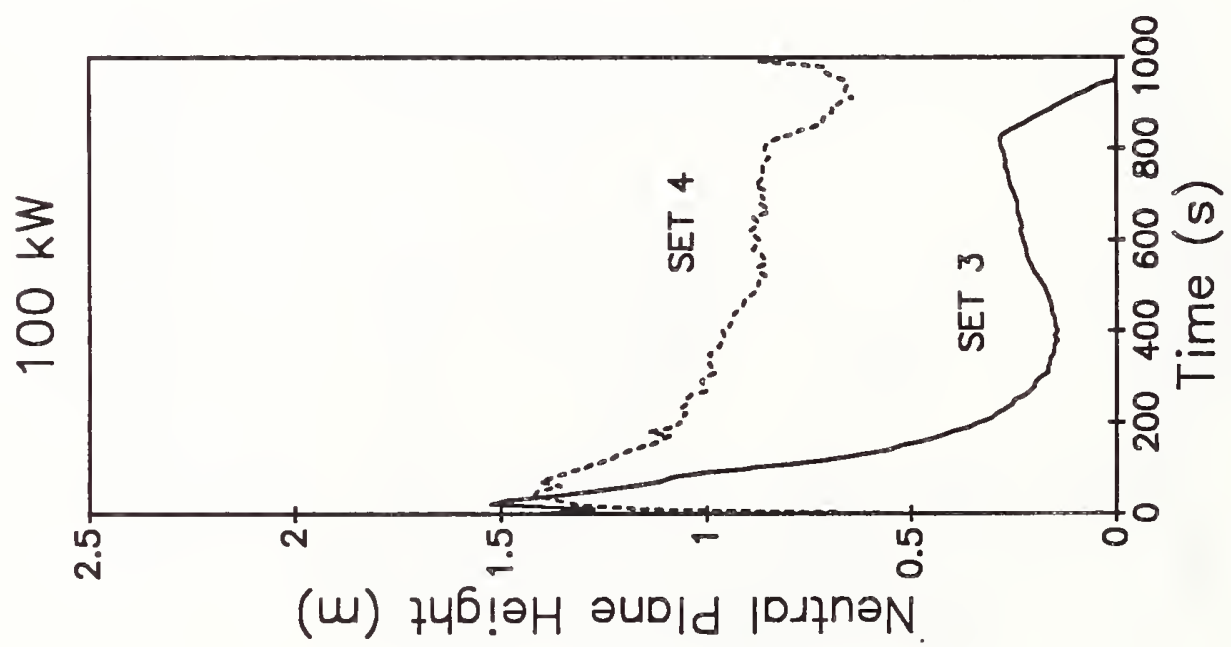

○ं

崩 


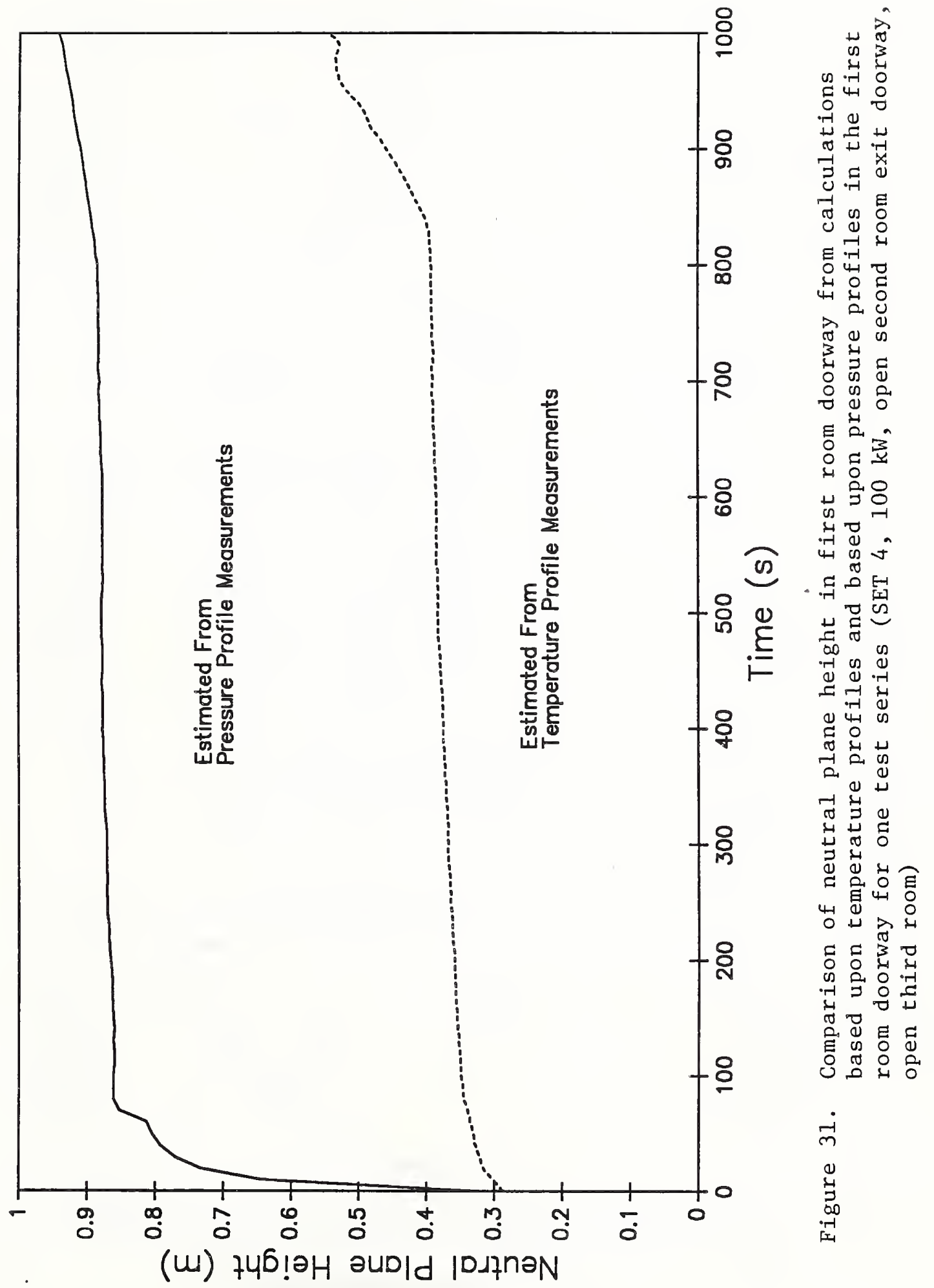




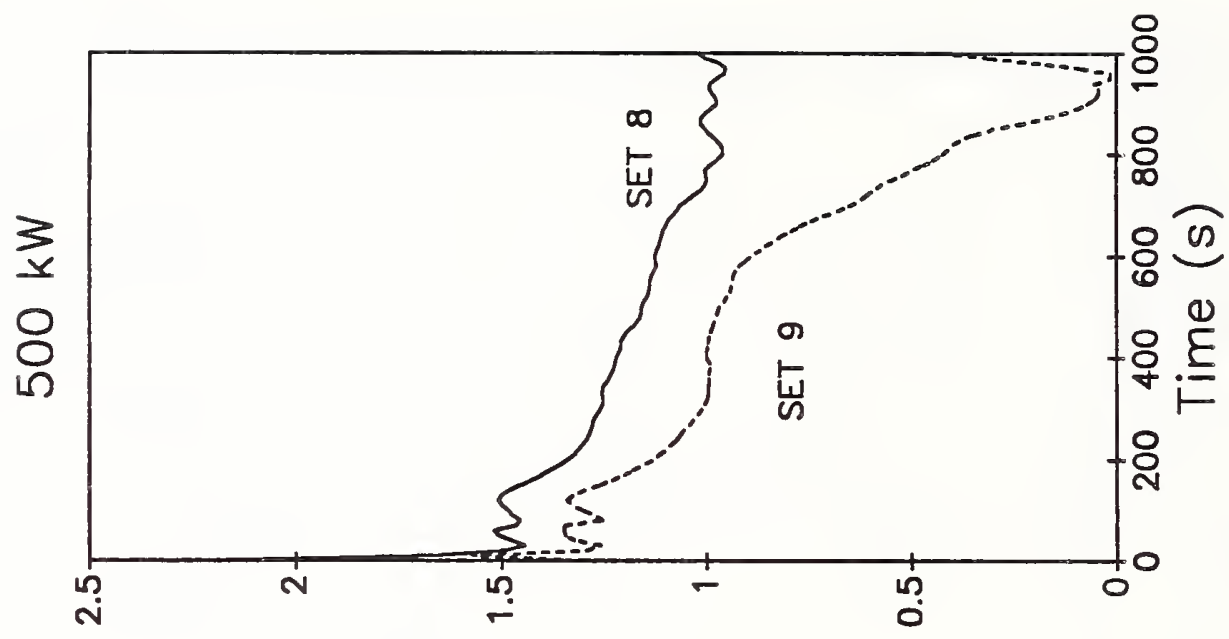

ठิ
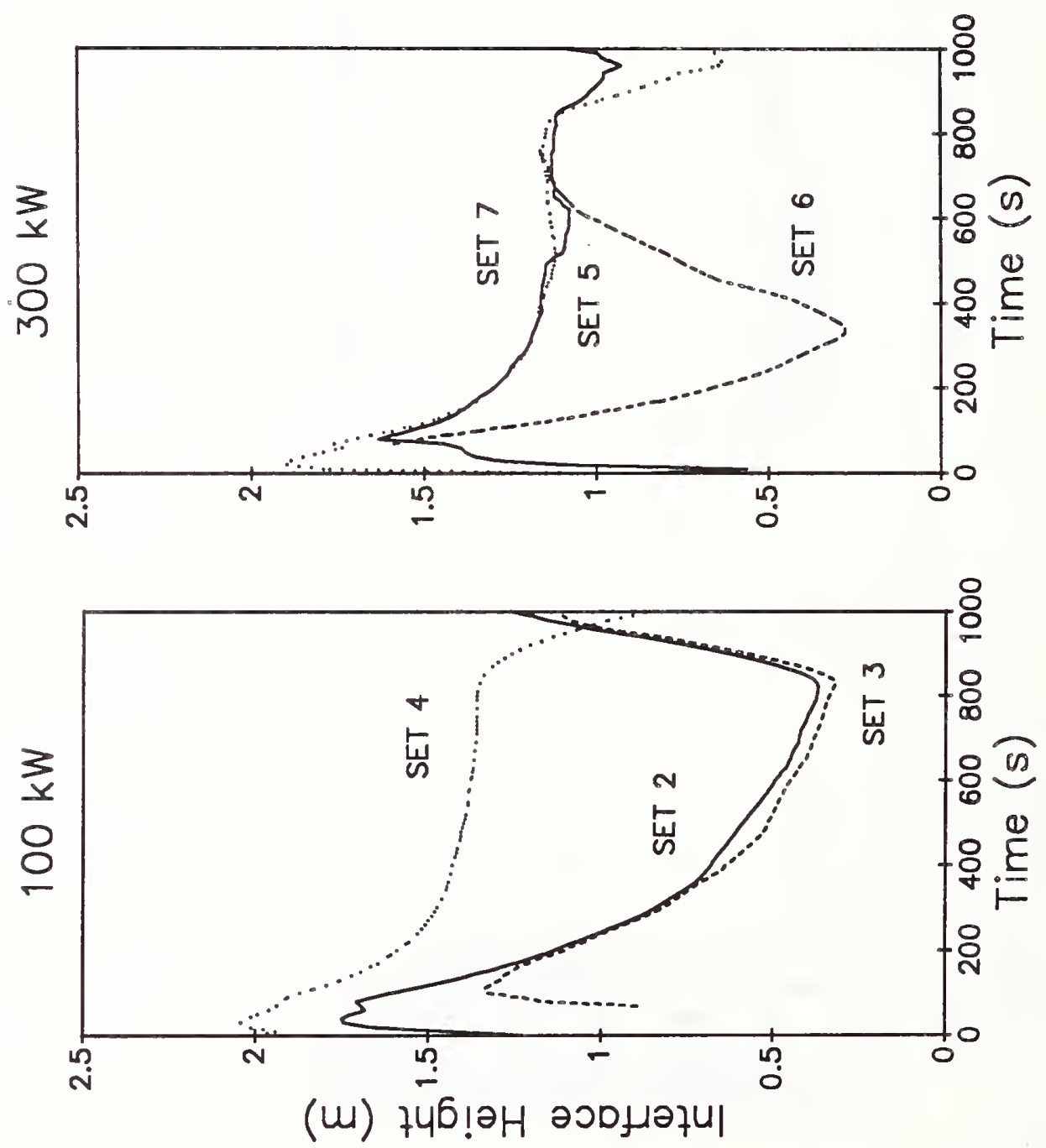

ป

(ш) $746 !$ 


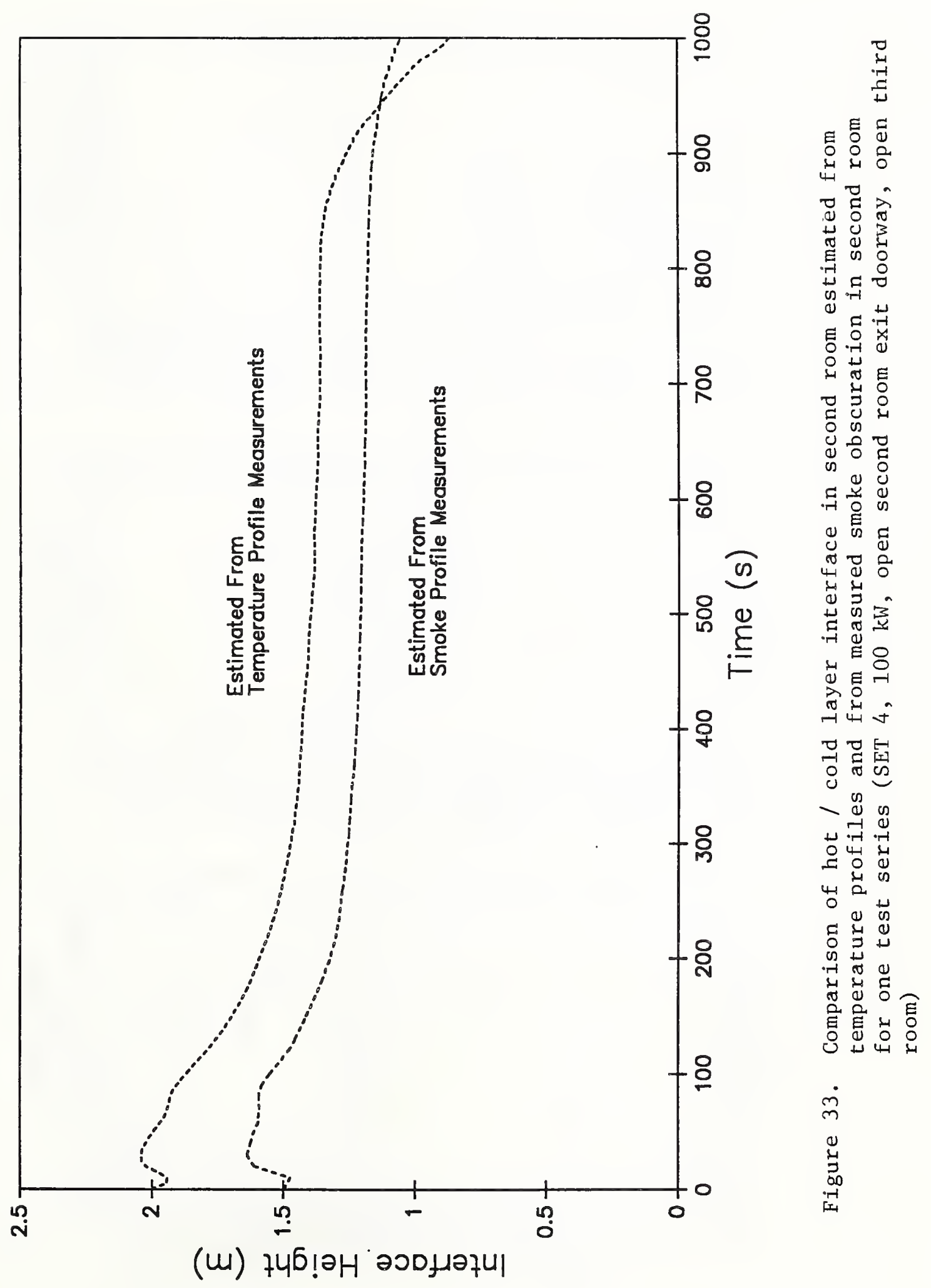



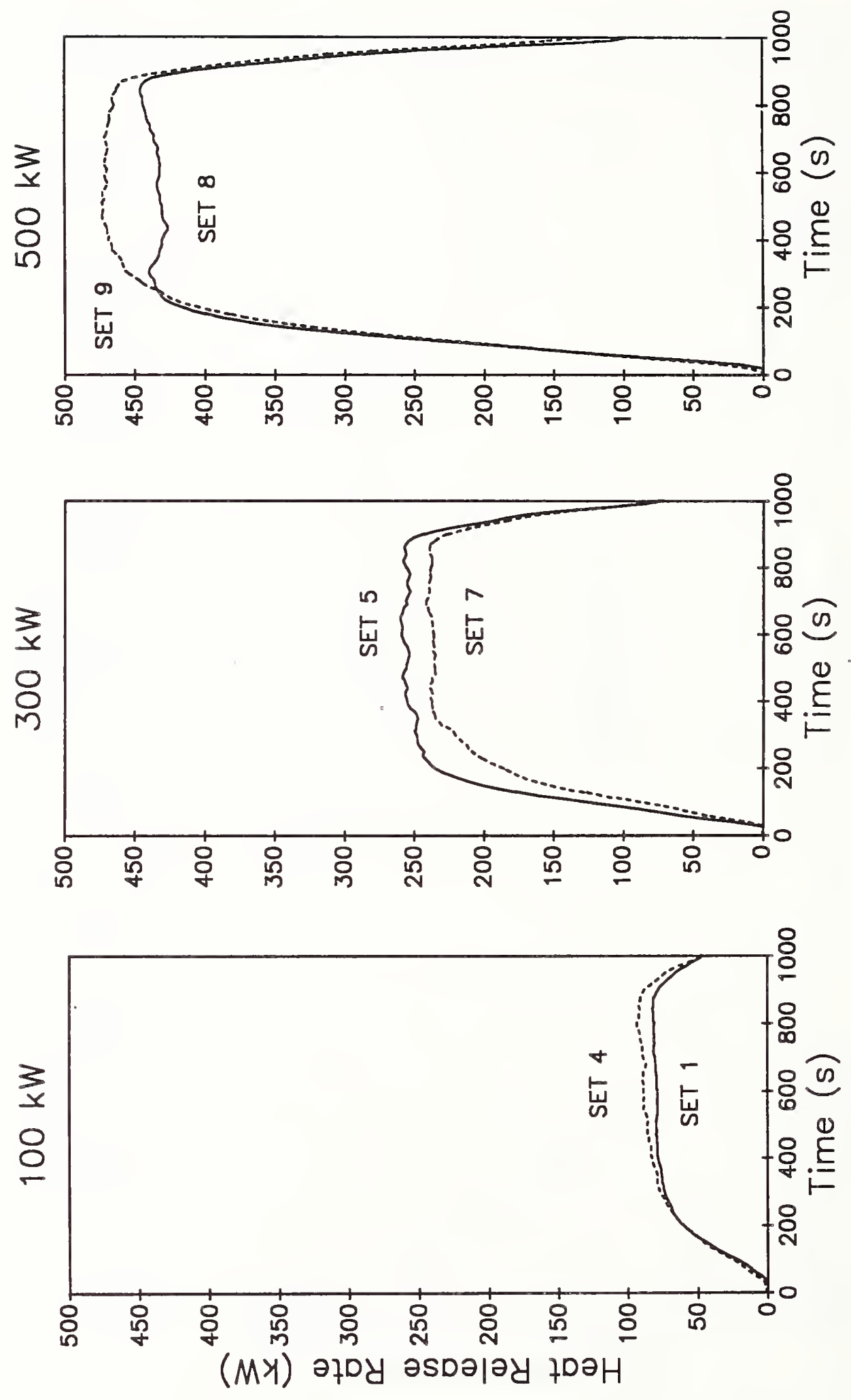

D 


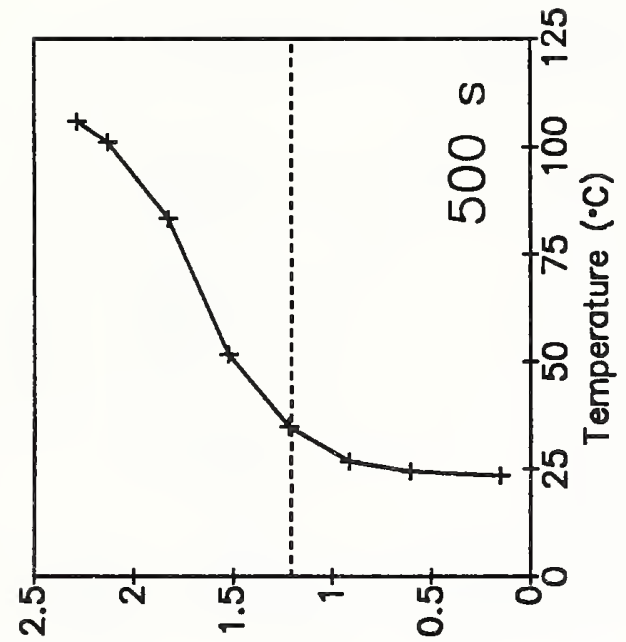

당

0
0
0
0
0
0
0
0
0
0

出登

点 0

त्

ป

幽 퇴

范

先 क
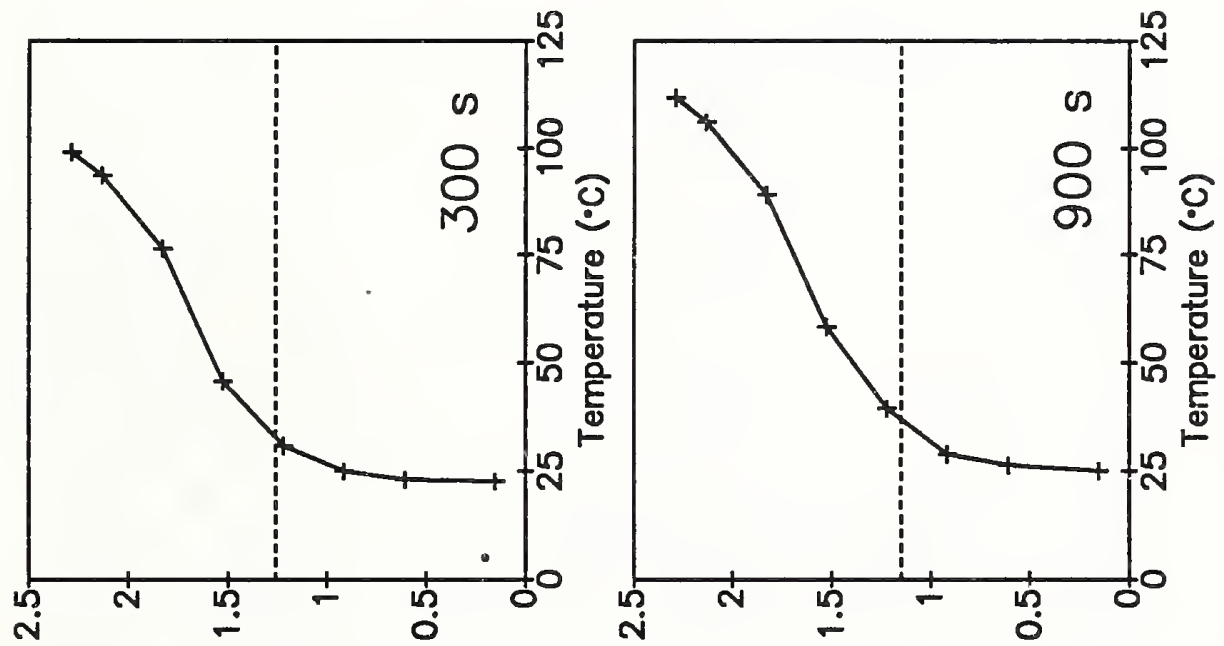

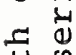

$\stackrel{+}{-1}$ 心

串㟧

욤ำ

๙

평 息

फ

명 명 뭉

荙

का

.

䨔.

出 $0 \frac{\pi}{3}$

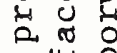

(1) 㟧 음

\&

$\exists$

ช

d

这

武 के

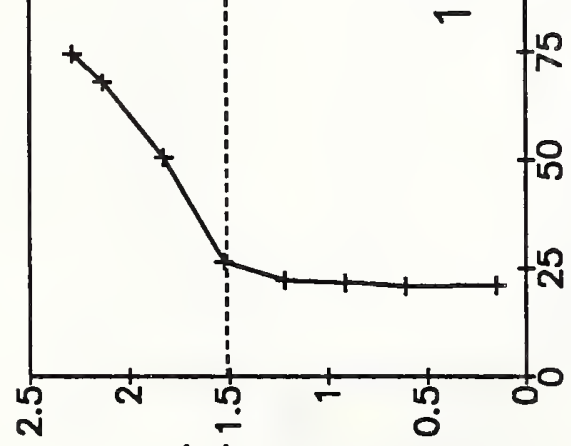

(w) uo! $7 ! \mathrm{sod}^{\mathrm{d}}$
每 


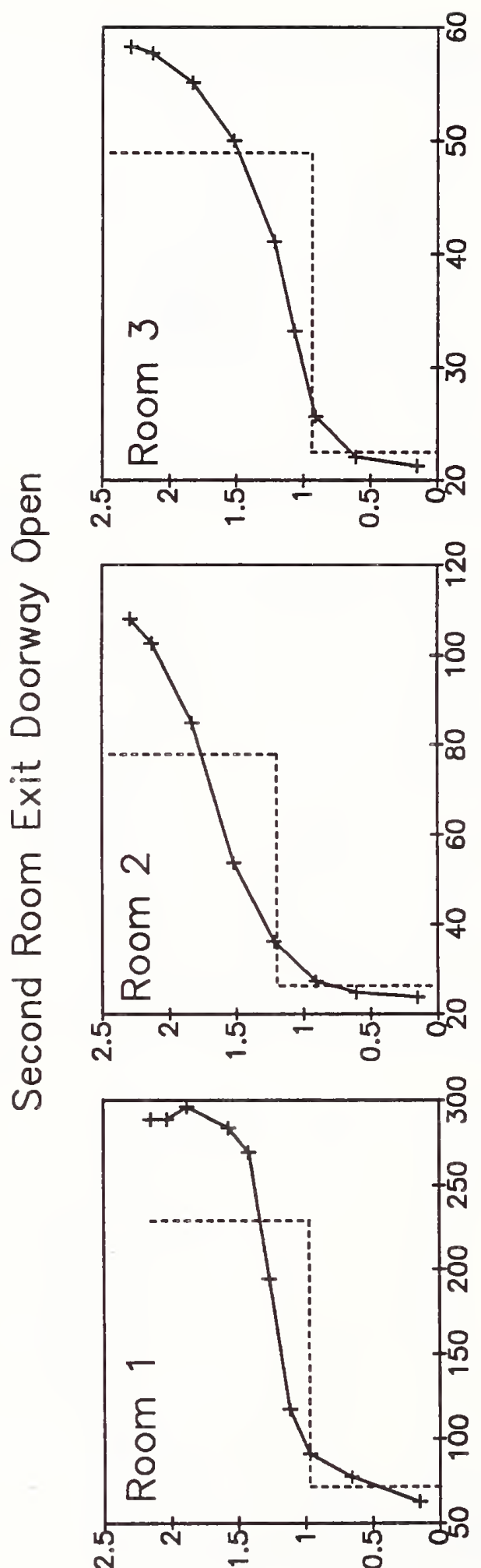

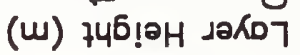

ำ
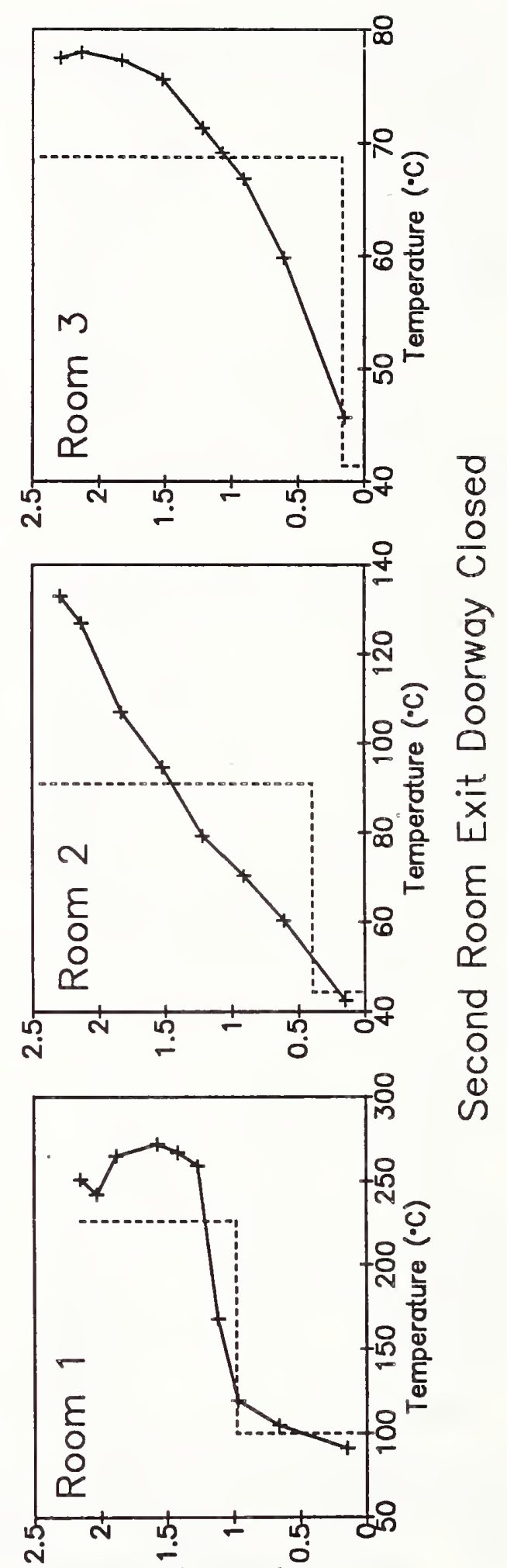

(w) $746 !$ 애 $د 2 K_{0} 7$
崩

站

唄

is

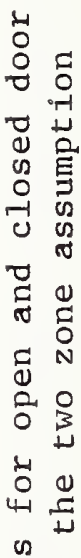

क 도

年然

난

过



3.

का थ

.

合的

过

(1) 㫕

車范

荠會

$\underset{m}{0}$ 


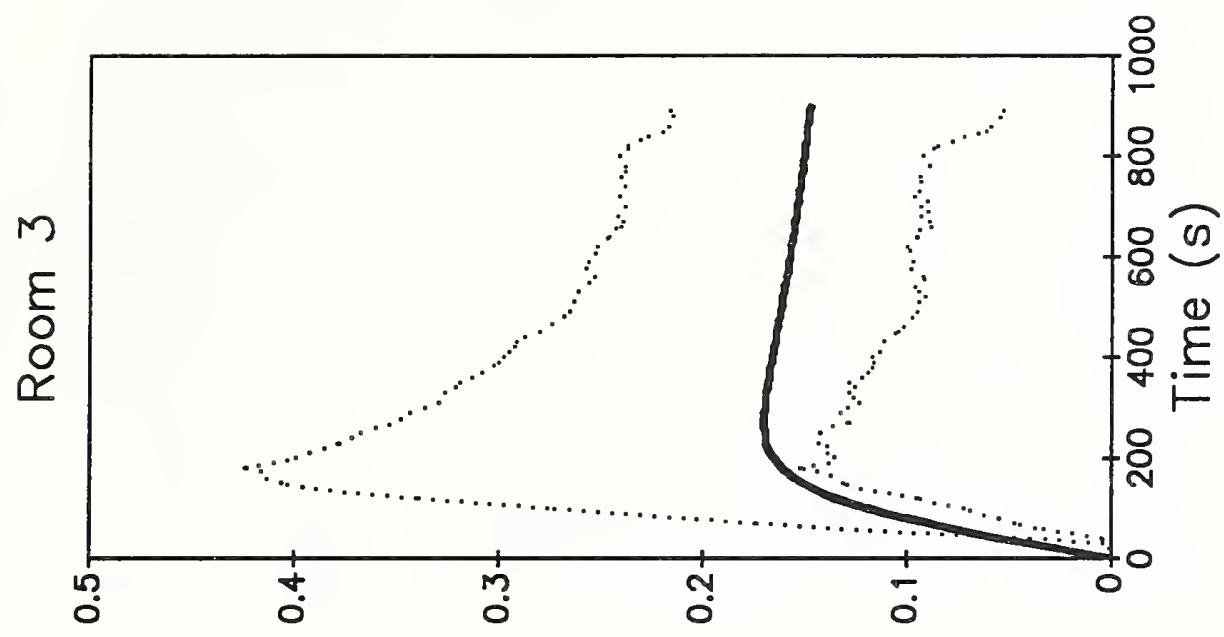

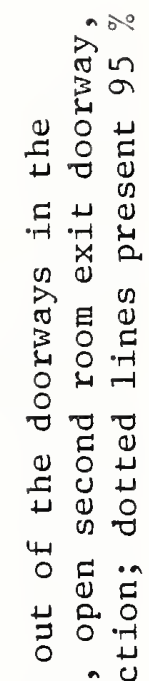

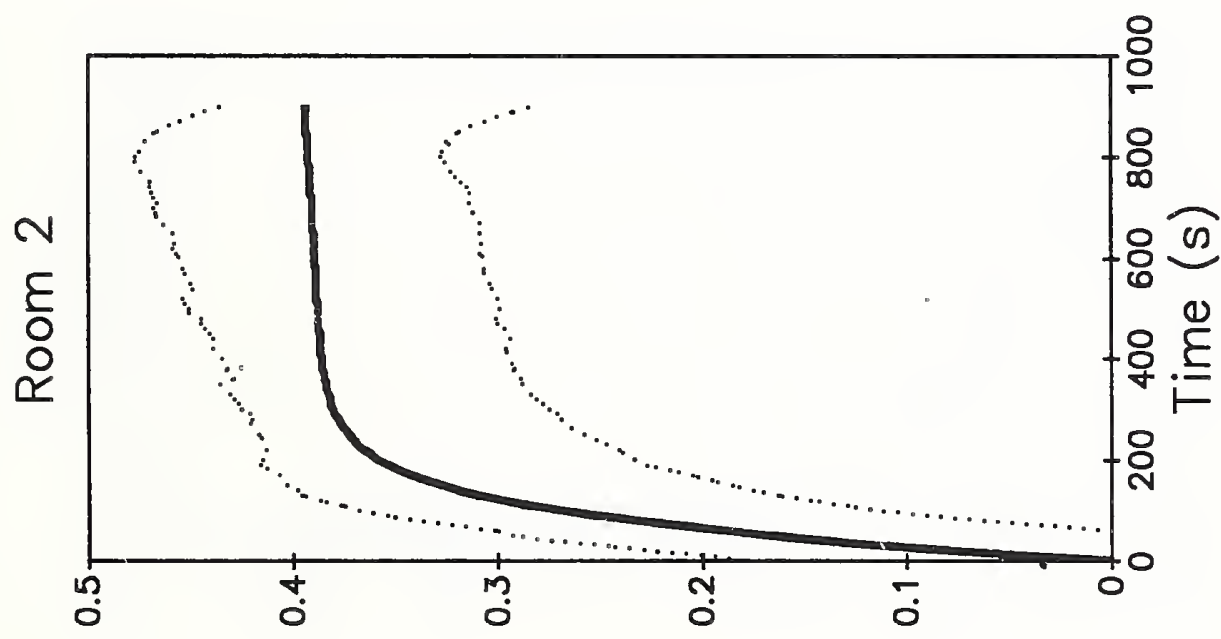

o 3 . U

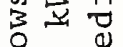

넝

o $\overbrace{-1}^{-1}$

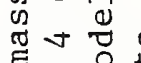

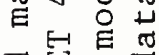

प्र 可

(1) 的的

牙

त 4 क

具导員

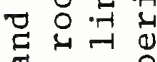

ஏ롱

㫕氠告

- 1 I 4

प्ट 0

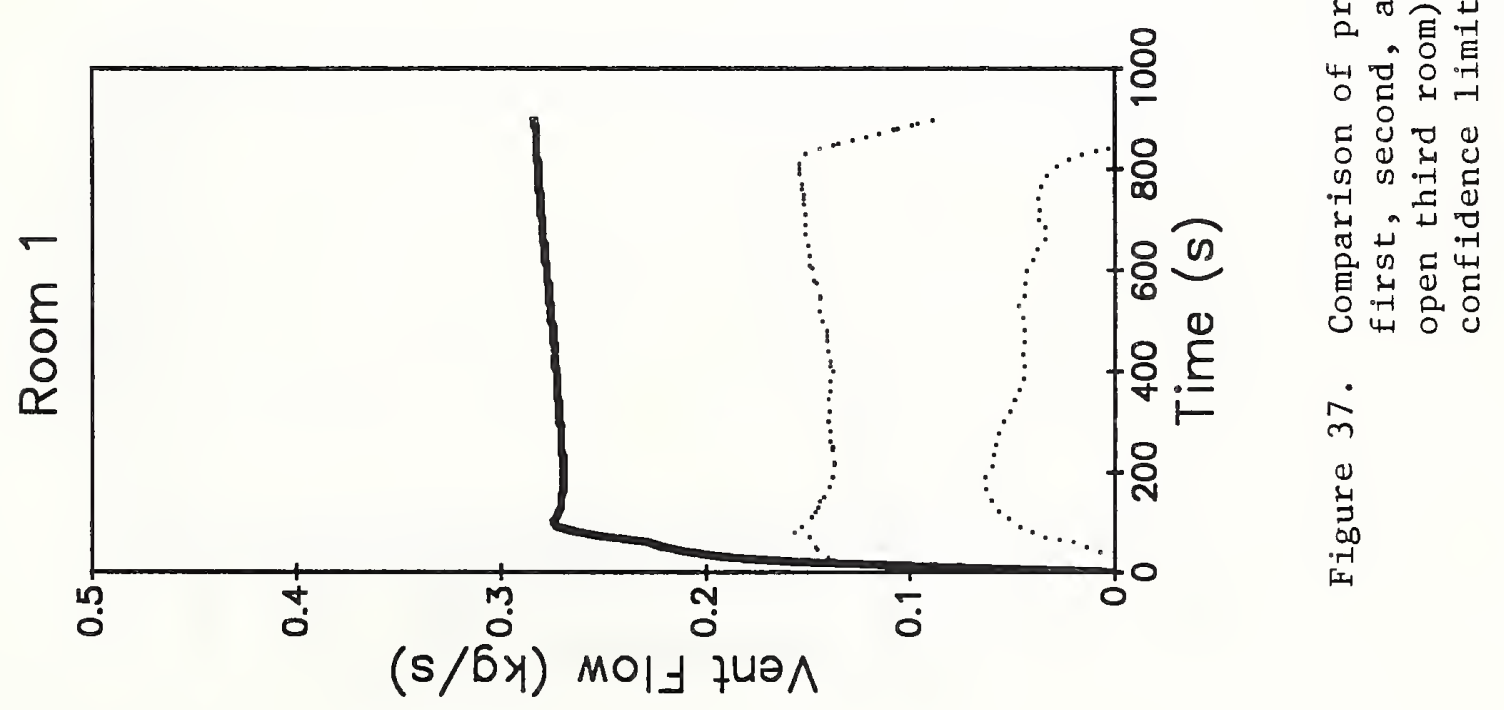



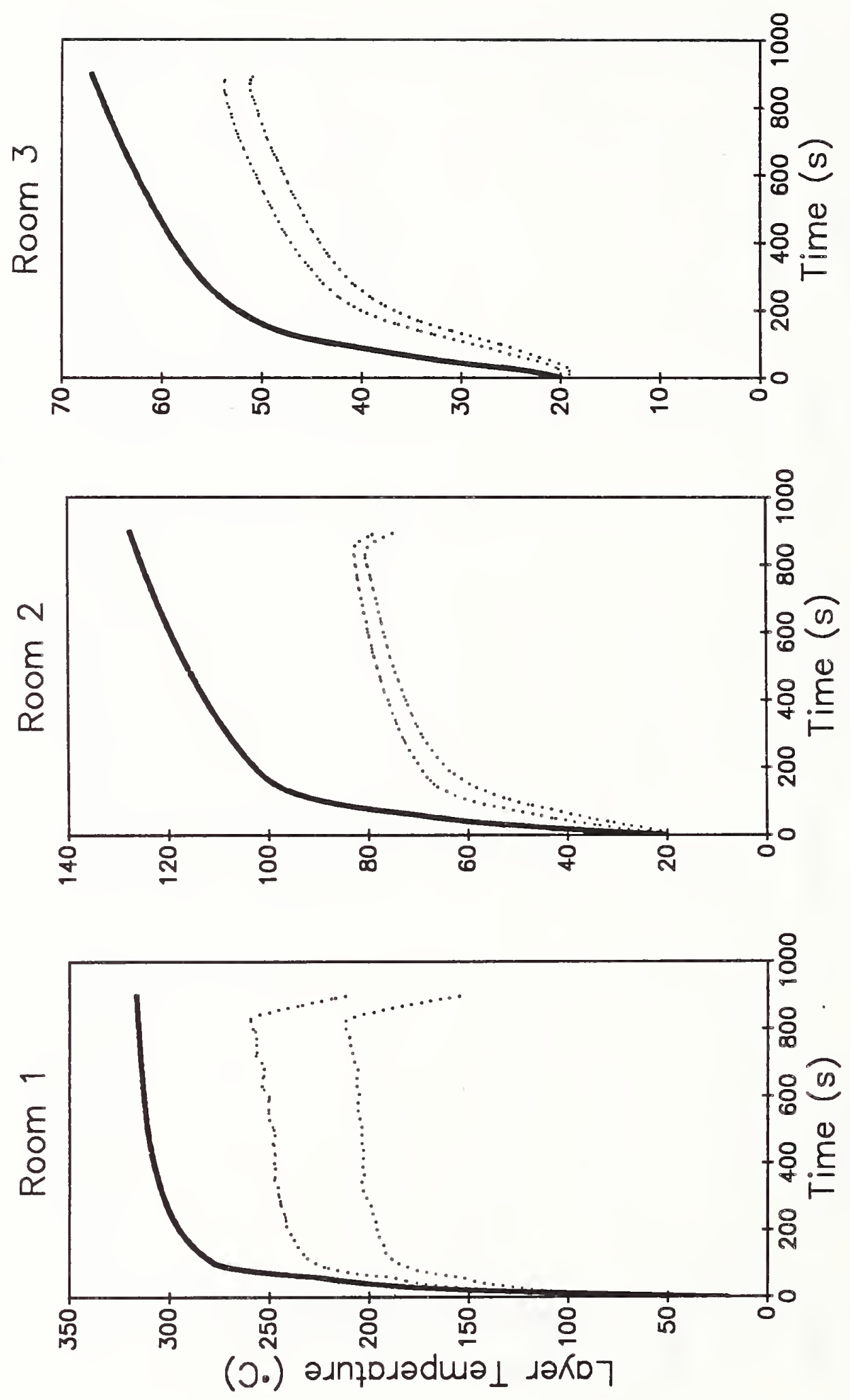

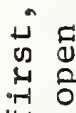

थ $\amalg$

$y \cdot \vec{x}$

車

แิ

을 안

d

-

过

- 1 号 $\pi$. 0.

$\infty 00$

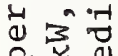

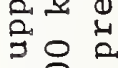
$>0$ 먼 덤 岁与号 कै 四 㽞 च ช य 0 - $\begin{array}{r}-1 \\ 0\end{array}$ चु के

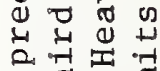
世告是

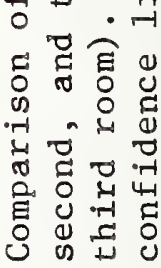

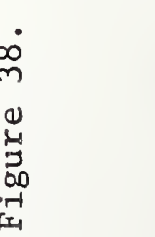



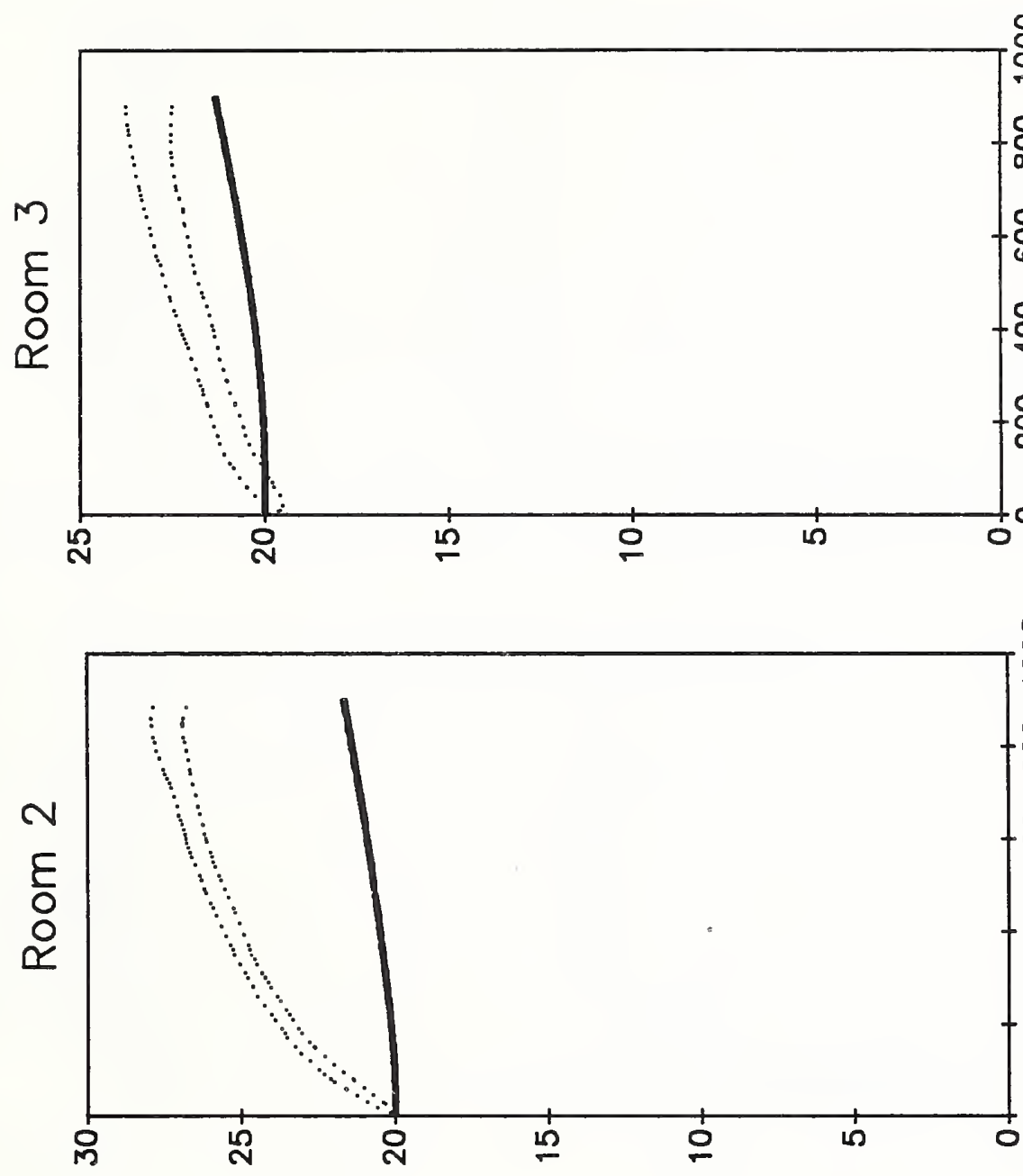

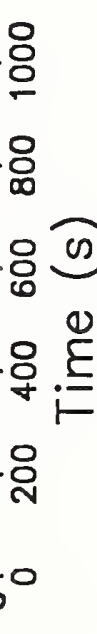

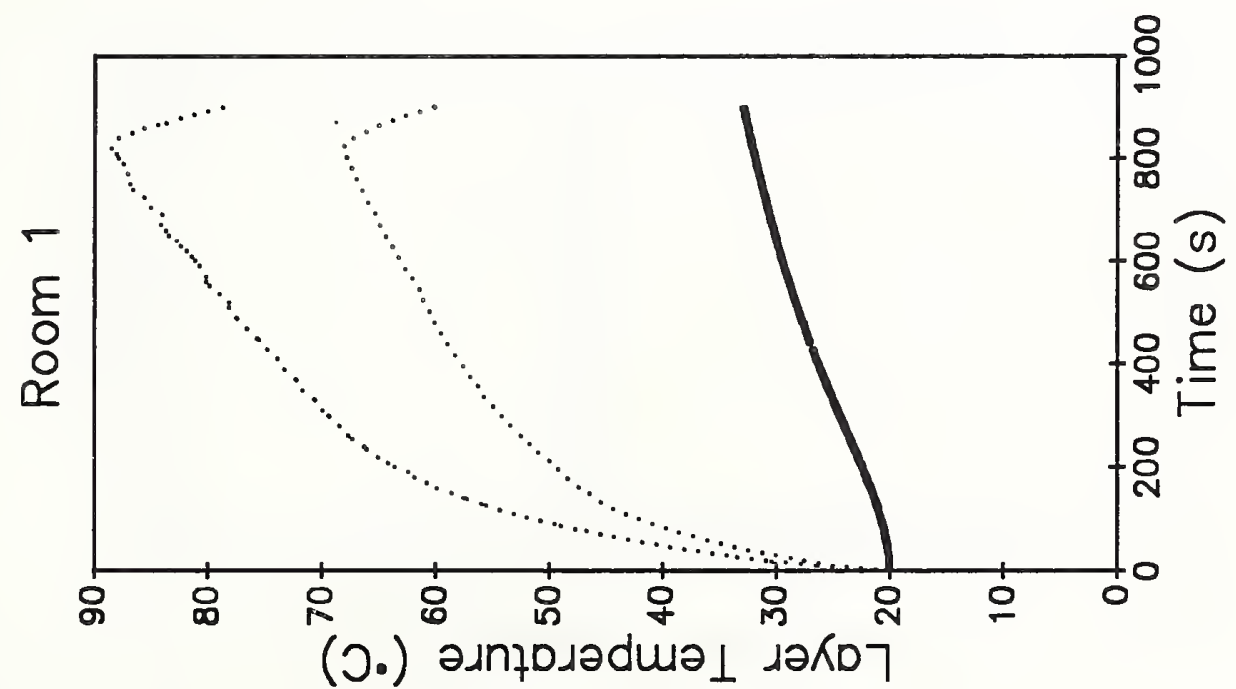

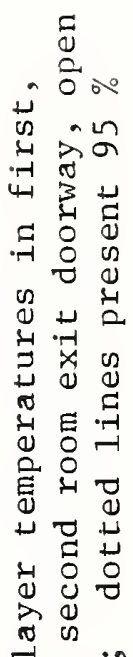

鬲

盛

告登

응 늠

먿웜

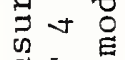

相毕的

者的起

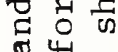

ฮั

$\cdot \rightarrow+y$

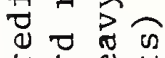

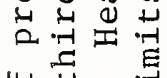

世

ธี ซี

-1 $\hat{y}^{-1}$ ब

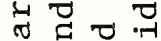

号总壳

过足

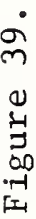

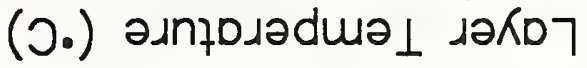



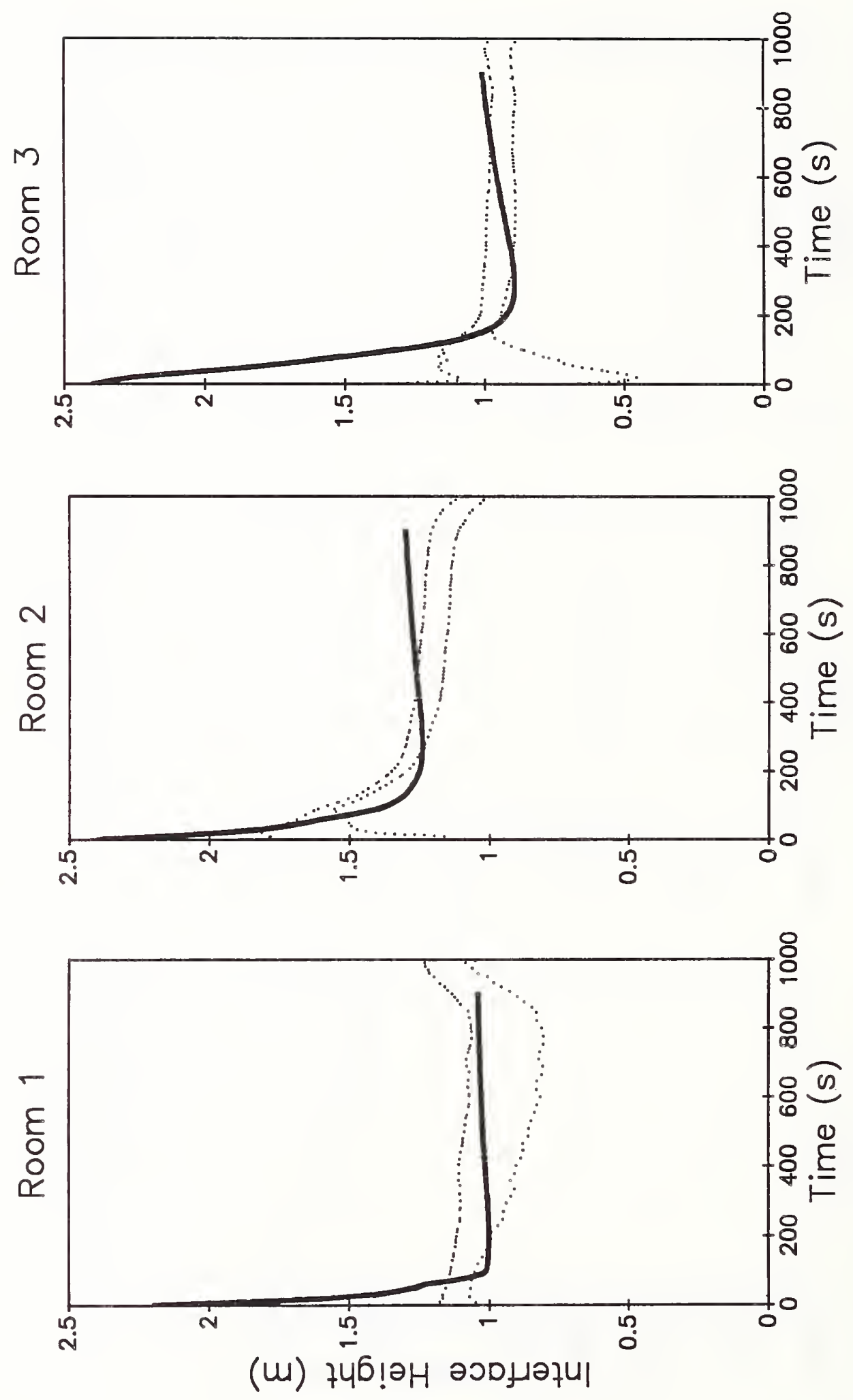

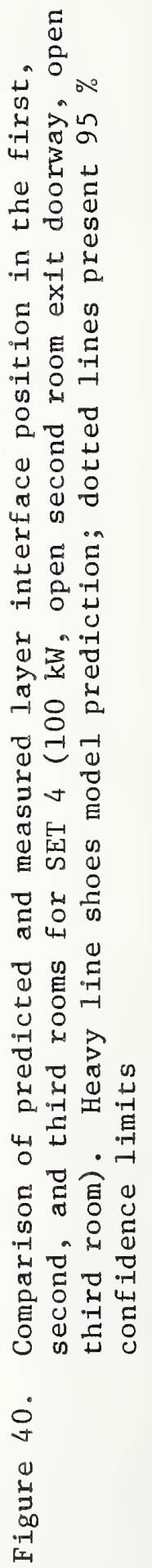


Table 1. Room Dimensions

Location

First room

First room stub corridor

First room doorway

Second room

Second room exit doorway

Third room

Third room stub corridor

Third room doorway
Dimensions (m)

$2.34 \mathrm{~W} \times 2.34 \mathrm{~L} \times 2.16 \mathrm{H}$

$1.02 \mathrm{~W} \times 1.03 \mathrm{~L} \times 2.00 \mathrm{H}$

$0.81 \mathrm{~W} \times 1.60 \mathrm{H}$

$2.44 \mathrm{~W} \times 12.19 \mathrm{~L} \times 2.44 \mathrm{H}$

$0.76 \mathrm{~W} \times 2.03 \mathrm{H}$

$2.24 \mathrm{~W} \times 2.22 \mathrm{~L} \times 2.43 \mathrm{H}$

$0.79 \mathrm{~W} \times 0.94 \mathrm{~L} \times 2.04 \mathrm{H}$

$0.79 \mathrm{~W} \times 2.04 \mathrm{H}$ 


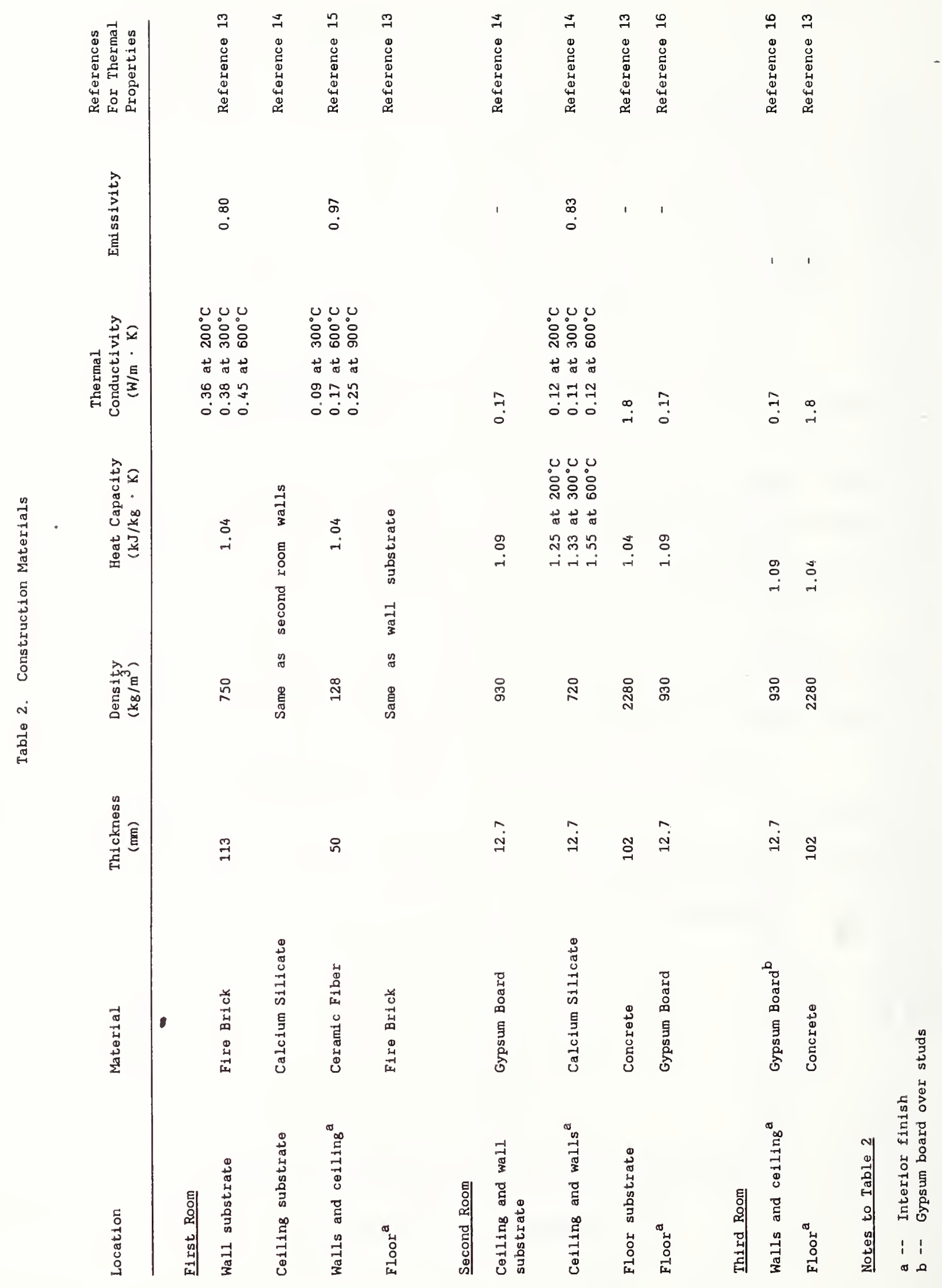


Table 3. Location of Instrumentation

I. Instrumentation in the Three Rooms

A. Thermocouple Trees, Gas Temperatures

Tree 1 in first room, Northwest quadrant - 9 thermocouples at 0.15 , $0.36,0.66,0.97,1.27,1.57,1.88,2.03$, and $2.15 \mathrm{~m}$ from floor.

Tree 2 in first room doorway - 6 thermocouples at $0.15,0.30,0.61$, $0.91,1.22$, and $1.52 \mathrm{~m}$ from floor.

Tree 3 in second room, $1.37 \mathrm{~m}$ from East end - 10 thermocouples at $0.15,0.30,0.61,0.91,1.22,1.52,1.83,2.13,2.29$, and $2.44 \mathrm{~m}$ (ceiling) from floor.

Tree 4 in second room, $5.49 \mathrm{~m}$ from East end - 10 thermocouples at $0.15,0.30,0.61,0.91,1.22,1.52,1.83,2.13,2.29$, and $2.44 \mathrm{~m}$ (ceiling) from floor and 1 thermocouple embedded in ceiling at 6.4 $\mathrm{mm}$ above exposed surface.

Tree 5 in second room, $11.73 \mathrm{~m}$ from East end -10 thermocouples at $0.15,0.30,0.61,0.91,1.22,1.52,1.83,2.13,2.29$, and $2.44 \mathrm{~m}$ (ceiling) from floor.

Tree 6 in second room exit doorway - 8 thermocouples at $0.15,0.30$, $0.61,0.91,1.22,1.52,1.83,2.13 \mathrm{~m}$ from floor.

Tree 7 in third room doorway - 8 thermocouples at $0.15,0.61,0.91$, $1.07,1.22,1.52,1.83$ and $1.93 \mathrm{~m}$ from floor.

Tree 8 in third room, Northeast quadrant - 10 thermocouples at $0.15,0.61,0.91,1.07,1.22,1.52,1.83,2.13,2.29$ and $2.43 \mathrm{~m}$ (ceiling) from floor. 
B. First room ceiling and wall thermocouples

Walls, $0.55 \mathrm{~m}$ and $1.64 \mathrm{~m}$ high -4 thermocouples at surface.

Ceiling, Southeast quadrant.

Floor, Southeast quadrant.

C. Second room wall thermocouples

North wal1, $1.37 \mathrm{~m}$ from East end - thermocouples at 0.61 and $1.83 \mathrm{~m}$ heights on surface.

North wall, $5.79 \mathrm{~m}$ from East end - thermocouples at 0.61 and $1.83 \mathrm{~m}$ heights on surface.

North wall, $10.67 \mathrm{~m}$ from East end - thermocouples at 0.61 and $1.83 \mathrm{~m}$ heights on surface.

D. Third room wall and ceiling thermocouples

None

E. Static pressure probes

First room, North wal1 - 5 probes at $25 \mathrm{~mm}, 0.30 \mathrm{~m}, 0.61 \mathrm{~m}, 1.22 \mathrm{~m}$, and $1.52 \mathrm{~m}$ from the floor.

Second room, West wall - 5 probes at $76 \mathrm{~mm}, 0.61 \mathrm{~m}, 1.22 \mathrm{~m}, 1.52 \mathrm{~m}$, and $1.83 \mathrm{~m}$ from the floor.

Third room, North wall - 1 probe at $0.08 \mathrm{~m}$ fxom the floor.

F. Smoke indicators

Second room, $5.49 \mathrm{~m}$ from East end - 6 horizontal smoke meters at $0.61,0.91,1.22,1.52,1.83$, and $2.29 \mathrm{~m}$ from floor.

Second room, $5.03 \mathrm{~m}$ from East end - 1 vertical smoke meter. 
II. Exhaust Hood

1 smoke meter.

1 probe for sampling carbon monoxide, carbon dioxide, and oxygen.

9 pitot static probes.

9 thermocouples.

III. Miscellaneous

First room, over burner 1 thermocouple $0.91 \mathrm{~m}$ above burner, $0.15 \mathrm{~m}$ from back wall. I thermocouple $0.20 \mathrm{~m}$ above burner, $0.15 \mathrm{~m}$ from back wall.

First room ceiling $\quad 1.17 \mathrm{~m}$ from East wall - 2 thermocouples on surface at $1.17 \mathrm{~m}$ and $0.61 \mathrm{~m}$ from North wall.

First room ceiling Northwest quadrant - 1 velocity probe, 1 brass disc with attached thermocouple, and one adjacent thermocouple.

First room

$1.17 \mathrm{~m}$ from East wall - 3 thermocouples on North wall surface at $0,0.71$, and $1.45 \mathrm{~m}$ below ceiling.

Second room $0.38 \mathrm{~m}$ from East wall - 2 thermocouples on ceiling surface at 0.61 and $1.22 \mathrm{~m}$ from North wall. 3 thermocouples on North wall surface at $0,0.81$, and $1.63 \mathrm{~m}$ below ceiling. 


\section{Instrumentation Changes}

Beginning with tests $100 \mathrm{H}, 300 \mathrm{C}$, and $500 \mathrm{C}$, the following changes were made:

Tree 11 thermocouple installed at $1.12 \mathrm{~m}$ from floor. 1 thermocouple at $0.36 \mathrm{~m}$ moved to $1.42 \mathrm{~m}$ from floor.

Tree 21 thermocouple installed at $1.07 \mathrm{~m}$ from floor. 1 thermocouple at $0.30 \mathrm{~m}$ moved to $1.37 \mathrm{~m}$ from floor.

Tree $3 \quad 1$ thermocouple at $0.30 \mathrm{~m}$ moved to tree 1 .

Tree 41 thermocouple at $0.30 \mathrm{~m}$ moved to tree 2.

Tree $5 \quad 1$ thermocouple at $0.30 \mathrm{~m}$ moved to $1.07 \mathrm{~m}$ from floor.

Tree 61 thermocouple at 0.30 moved to $1.07 \mathrm{~m}$ from floor.

One surface thermocouple installed on unexposed back side at each of the six wall locations under section I C.

One surface thermocouple installed on unexposed back side at each ceiling location over trees 3,4 , and 5 under section I A. 


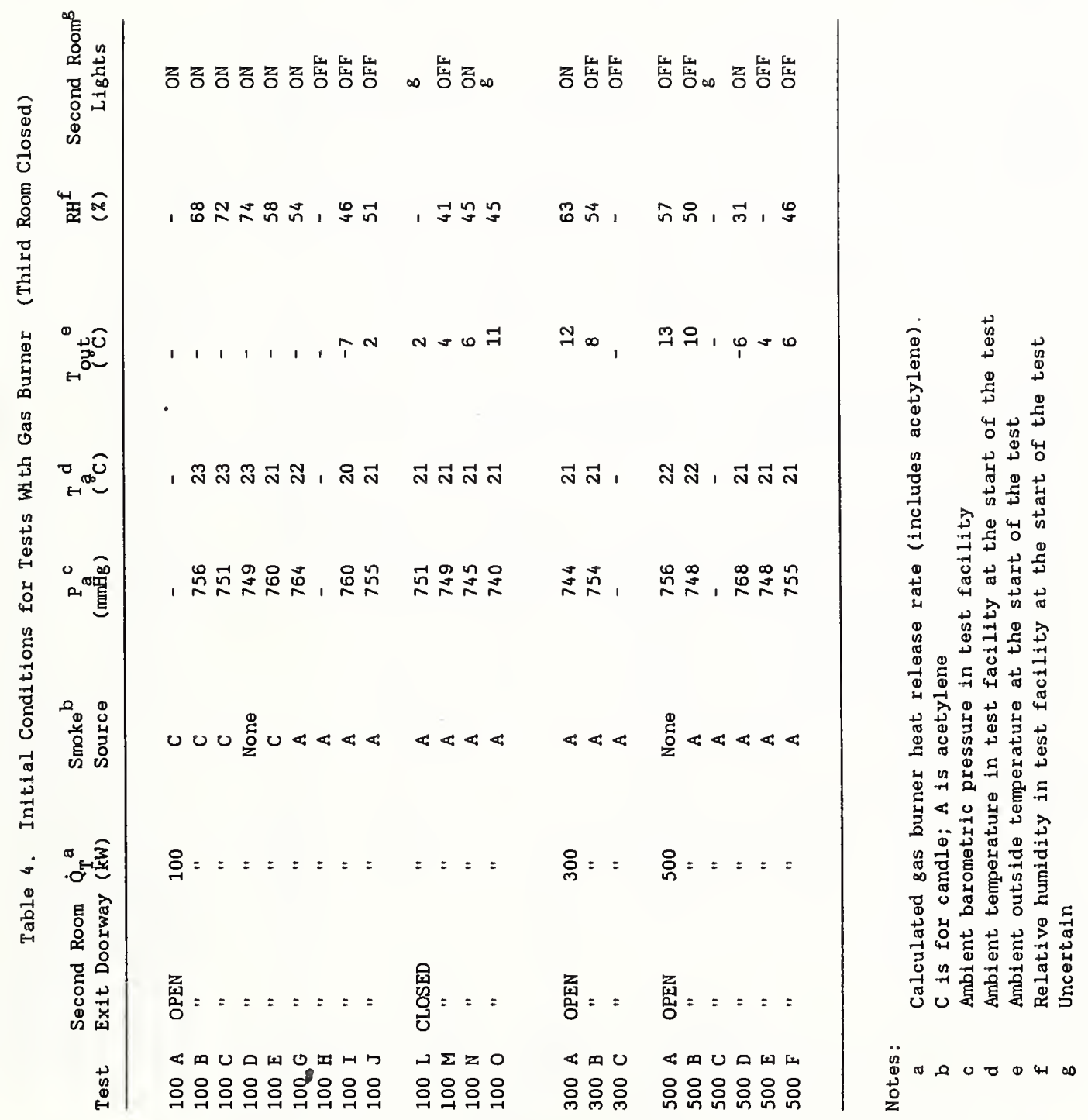




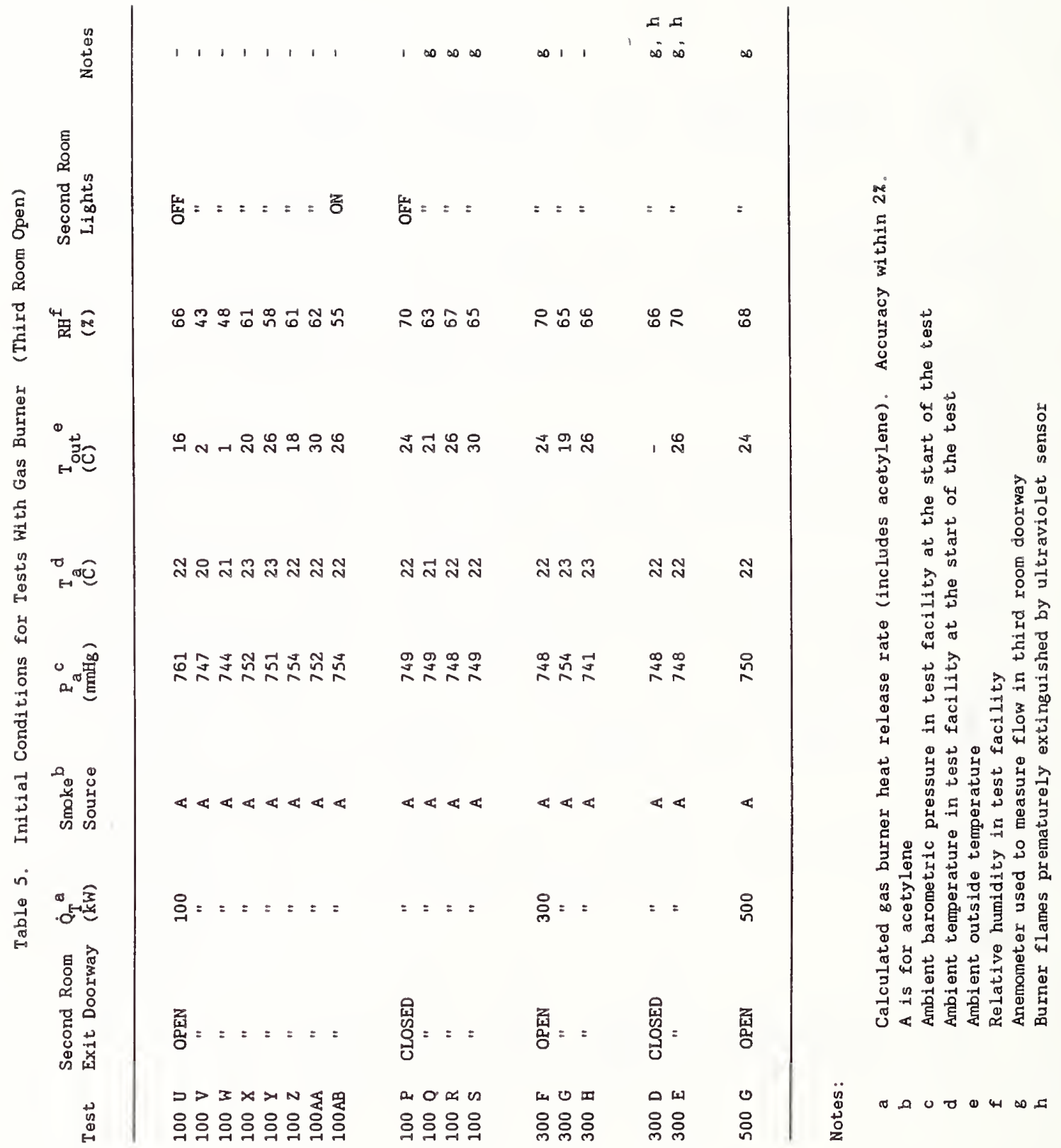




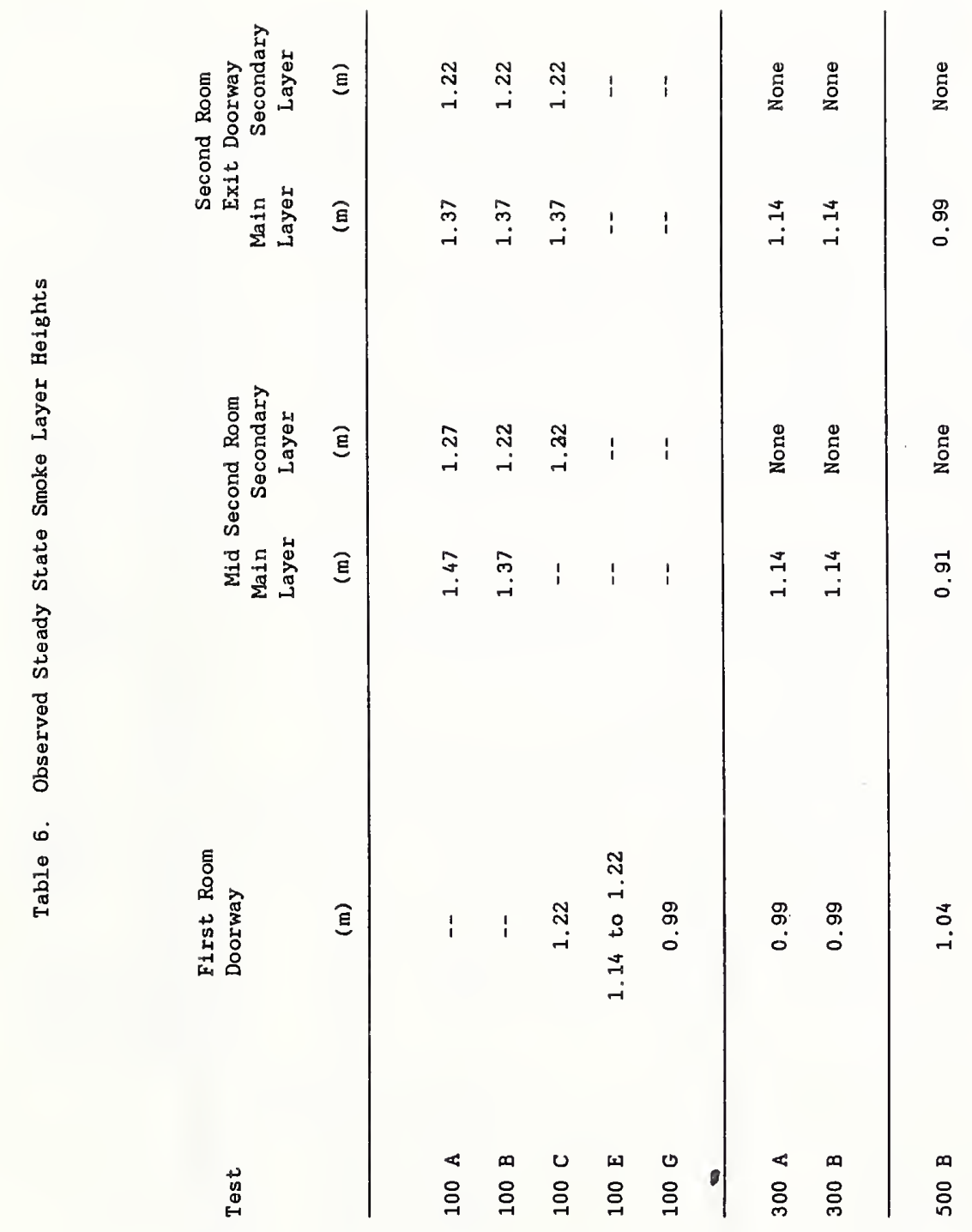




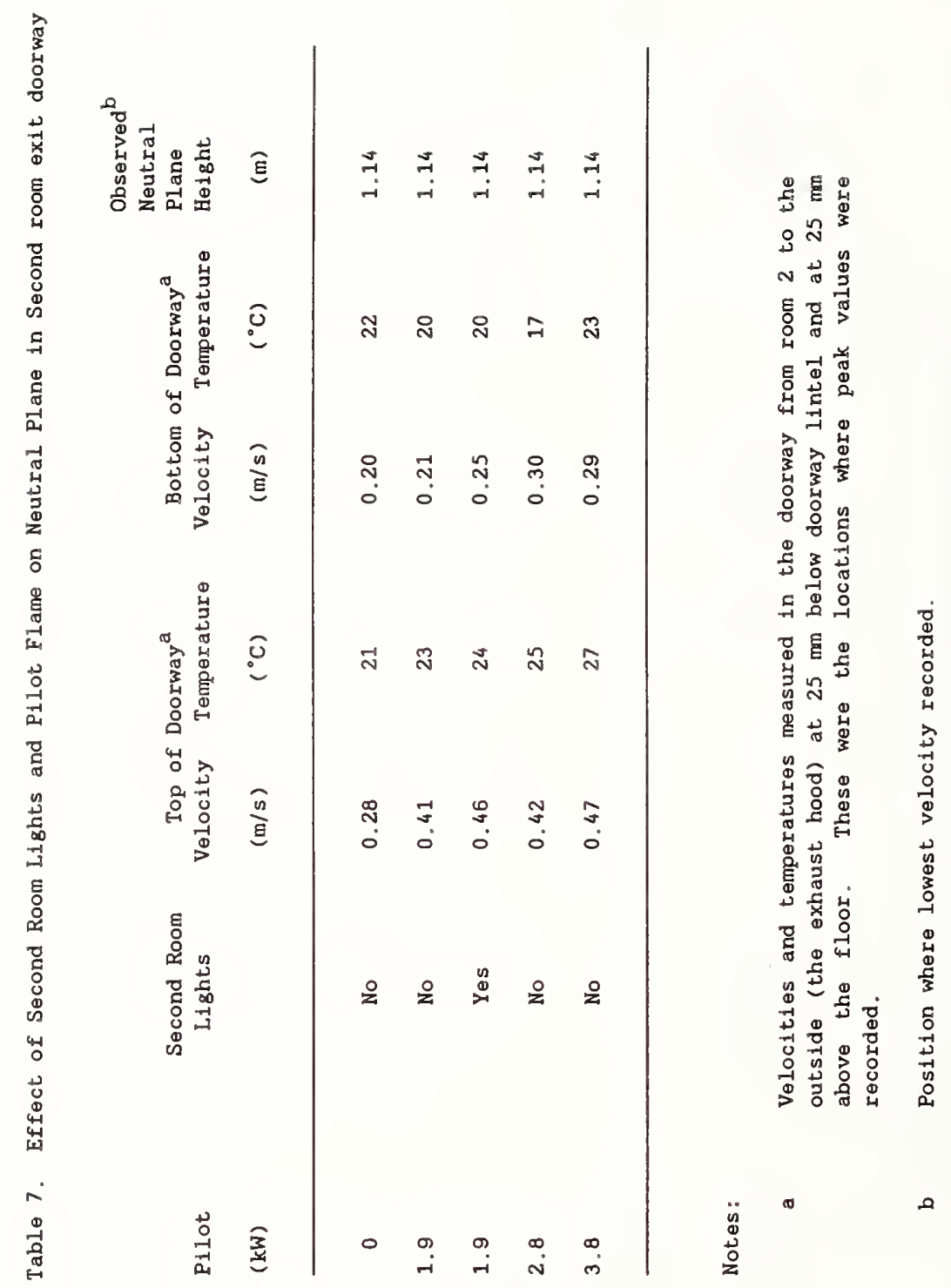




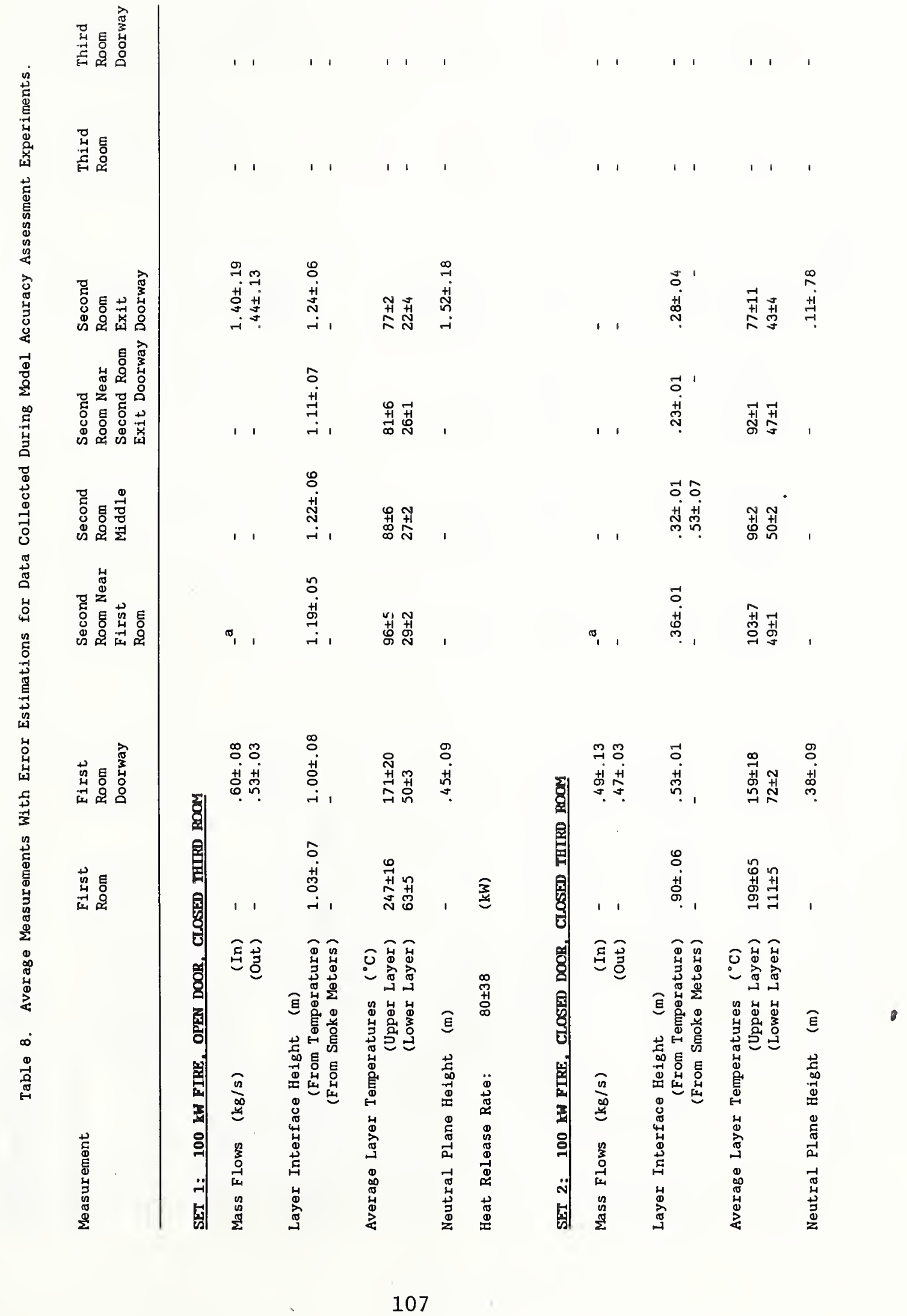




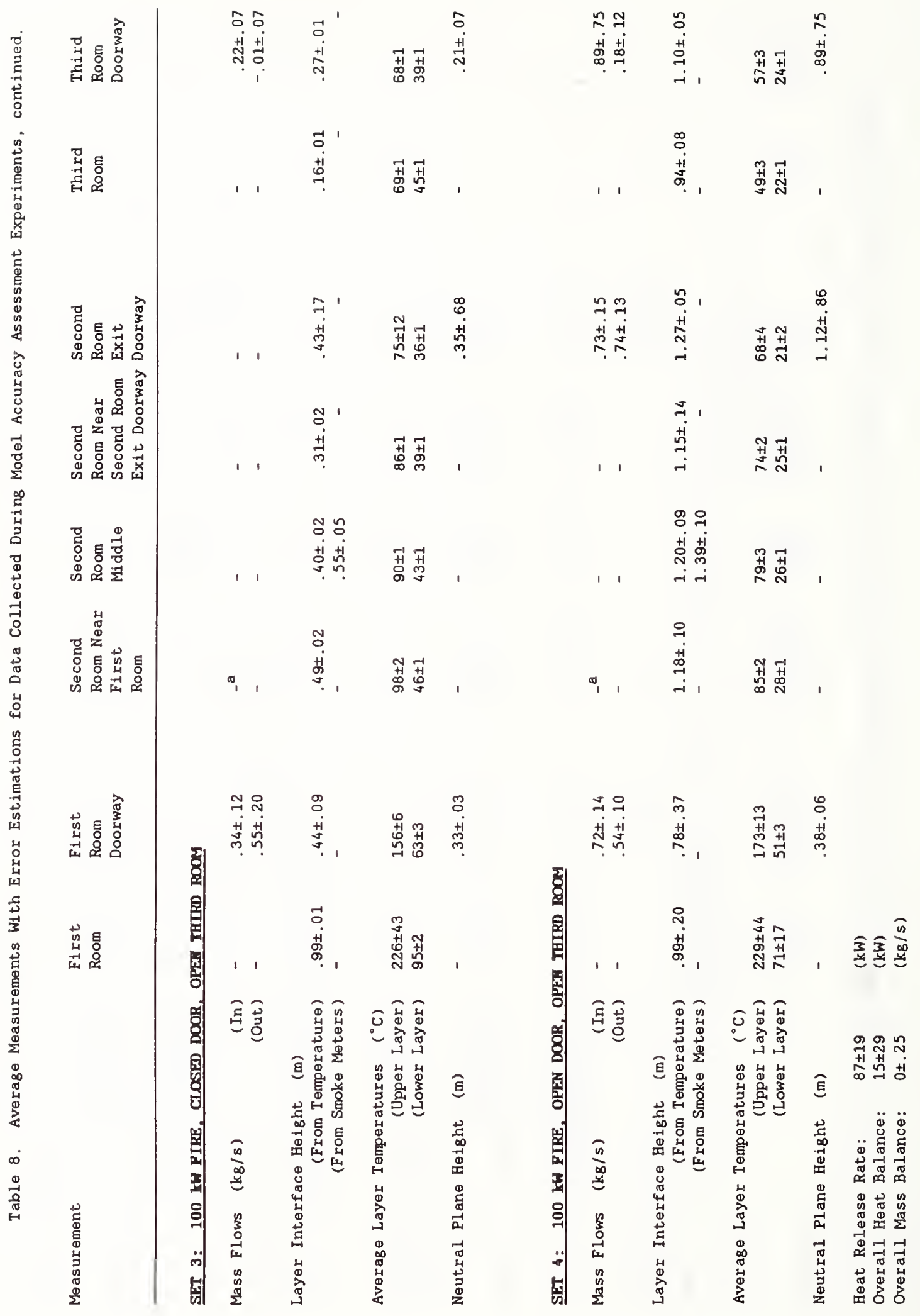




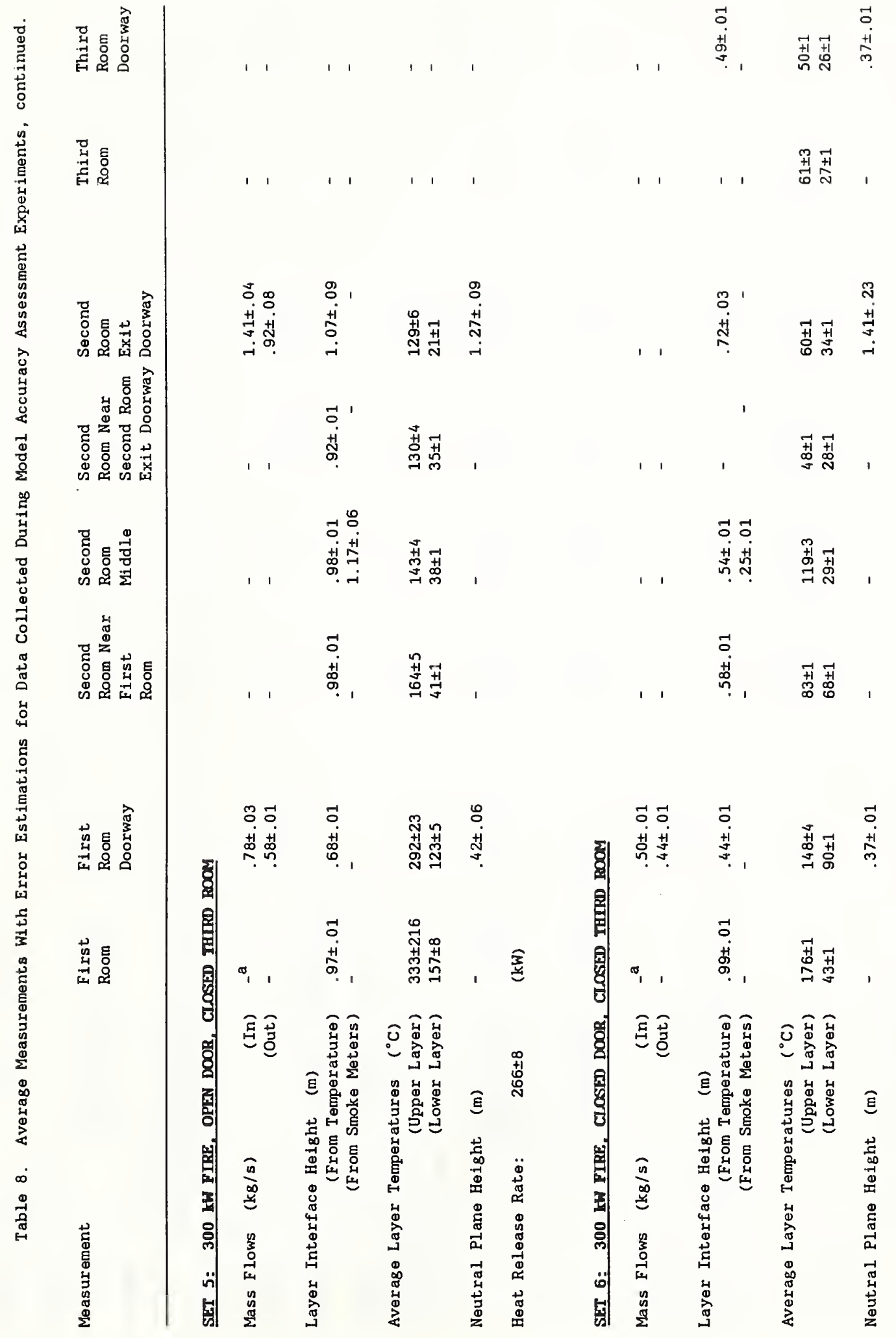




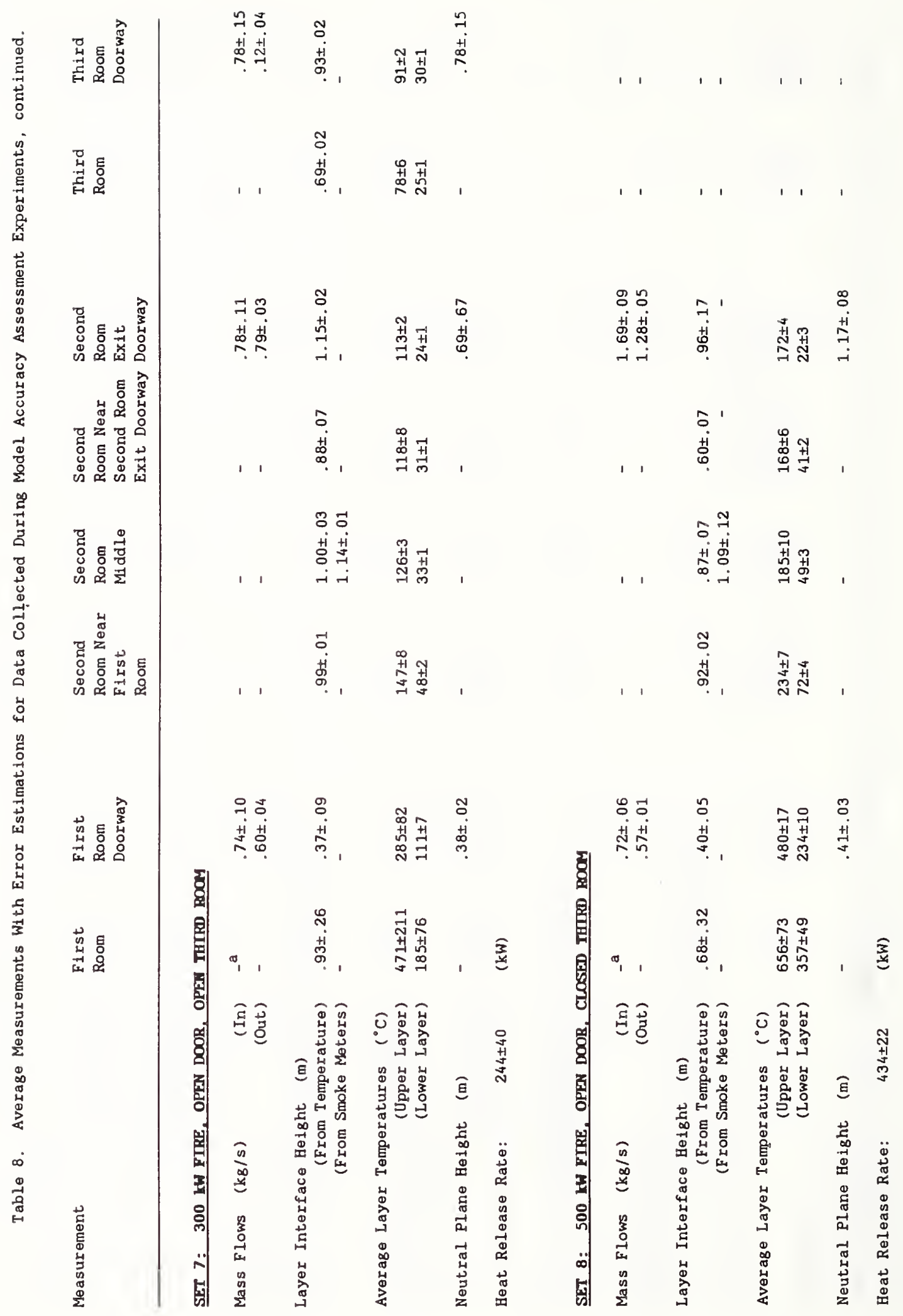




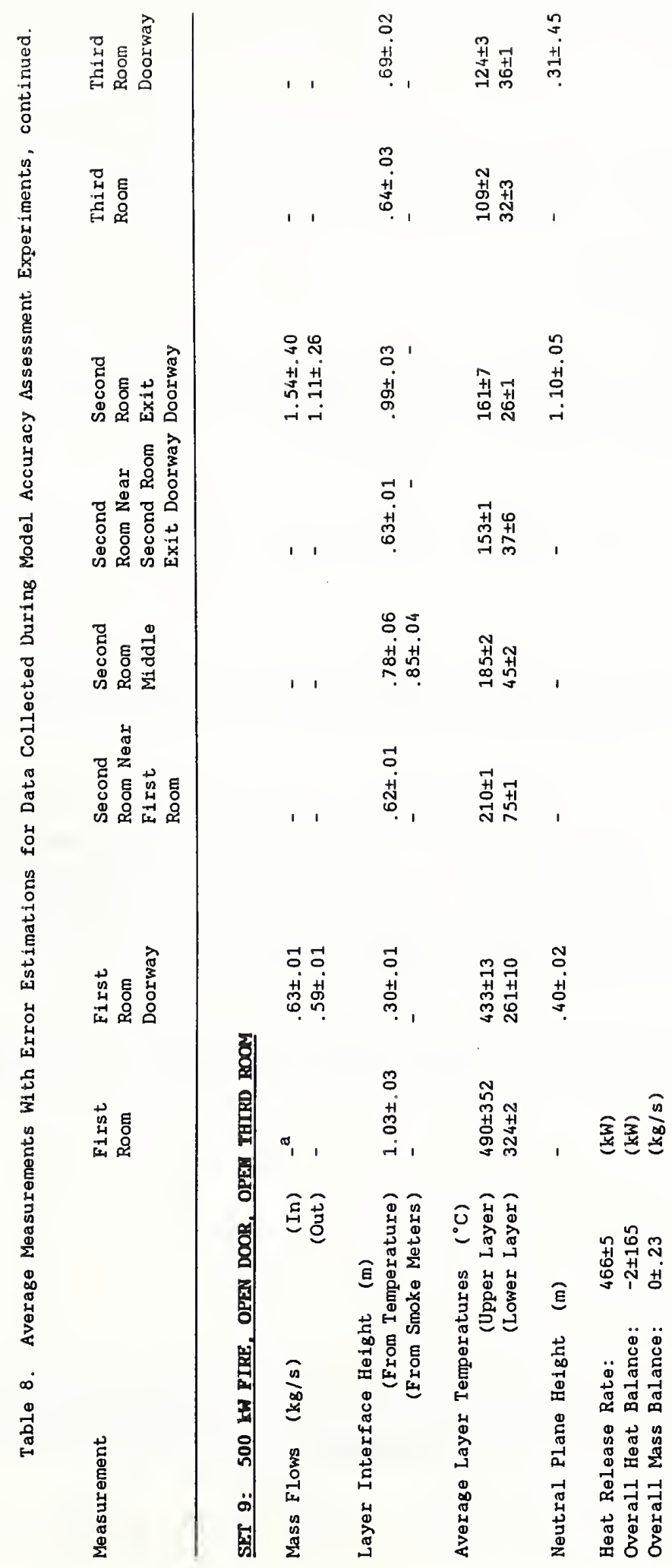




\begin{tabular}{|c|c|c|c|}
\hline $\begin{array}{l}\text { U.S. DEPT. OF COMM. } \\
\text { BIBLIOGRAPHIC DATA } \\
\text { SHEET (See instructions) }\end{array}$ & $\begin{array}{l}\text { 1. PUBLICATION OR } \\
\text { REPORTNO. } \\
\text { NBSIR } 88-3752\end{array}$ & 2. Performing Organ. Report No. & $\begin{array}{l}\text { 3. Publication Date } \\
\text { APRIL } 1988\end{array}$ \\
\hline \multicolumn{4}{|l|}{ 4. TITLE AND SUBTITLE } \\
\hline \multicolumn{4}{|c|}{$\begin{array}{l}\text { 5. AUTHOR(S) } \\
\qquad \text { Richard D. Peacock, Sanford Davis, and Billy T. Lee }\end{array}$} \\
\hline \multicolumn{3}{|c|}{$\begin{array}{l}\text { 6. PERFORMING ORGANIZATION (If joint or other than NBS. see instructions) } \\
\text { NATIONAL BUREAU OF STANDARDS } \\
\text { U.S. DEPARTMENT OF COMMERCE } \\
\text { GAITHERSBURG, MD } 20899\end{array}$} & 7. Contract/Grant No. \\
\hline & $\begin{array}{l}\text { ional Bureau of St } \\
\text { thersburg, MD } 208\end{array}$ & & \\
\hline
\end{tabular}

10. SUPPLEMENTARY NOTES

Document describes a computer program; SF-185, FIPS Software Summary, is attached。

11. ABSTRACT (A 200-word or less factual summary of most significant information. If document includes a significant bibliogrophy or literature survey. mention it here)

The development of experimental data for use in computer fire model accuracy assessment is described. The tests were conducted in a heavily instrumented structure to provide data on temperatures and mass and heat flows in a simple multi-room configuration. Several series of carefully designed experiments were carried out changing important physical parameters one at a time with several replicates of each configuration.

The current state of understanding in computer fire model accuracy assessment is discussed with the data presented forming an example of one step of the process.

12. KEY WORDS (Six to twelve entries; alphabetical order; capitalize only proper names: and separate key words by semicolons) Accuracy assessment; data analysis; experiments; fire tests; fire models; instruments

\section{AVAILABILITY}

[X] Unlimited

For Official Distribution. Do Not Release to NTIS

Order From Superintendent of Documents, U.S. Government Printing Office, Washington, DC 20402.

X) Order From National Technical Information Service (NTIS), Springfield, VA
14. NO. OF PRINTED PAGES 120

15. Price

$\$ 18,95$ 


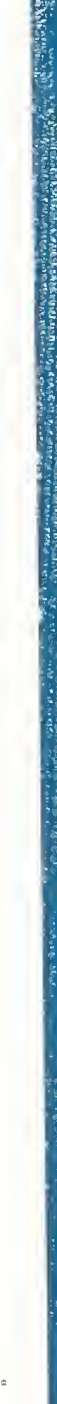



$-$ 
(16) 
